\title{
Decontamination and Decommissioning Program
}

Argonne National Laboratory 9700 South Cass Avenue

Argonne, lllinois 60439
Operated by The University of Chicago, under Contract W-31-109-ENG-38, for the United States Department of Energy 


\section{Argonne National Laboratory}

Argonne National Laboratory, with facilities in the states of Illinois and Idaho, is owned by the United States Govemment, and operated by the University of Chicago under the provisions of a contract with the Department of Energy.

This technical report is a product of Argonne's Technology Development Division, Decontamination and Decommissioning Program. For information on the division's activities, contact:

Director, Technology Development Division

Argonne National Laboratory

Argonne, llinois 60439-4815

Telephone (708) 252-6050

Publishing support services were provided by Argonne's Information and Publishing Division.

\section{Disclaimer}

This report was prepared as an account of work sponsored by an agency of the United States Govemment. Neither the United States Government nor any agency thereof, nor any of their employees, makes any warranty, express or implled, or assumes any legal liability or responsibility for the accuracy, completeness, or usefulness of any information, apparatus, product, or process disclosed, or represents that its use would not infringe privately owned rights. Reference herein to any specific commercial product, process, or service by trade name, trademark, manufacturer, or otherwise, does not necessarily constitute or imply its endorsement," recommendation, or favoring by the United States Govemment or any agency thereof. The views and opinions of authors expressed herein do not necessarily state or reflect those of the United States Government or any agency thereof. 
Waste Minimization Handbook, Volume 1

by Lawrence E. Boing and Michael J. Coffey

Decontamination and Decommissioning Program, Technology Development Division Argonne National Laboratory, 9700 South Cass Avenue, Argonne, Illinois 60439

December 1995

Work sponsored by United States Department of Energy, Office of Environmental Management 
This report is printed on recycled paper.

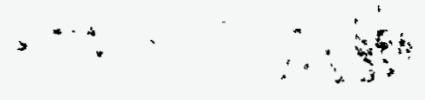




\section{CONTENTS}

ACKNOWLEDGMENTS $\ldots \ldots \ldots \ldots \ldots \ldots \ldots \ldots \ldots \ldots \ldots \ldots \ldots \ldots \ldots \ldots \ldots$ viii

NOTATION $\ldots \ldots \ldots \ldots \ldots \ldots \ldots \ldots \ldots \ldots \ldots \ldots \ldots \ldots \ldots \ldots \ldots \ldots \ldots \ldots$

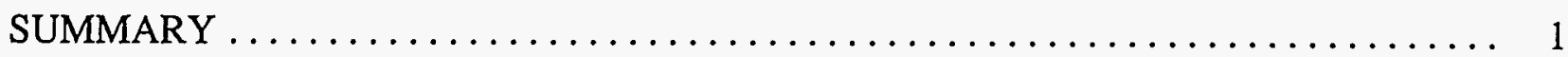

ABSTRACT $\ldots \ldots \ldots \ldots \ldots \ldots \ldots \ldots \ldots \ldots \ldots \ldots \ldots \ldots \ldots \ldots \ldots \ldots \ldots$

1 INTRODUCTION $\ldots \ldots \ldots \ldots \ldots \ldots \ldots \ldots \ldots \ldots \ldots \ldots \ldots \ldots \ldots \ldots \ldots \ldots \ldots \ldots$

1.1 Waste Minimization Program Overview $\ldots \ldots \ldots \ldots \ldots \ldots \ldots \ldots \ldots \ldots$

1.2 Purpose and Scope $\ldots \ldots \ldots \ldots \ldots \ldots \ldots \ldots \ldots \ldots \ldots \ldots \ldots \ldots \ldots \ldots$

1.3 Handbook Organization $\ldots \ldots \ldots \ldots \ldots \ldots \ldots \ldots \ldots \ldots \ldots \ldots \ldots \ldots$

$2 \operatorname{METALS} \ldots \ldots \ldots \ldots \ldots \ldots \ldots \ldots \ldots \ldots \ldots \ldots \ldots \ldots \ldots \ldots \ldots$

2.1 Smelting Techniques $\ldots \ldots \ldots \ldots \ldots \ldots \ldots \ldots \ldots \ldots \ldots \ldots \ldots \ldots$

2.1.1 Smelting at the Siempelkamp Foundry ................. 9

2.1.2 Smelting at the Scientific Ecology Group $\ldots \ldots \ldots \ldots \ldots \ldots \ldots \ldots \ldots \ldots$

2.1.3 Smelting at the Capenhurst Works Facility $\ldots \ldots \ldots \ldots \ldots \ldots \ldots \ldots \ldots$

2.2 Plasma Arc Cutting $\ldots \ldots \ldots \ldots \ldots \ldots \ldots \ldots \ldots \ldots \ldots \ldots \ldots \ldots \ldots$

2.2.1 Plasma Arc Cutting at Los Alamos National Laboratory . . . . . . . . . . 17

2.2.2 Plasma Arc Cutting at Capenhurst Works — British

Nuclear Fuels, plc ............................... 19



2.3.1 Supercompaction at the Winfrith Technology Center $\ldots \ldots \ldots \ldots \ldots \ldots 23$

2.3.2 Supercompaction at Scientific Ecology Group . . . . . . . . . . . . . . 25

2.3.3 Supercompaction at the Kernforschungszentrum Karlsruhe $\mathrm{GmbH} \ldots \ldots 27$

2.3.4 Fontijne Holland/Stock Equipment Company Supercompactor . . . . . . . . . 29

2.3.5 Supercompaction at the Cogema Reprocessing Plant . . . . . . . . . . . . 32

2.3.6 Supercompaction at Kernkraftwerke Gundremmingen

Betriebsgesellschaft $\mathrm{mbH} \ldots \ldots \ldots \ldots \ldots \ldots \ldots \ldots \ldots \ldots \ldots$

2.3.7 Metallic Waste Baler at Harwell . . . . . . . . . . . . . . . . 35

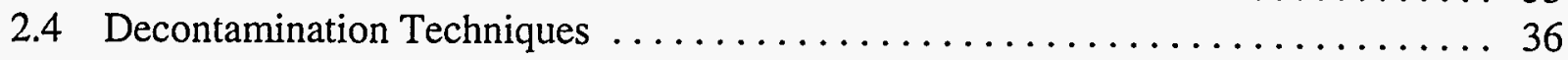

2.4.1 Electropolishing at the Kernkraftwerke Gundremmingen

Betriebsgesellschaft $\mathrm{mbH} \ldots \ldots \ldots \ldots \ldots \ldots \ldots \ldots \ldots \ldots \ldots$

2.4.2 Chemical Decontamination Methods at Capenhurst $\ldots \ldots \ldots \ldots \ldots \ldots \ldots . . \ldots$

2.4.3 Decontamination Methods Used at AEA Technology .............. 40

2.4.4 Carbon Dioxide Decontamination Methods Used at Rocky Flats

Environmental Technology Site . . . . . . . . . . . . . . . 44

2.4.5 Decontamination Center at the Dounreay Nuclear Establishment . . . . . . . 46

2.4.6 Decontamination Techniques at the Sellafield Nuclear Facility . . . . . . 48 


\section{CONTENTS (Cont.)}

2.4.7 Decontamination Methods Used at the Savannah River Site . . . . . . . . . 50

2.4.8 Decontamination Studies at Idaho National Engineering Laboratory . . . . 52

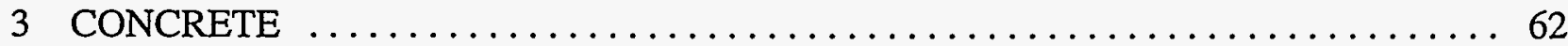

3.1 Chemical Decontamination $\ldots \ldots \ldots \ldots \ldots \ldots \ldots \ldots \ldots \ldots \ldots \ldots \ldots \ldots \ldots$

3.1.1 EET, Inc., Chemical Extraction Technology $\ldots \ldots \ldots \ldots \ldots \ldots \ldots \ldots \ldots 6$

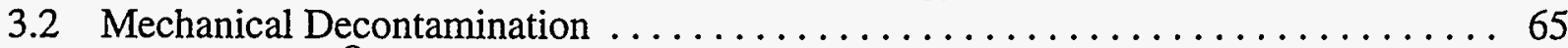

3.2.1 Pentek ${ }^{\circledR}$ Dustless Decontamination System at Rocky Flats

Environmental Technology Site . . . . . . . . . . . . . . . 65

3.2.2 Pentek Dustless Decontamination Systems . . . . . . . . . . . 67

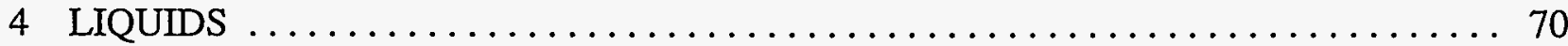

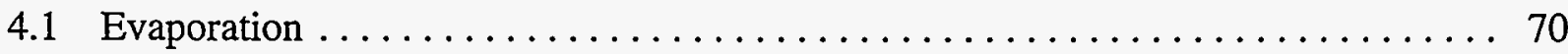

4.1.1 Evaporation of Liquids at Kernforschungszentrum Karlsruhe . . . . . . . . 70

4.1.2 Concentrated Waste Dryer System: Stock Equipment Company . . . . . . . 72

4.1 .3 Resources Conservation Company .................... 74



4.2.1 Incineration at Kernforschungszentrum Karlsruhe $\ldots \ldots \ldots \ldots \ldots \ldots \ldots 77$

4.2.2 Incineration at Scientific Ecology Group — Liquid Waste . . . . . . . . . 78

4.3 Miscellaneous Treatment of Liquid Waste $\ldots \ldots \ldots \ldots \ldots \ldots \ldots \ldots \ldots$

4.3.1 Process Waste Treatment Plant and Collection System at Oak Ridge National Laboratory . . . . . . . . . . . . . . . . . . 83

4.3.2 Liquid Treatment at the Winfrith Technology Center ........... 84

5 DISPOSABLES $\ldots \ldots \ldots \ldots \ldots \ldots \ldots \ldots \ldots \ldots \ldots \ldots \ldots \ldots \ldots \ldots$

5.1 Compaction $\ldots \ldots \ldots \ldots \ldots \ldots \ldots \ldots \ldots \ldots \ldots \ldots \ldots \ldots \ldots$

5.1.1 Consolidated Baling Machine Company . . . . . . . . . . . . . . 88

5.1.2 Compacting Equipment from Stock Equipment Company . . . . . . . . . 90

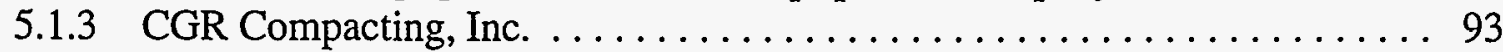

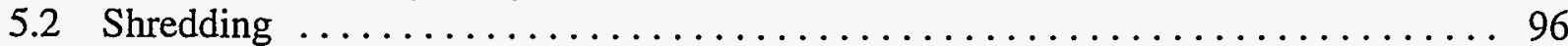

5.2.1 SSI Shredding Systems, Inc. . . . . . . . . . . . . . . . . 97

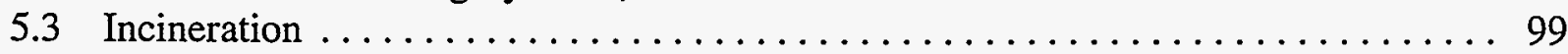

5.3.1 Incineration at Kernforschungszentrum Karlsruhe . . . . . . . . . . . . . 99

5.3.2 Incineration at the Dounreay Nuclear Facility $\ldots \ldots \ldots \ldots \ldots \ldots \ldots \ldots 1$

5.3.3 Incineration at Scientific Ecology Group - Solid Waste . . . . . . . . . 103

5.3.4 Incineration at Los Alamos National Laboratory . . . . . . . . . . . . . . . . 107

5.3.5 Incineration at the Savannah River Site . . . . . . . . . . . . . . . . 109

5.3.6 Harper Electric Furnace Corporation Furnaces and Kilns . . . . . . . . . 110 


\section{CONTENTS (Cont.)}

6 OTHER WASTE MINIMIZATION PRACTICES $\ldots \ldots \ldots \ldots \ldots \ldots \ldots \ldots \ldots \ldots \ldots$

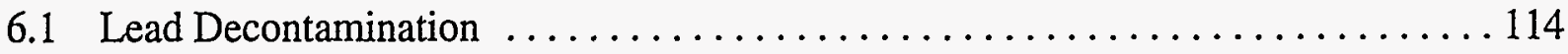

6.1.1 Lead Decontamination at the Scientific Ecology Group . . ........... 114

6.1.2 Lead Decontamination Techniques at Oak Ridge National Laboratory . . . . . 116

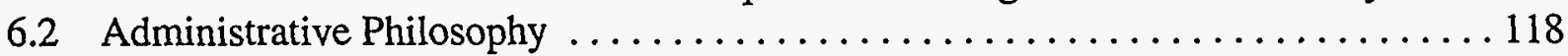

6.2.1 Pollution Prevention Waste Minimization Philosophy at Idaho

National Engineering Laboratory ....................... 118

6.2.2 Waste Minimization Philosophy at Westinghouse Hanford Company . . . . 120

6.2.3 Waste Minimization Philosophy at Pacific Northwest Laboratory . . . . . . 122

6.2.4 Waste Minimization Philosophy at the Winfrith Technology Center ..... 124

6.2.5 Waste Minimization Philosophy at the Sellafield Nuclear Facility ....... 126

6.2.6 Waste Minimization Philosophy at Kernkraftwerke Gundremmingen Betriebsgesellschaft mbH ......................... 127

6.2.7 Waste Minimization Philosophy at the Savannah River Site . . . . . . . . . 129

6.2.8 Waste Minimization Philosophy at Argonne National

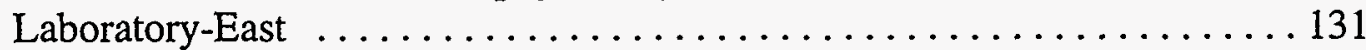

6.3 Independent Studies and Developing Technologies ................. 133

6.3.1 Transuranic Size Reducing Facility at Los Alamos



6.3.2 ASME Radwaste Systems Transportation Packaging and Disposal Subcommittee Questionnaire: Power Plant Waste Minimization Techniques ......................... 135

6.3.3 Molten Metal Technology, Inc.: CEP and Quantum-CEPTM ........... 139

6.3.4 Plasma Hearth Process Demonstration at Argonne National Laboratory-West .............................. 144

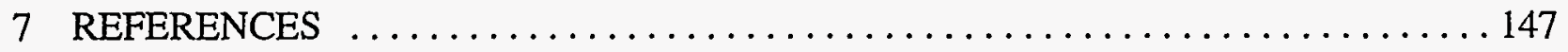

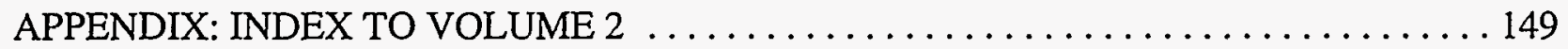

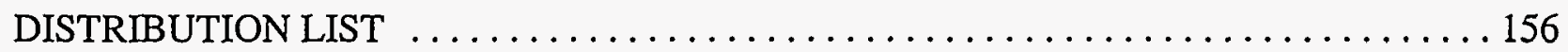

\section{TABLES}

1 SEG Radiological Criteria for Metal Recycling $\ldots \ldots \ldots \ldots \ldots \ldots \ldots \ldots \ldots$

2 SEG Radiological Criteria for Reducing the Volume of Metal ................ 14

3 Composition of Plutonium-52 and Plutonium- $83 \ldots \ldots \ldots \ldots \ldots \ldots \ldots \ldots \ldots$ 


\section{TABLES (Cont.)}

4 Volume Reduction from Supercompaction $\ldots \ldots \ldots \ldots \ldots \ldots \ldots \ldots \ldots \ldots \ldots \ldots \ldots \ldots \ldots$

5 SEG Radiological Criteria for Dry Active Waste Compaction $\ldots \ldots \ldots \ldots \ldots \ldots .27$

6 Decontamination Factor Measurements for Various Abrasives $\ldots \ldots \ldots \ldots \ldots \ldots 4$

7 Summary of Results Obtained When Judging a Decontamination Technique $\ldots \ldots \ldots$. 58

8 Evaporation Plants at Kernforschungszentrum Karlsruhe $\ldots \ldots \ldots \ldots \ldots \ldots \ldots \ldots$

9 RCRA/TSCA Radiological Limits for Both Burnable Oil and Aqueous Liquids . . . . . . 79

10 SEG RCRA/TSCA Limits for the Incineration of Both Burnable Oil and Aqueous Liquids $\ldots \ldots \ldots \ldots \ldots \ldots \ldots \ldots \ldots \ldots \ldots \ldots \ldots \ldots \ldots$

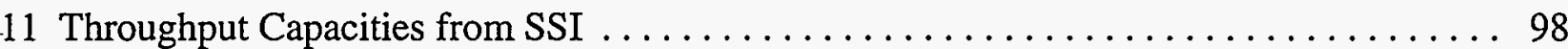

12 Radiological Limits for Bulk Dry Active Waste . . . . . . . . . . . . . . . . . . . . . 104

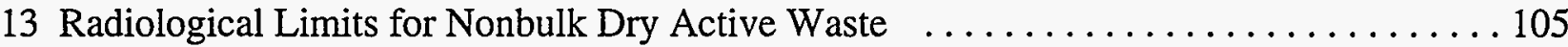

14 Radiological Limits for Animal/Biological Waste $\ldots \ldots \ldots \ldots \ldots \ldots . \ldots \ldots \ldots$

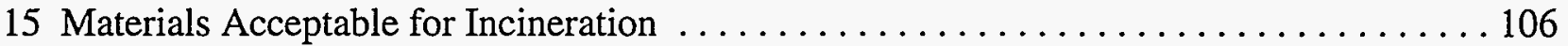

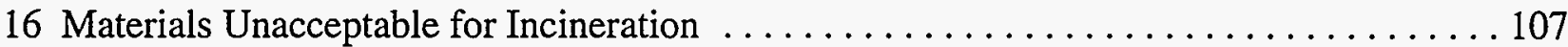

17 Types of Wastes Processed by Contractor and Number of Survey Mentions . . . . . . 136

18 Radwaste Volume Reduction Methods Identified as "Most Effective"

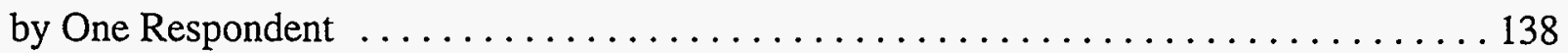

19 Techniques Identified by One Respondent as Worthy of Implementation . . . . . . . 139

20 Radionuclide Partitioning for Contaminated Metals ................... 142

21 Ion-Exchange Resin Bench-Scale Tests — Partitioning Strategy vs. Volume Reduction . . . . . . . . . . . . . . . . . . . . . . . . . . . . . . . . . 143

22 Ion-Exchange Resins Bench Tests - Decontamination Factor $\ldots \ldots \ldots \ldots \ldots \ldots$ 


\section{FIGURES}

1 Secondary Waste Mass Distribution from a Melting Program at the

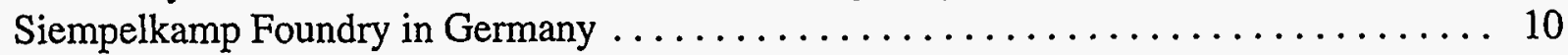

2 Distribution of Materials after Melting at the Siempelkamp Foundry in Germany ...... 11

3 Distribution of Radioactivity after Melting at the Siempelkamp

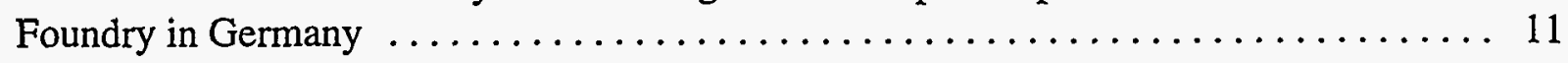

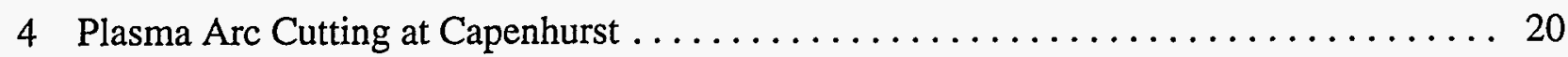

5 Daily Throughput of the Supercompactor at Winfrith for $1993 \ldots \ldots \ldots \ldots \ldots . \ldots 24$

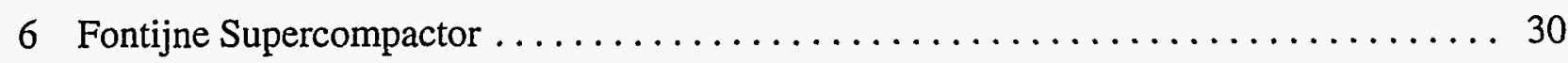

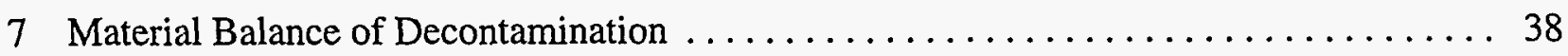

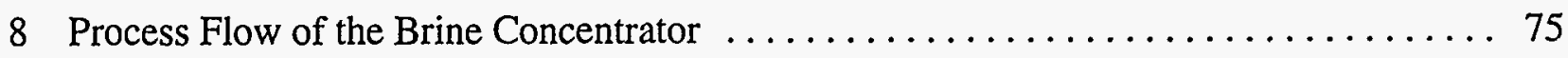

9 Consolidated Baling Machine Company Model DOS-RAW-W1 $\ldots \ldots \ldots \ldots \ldots \ldots 8$

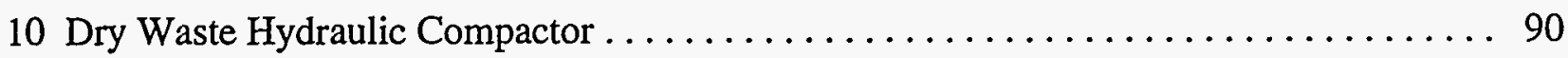

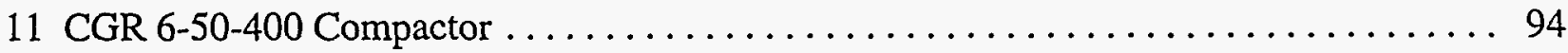

12 Shredder Made by SSI Shredding Systems, Inc. . . . . . . . . . . . . . . 97

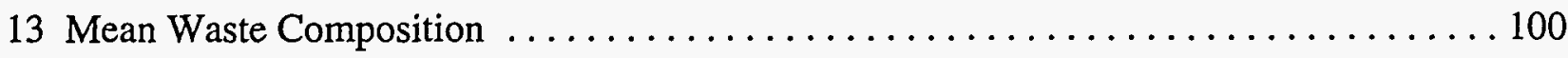

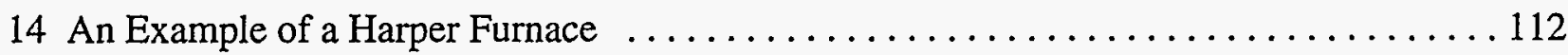

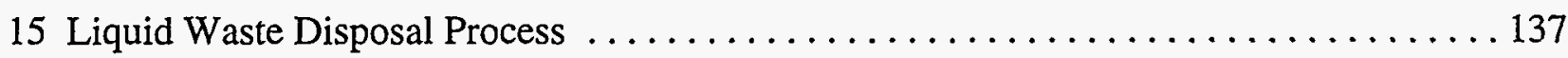

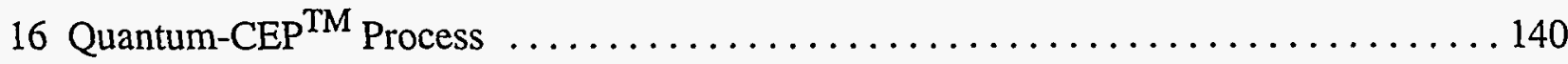




\section{ACKNOWLEDGMENTS}

The Decontamination and Decommissioning Projects Department of Argonne National Laboratory's Technology Development Division wishes to acknowledge the contributions of Dennis Reisenweaver and John Aldana of NES, Inc., in preparing this handbook. An additional expression of appreciation is extended to Park Owen and the Remedial Action Program Information Center staff of Lockheed Martin Energy Systems at Oak Ridge National Laboratory for providing the initial database of bibliographic information. We also thank the following organizations that contributed in technical areas and/or reviews:

AEA O'Donnell, Inc.

American Society of Mechanical Engineers

British Nuclear Fuels, plc

- Capenhurst Works

- Sellafield

Cogema, Inc.

Consolidated Baling Machine Company

CRG Compacting, Inc

EET, Inc.

EG\&G Rocky Flats

Fontijne Supercompactors

Harper Electric Furnace Corporation

Idaho National Engineering Laboratory :

Kernforschungszentrum Karlsruhe $\mathrm{GmbH}$

Kernkraftwerke Gundremmingen

Betriebsgesellschaft mbH
Los Alamos National Laboratory

Molten Metal Technology, Inc.

Oak Ridge National Laboratory

Pacific Northwest National Laboratory

Pentek, Inc.

Resource Conservation Company

Savannah River Site

Scientific Ecology Group

Siempelkamp Giesserei GmbH

SSI Shredding Systems, Inc.

Stock Equipment Company

U.K. Atomic Energy Authority

- Dounreay

- Harwell

- Winfrith

Westinghouse Hanford Company 


\section{NOTATION}

The following is a list of the acronyms, initialisms, and abbreviations (including chemicals and units of measurement) used in this document.

\section{ACRONYMS, INITIALISMS, AND ABBREVIATIONS}

\begin{tabular}{|c|c|}
\hline AEA & U.K. Atomic Energy Authority \\
\hline ALARA & as low as reasonably achievable \\
\hline ANL & Argonne National Laboratory \\
\hline ASME & American Society of Mechanical Engineers \\
\hline BNFL & British Nuclear Fuels, plc \\
\hline CEP & catalytic extraction process \\
\hline CWDS & concentrated waste dryer system \\
\hline$D \& D$ & decontamination and decommissioning \\
\hline DAW & dry active waste \\
\hline DDS & dustless decontamination system \\
\hline DOE & U.S. Department of Energy \\
\hline $\mathrm{E} / \mathrm{C}$ & evaporator/condenser \\
\hline ECD & Environmental Control Division (at Idaho National Engineering Laboratory) \\
\hline ECP & environmental control product \\
\hline $\mathrm{EHC}$ & electrohydraulic control \\
\hline EPA & U.S. Environmental Protection Agency \\
\hline EPRI & Electric Power Research Institute \\
\hline GNS & Gesellschaft für Nuklear Service \\
\hline $\mathrm{HDB}$ & Hauptabteilung Dekontaminationsbetriebe \\
\hline HEPA & high-efficiency particulate air \\
\hline ICPP & Idaho Chemical Processing Plant \\
\hline INEL & Idaho National Engineering Laboratory \\
\hline ISO & International Organization for Standardization \\
\hline $\mathrm{KfK}$ & ntrum Karlsruhe (Nuclear Research Center) \\
\hline
\end{tabular}


LANL Los Alamos National Laboratory

LLNL Lawrence Livermore National Laboratory

LLW low-level radioactive waste

MLW medium-level waste

MMT Molten Metal Technology, Inc.

NFPA National Fire Protection Association

NRC U.S. Nuclear Regulatory Commission

NTIS National Technical Information Service

ORNL Oak Ridge National Laboratory

PAC plasma arc cutting

PHP plasma hearth process

PNL Pacific Northwest Laboratory

PVC polyvinyl chloride

PWA process waste assessment

PWR pressurized water reactor

PWTP process waste treatment plant

RAPIC Remedial Action Program Information Center

RCA radiological control area

RCC Resources Conservation Company

RCRA Resource Conservation and Recovery Act

RMW radioactive mixed waste

SAIC Science Applications International Corporation

SEG Scientific Ecology Group, Inc.

SRF Size Reduction Facility (at Los Alamos)

SRS Savannah River Site

TCLP toxicity characteristic leaching procedure

TDS total dissolved solids

TRU transuranic (waste)

TSCA Toxic Substances Control Act

WHC Westinghouse Hanford Company

WINCO Westinghouse Idaho Nuclear Company, Inc.

WIPP Waste Isolation Pilot Plant

WRC Waste Reduction Center (at Babcock \& Wilcox) 


\section{CHEMICALS}

$\mathrm{CO}_{2} \quad$ carbon dioxide

$\mathrm{NO}_{\mathrm{x}} \quad$ nitrogen oxide(s)

PCB polychlorinated biphenyl(s)

$\mathrm{SO}_{\mathrm{x}} \quad$ sulfur oxide(s)

\section{UNITS OF MEASUREMENT}

A

bar

$\mathrm{Bq}$

Btu

${ }^{\circ} \mathrm{C}$

$\mathrm{cm}$

$\mathrm{cm}^{2}$

$\mathrm{cm}^{3}$

$\mathrm{cpm}$

d

${ }^{\circ} \mathrm{F}$

$\mathrm{ft}$

$\mathrm{ft}^{2}$

$\mathrm{ft}^{3}$

$\mathrm{ft}^{3} / \mathrm{min}$

g

gal

$\mathrm{GBq}$

$\mathrm{h}$

hp

$\mathrm{Hz}$

in. inch(es)

ampere(s)

$\operatorname{bar}(\mathrm{s})$

becquerel(s)

British thermal unit(s)

degree(s) Celsius

centimeter(s)

square centimeter(s)

cubic centimeter(s)

count(s) per minute

day(s)

degree(s) Fahrenheit

foot (feet)

square foot (feet)

cubic foot (feet)

cubic feet per minute

$\operatorname{gram}(\mathrm{s})$

gallon(s)

gigabecquerel(s)

hour(s)

horsepower

hertz 


\begin{tabular}{|c|c|}
\hline $\mathrm{K}$ & degrees Kelvin \\
\hline $\mathrm{kBq}$ & kilobecquerel(s) \\
\hline $\mathrm{kg}$ & kilogram(s) \\
\hline $\mathrm{kN}$ & kilonewton(s) \\
\hline $\mathrm{kPa}$ & kilopascal(s) \\
\hline $\mathrm{kWh}$ & kilowatt-hour(s) \\
\hline $\mathrm{L}$ & liter(s) \\
\hline $\mathrm{lb}$ & pound(s) \\
\hline $\mathrm{m}$ & meter(s) \\
\hline $\mathrm{m}^{2}$ & square meter(s) \\
\hline $\mathrm{m}^{3}$ & cubic meter(s) \\
\hline $\min$ & minute(s) \\
\hline $\mathrm{MPa}$ & megapascal(s) \\
\hline mrem & millirem(s) \\
\hline $\mathrm{mSv}$ & millisievert(s) \\
\hline$\mu \mathrm{Sv}$ & microsievert(s) \\
\hline MW & megawatt(s) \\
\hline $\mathrm{nCi}$ & nanocurie(s) \\
\hline ppm & part(s) per million \\
\hline psi & pound(s) per square inch \\
\hline $\mathrm{rpm}$ & revolution(s) per minute \\
\hline ssu & second(s) saybolt universal \\
\hline $\mathrm{Sv}$ & sievert(s) \\
\hline $\mathrm{t}$ & metric ton(s) \\
\hline $\mathrm{TBq}$ & teslabecquerel(s) \\
\hline ton & short ton(s) \\
\hline V & volt(s) \\
\hline yr & year(s) \\
\hline
\end{tabular}




\title{
WASTE MINIMIZATION HANDBOOK
}

by

Lawrence E. Boing and Michael J. Coffey

\section{SUMMARY}

This Waste Minimization Handbook is a two-volume technical guide that provides information for minimizing low-level radioactive waste generated during decommissioning activities. The operation and subsequent decommissioning of a nuclear facility generate significant amounts of radioactive waste material. Volume 1 of this handbook identifies the technologies and techniques currently used to minimize this waste. The emphasis is on reducing generated radioactive waste that will require disposal. The handbook is divided into sections that pertain to metallic, concrete, liquid, disposable, and miscellaneous wastes, respectively. An index refers the reader to contact names and companies for further details on specific techniques.

Volume 2 of the Waste Minimization Handbook will be released in late 1996. It will include techniques used to recycle and reuse waste materials and to reduce the overall volume of radioactive waste. It will consist of abstracts of more than 600 topical papers related to waste minimization techniques and data. Once Volume 2 is published, readers can use the index and list of keywords to identify the technologies and research papers most applicable to their waste streams. The two volumes will give a comprehensive overview of available and developing waste minimization technologies.

This handbook should be used in conjunction with the Decommissioning Handbook, prepared for the U.S. Department of Energy, for a complete summary of current decontamination, waste minimization, and decommissioning techniques.

\begin{abstract}
This technical guide presents various methods used by industry to minimize low-level radioactive waste (LLW) generated during decommissioning and decontamination (D\&D) activities. Such activities generate significant amounts of LLW during their operations. Waste minimization refers to any measure, procedure, or technique that reduces the amount of waste generated during a specific operation or project. Preventive waste minimization techniques
\end{abstract}


implemented when a project is initiated can significantly reduce waste. Techniques implemented during decontamination activities reduce the cost of decommissioning. The application of waste minimization techniques is not limited to D\&D activities; it is also useful during any phase of a facility's life cycle. This compendium will be supplemented with a second volume of abstracts of hundreds of papers related to minimizing low-level nuclear waste.

\section{INTRODUCTION}

This Waste Minimization Handbook provides technical guidance for minimizing low-level radioactive waste (LLW) during decontamination and decommissioning (D\&D) operations. Waste minimization refers to any measure, procedure, or technique that reduces the amount of waste generated during a specific operation or project. Waste minimization can be divided into three general categories: techniques that control the generation of waste, techniques that decontaminate or otherwise remove material from the waste stream, and techniques that reduce the volume of space occupied by generated waste. Project management can apply waste minimization techniques at all stages of a facility's life cycle. For example, preventive waste minimization techniques implemented early in the facility's life cycle can significantly reduce waste. Waste minimization techniques implemented during decontamination activities reduce the overall cost of decommissioning. The U.S. Department of Energy (DOE) has therefore established a policy for all sites to minimize or reduce the amount of radioactive and hazardous waste generated during remediation activities.

This handbook describes waste minimization methods associated with the D\&D of nuclear facilities. The $D \& D$ of a facility refers to measures necessary for safe shutdown of a nuclear facility. Decontamination is a process for removing radioactive contamination and materials from personnel, equipment, or areas. Decontamination techniques include washing, heating, chemical or electrochemical action, mechanical cleaning, and so on. Decommissioning is the process of removing nuclear and hazardous material from a facility so that the facility can be used for unrelated purposes. The methods included in this handbook apply primarily to the minimization of LLW, although they may be incorporated to minimize other forms of waste. However, they do not necessarily apply to high- or intermediate-level waste nor are they designed to minimize the generation of hazardous or "clean" (i.e., nonradioactive, nonhazardous) waste.

Although this handbook contains waste minimization techniques for $\mathrm{D} \& \mathrm{D}$, the application of these techniques is not limited to activities associated with D\&D. Many of the techniques included in this handbook can be implemented during any phase of the facility life cycle, from construction through operations to D\&D. 


\subsection{WASTE MINIMUZATION PROGRAM OVERVIEW}

The objective of a waste minimization program is to reduce LLW generated during D\&D projects, although many techniques included herein also apply to waste generated throughout a facility's lifetime. This handbook presents an overview of techniques and methods currently used to minimize LLW. These techniques and services apply to facilities under construction, in operation, or in safe shutdown. They range from methods that include multimillion-dollar, state-of-the-art technical equipment to simple administrative controls. The importance of implementing a waste minimization program is summarized as follows:

- Waste minimization practices reduce detrimental impacts on the environment that are associated with radionuclide migration and contamination by reducing the volume of waste that requires disposal.

- Activities associated with the processing, treatment, surveillance, maintenance, and disposal of radioactive waste are expensive and timeconsuming. Often the original facility cost estimates do not account for the costs associated with $\mathrm{D} \& \mathrm{D}$ and waste storage. Waste minimization practices help to reduce the overall expenses related to decommissioning a radioactive facility by reducing these additional costs.

- Finally, a less tangible, but equally important, benefit of waste minimization is public perception. Waste minimization increases the public perception that waste generators are expanding efforts to clean the environment and maintain good public relations.

Many of the sites visited while conducting research for this project addressed a number of common concerns. The Oak Ridge National Laboratory (ORNL) Complex, Los Alamos National Laboratory (LANL), Idaho National Engineering Laboratory (INEL), and other sites identified the lack of definitive release criteria for radioactive materials as a major concern. For example, if an item at INEL is slightly contaminated, the entire item is considered contaminated and is disposed of as radioactive waste. Definitive release criteria would allow the disposal of portions of the item as clean waste, as long as contamination levels were below defined limits. Further, transferring LLW to different departments within a national laboratory or to a private contractor for treatment often follows unclear transition processes. The transition process must be clarified to maintain compliance with applicable federal, state, local, and DOE regulations. Finally, a major concern identified by the ORNL Complex is the volume of recyclable waste generated annually versus current recycling capabilities. Current capabilities allow the total annual recycling of approximately $907,000 \mathrm{~kg}$ ( 2 million $\mathrm{lb}$ ) of radioactive material. However, approximately 3.18 million $\mathrm{kg}$ ( 7 million $\mathrm{lb}$ ) of recyclable material is expected to be generated annually from a single decommissioning project - the Y-12 Project in Oak Ridge, Tennessee. This handbook does not provide solutions to 
these concerns; however, it does take the first step in identifying these common concerns and finding ways to reach viable solutions.

\subsection{PURPOSE AND SCOPE}

The purpose of the Waste Minimization Handbook is to provide easy access to descriptions of current waste minimization techniques and practices. This single, convenient resource provides an efficient means for the reader to research waste minimization technologies. This comprehensive reference manual focuses on successfully implemented, state-of-the-art technologies.

The descriptions (overviews) included in this handbook offer technical guidance on current waste minimization techniques, focusing on available or developing technologies. This focus allows readers to further research the technologies and specific techniques most appropriate to their needs. Each overview lists reference documents or contact names and numbers for obtaining additional information about a specific technique or product. This handbook is primarily a technology identification document. To encompass all technological aspects of all waste minimization techniques is beyond the scope of this handbook.

The Waste Minimization Handbook includes abstracts from a Waste Minimization Database. This database contains additional pertinent information on recently published waste minimization research papers. Many of the techniques identified in this database are included in this handbook. A comprehensive literature search was performed to develop the Waste Minimization Database. Current information in existing databases was obtained from the Remedial Action Program Information Center (RAPIC), the Electric Power Research Institute, the National Technical Information Service, the U.S. Environmental Protection Agency (EPA), the U.S. Nuclear Regulatory Commission (NRC), and foreign institutions. The Waste Minimization Database is the result of reviewing and reducing the source databases for information applicable to waste minimization, with an emphasis on techniques used during D\&D activities.

Volume 2 of this handbook will contain all of the abstracts entered in this database. ${ }^{1}$ Users can identify relevant papers through the index by using keywords (see Appendix). The abstracts summarize specific field research, whereas the Waste Minimization Handbook gives a broad overview of various minimization techniques. Thus, when the two volumes are used together, the reader will have a comprehensive overview of waste minimization techniques. Copies of complete papers can be obtained through the information services listed in the database.

Waste minimization information was also obtained by visiting sites that have incorporated waste minimization techniques, including DOE facilities around the United States and sites in

\footnotetext{
1 Volume 2 will be published in late 1996.
} 
France, Germany, and the United Kingdom. Emphasis was placed on D\&D waste minimization/source reduction techniques. The techniques included in this handbook are based on the information gathered during the literature search and on information obtained during DOE and foreign site visits.

Many innovative decommissioning techniques were observed at the foreign sites. Although these techniques are outside the scope of this project, they are worth mentioning. For example, ice helped in dismantling a steam generator at the Gundremmingen decommissioning project in Germany. A circular saw first cut the generator into bands. The generator was then filled with water, which was frozen before cutting activities began. The ice stabilized the steam generator, cooled the saw, and acted as a radiation shield while dismantling the generator.

\subsection{HANDBOOK ORGANIZATION}

The Waste Minimization Handbook provides methods applicable for decommissioning operations to organizations responsible for facility D\&D. It is organized into technologies applicable to various types of LLW. The technologies are then subdivided into descriptions of specific techniques and practices within the technology. These descriptions are collected from recently completed and current decommissioning projects and are aimed at determining how the waste minimization philosophy was incorporated into the various projects. Often a facility had specific equipment designed for routine volume reduction and waste minimization, such as a compactor or incinerator. In this case, information, including costs, throughput rates, and volume reduction/decontamination ratios, is given for incorporating the equipment into the facility, if the information is available. Vendors and corporations designed to receive and process radioactive waste also supplied information concerning product capabilities. The general topics covered in each of the waste minimization descriptions include the following:

- Technique or product information, specifications, and descriptions, including generators responsible for incorporating the equipment or technique and the location;

- Required condition of waste, including physical, radiological, or chemical limitations;

- Administrative and training requirements;

- Applicable results, including

- Costs associated with the technique or equipment,

- Volume reduction and decontamination ratios, including the effectiveness of the equipment or technique, and

- Recycle/reuse applications; 
- Advantages, disadvantages, and problems identified in the application of the technique or equipment; and

- Referral contacts.

The content of this handbook is based on information provided by contributors, as identified. Information on these topics is identified by topic heading, or section, in each overview, as applicable. Some techniques may not lend themselves to certain topics, and information on topics for particular examples may not be available. When information is not included in the technique descriptions, a note states that the information was unavailable.

The handbook is divided into six sections: the introduction and those sections pertaining to a particular waste stream, including metal, concrete, liquid, disposable, and miscellaneous waste. Each section is further divided into waste minimization technologies. For example, the section on disposable waste is divided into compaction, shredding, and incineration technologies. Each technology description contains specific examples or techniques, demonstrating successful implementation of the minimization method. Entries that did not fit into a specific waste stream were placed into "Miscellaneous." This final section also includes waste minimization philosophies incorporated at various facilities and laboratories.

Each technique description is identified by the $D \& D$ project where the technique was implemented, the manufacturer of a product used to minimize LLW, or the facility that provided waste minimization services. Background information about the technique is summarized. Any required pretreatment conditions or radiological limits for the waste are included. Results given include costs, volume reduction ratio and rates, and recycle/reuse applicability:

- Cost results present all expenditures and savings associated with the technique, including initial expenses, surveillance and maintenance expenses, costs per unit volume or weight, and savings associated with this method versus other applicable methods.

- Volume reduction ratio and rate results contain information about the achieved volume reduction and decontamination ratios, feed throughputs, and any additional waste minimization results.

- Recycle/reuse applicability contains all information on the intended recycling or reuse of the decontaminated material or the decontamination media.

The discussion on the advantages and disadvantages of using the technique under specific circumstances includes any identified operational problems and their solutions. Finally, contact names and numbers are provided to enable the user to obtain additional information. 
The index, provided in the Appendix, lists keywords and the number of the associated abstract, which will be available in Volume 2 in late 1996. The user can search the abstracts to find additional keywords. 


\section{METALS}

The waste minimization techniques described herein pertain to the reduction of metallic LLW. The minimization technologies include smelting, plasma arc cutting, supercompaction, and decontamination. The technique descriptions provide information concerning the precondition of the waste, specifics on individual technical parameters, volume reduction and decontamination factors, available cost information, and any practical limitations. Readers should base the decision to adapt a practical technique of a particular technology on their specific needs, the total dose received by personnel implementing the technique, and a cost comparison. The cost comparison should compare the total cost of implementing the technique and disposing of the resultant concentrated radioactive material with the cost savings from the waste volume reduction. While detailed cost analyses are facility-specific and beyond the scope of this handbook, basic cost information is provided when available. The user should refer to the contact names for more detailed information.

\subsection{SMELTING TECHNIQUES}

Smelting is the process by which radioactive contamination is removed from metallic waste by transforming the contaminated scrap metal into a liquid state within an electric induction furnace. Compounds can be melted in a refractory chamber at varying temperatures, allowing for separation of the component metals. The design of the smelting system primarily depends on the metal input (feedstock), the method of placing the feedstock into the furnace, and the way in which the molten product is poured. The primary processing variables in the smelting and metal refining process are the admixtures and the temperature of the molten bath. By controlling these variables, the operator can maintain a homogenous mixture in the molten bath and maximize the amount of radioactive contamination captured in the slag. This capability allows the desired reactions to occur, resulting in the appearance of three strata: molten metal, slag, and charge. In metal refining, the molten metal stratum may consist of several metals. The slag forms on the surface of the melt and usually contains the majority of radioactive contamination. The remaining metal may then be recycled and reused in various applications. The slag is disposed of as radioactive waste.

The frequency and manner of temperature variations, and the type of detrimental chemical reactions that occur during the smelting process, control the overall refractory life. For example, controlled water flow through the membrane furnace walls creates a frozen slag liner that reduces the detrimental chemical reaction rates. This capability extends refractory life at a slight expense, (i.e., additional energy loss).

Two types of feedstock loaders - feed chutes and screw conveyors - are used during continuous operation because each conveyor can easily be designed to minimize inleakage. Admixture inlets, electrodes, and torches can be attached to the roof, ensuring easy maintenance 
activities and minimizing line losses between the electrodes and the transformers. However, this limits the feed-chute area, which in turn limits the charge size. Through means of a crane and bucket, batch operations provide an alternative loading system. In one smelting operation, one furnace load requires three bucket loads. Batch operations reduce the average throughput rate, increase maintenance costs, and potentially increase the emission rate. However, batch operations decrease the costs associated with feedstock preparation.

Three facilities were visited to obtain waste minimization data on smelting techniques: the Siempelkamp Giesserei GmbH (hereafter referred to as the Siempelkamp foundry) foundry in Germany, the Scientific Ecology Group (SEG) foundry in Tennessee, and the Capenhurst Works facility in the United Kingdom. The smelting techniques and waste minimization, recycling, and reuse results were compared and contrasted among these three facilities.

\subsubsection{Smelting at the Siempelkamp Foundry}

Radioactive metallic waste is shipped to the Siempelkamp foundry in 200-L drums or 6.1-m (20-ft) ISO containers. Drums that contain material are placed directly into the furnace. Material provided in ISO containers is sorted, placed in a compactor, and shredded with shears to provide minimum void spaces. The compactor is a 450-metric ton ( $t$ ) hydraulic unit made by Becker (Dortmund, Germany). The compacted, shredded scrap metal is placed in bins for emptying into the furnace. The metal is first put through the primary melt in which the metal is molten and cast into ingots for storage. The primary melting unit is a 3.2-t-capacity, medium-frequency induction furnace. The scrap metal is placed into the furnace with $2 \%$ silicon and $3 \%$ coke. The furnace is completely encapsulated, and dust generated during the process is immediately drawn off through a filter plant. The filter plant has a capacity of $36,000 \mathrm{~m}^{3} / \mathrm{h}$ with directional air guidance. A redundant filter system is linked through a computer to activate immediately if the primary system fails. Each filter system consists of a cyclone filter, a bag filter, and a high-efficiency particulate air (HEPA) filter.

The radioactive slag and filter dust are separated from the molten metal and returned to the material supplier in 200-L drums. The slag comprises approximately 5\% of the metal. After the smelting process, $1 \%$ of the alpha contamination (uranium, plutonium, americium) remains in the metal, with $98 \%$ collected in the slag and $1 \%$ collected in the dust. Approximately $50 \%$ of the betagamma activity is retained in the slag and dust. All tritium contamination is released through the stack or into charcoal filters, all zinc- 65 contamination is released through the ventilation system, and $95 \%$ of europium contamination is retained in the slag. The dust contains approximately $55 \%$ of any cesium contamination, and an additional $45 \%$ is retained in the slag. Figure 1 represents the mass distribution of secondary waste from a $100-t$ melting program for uranium-contaminated steel performed at Siempelkamp. 


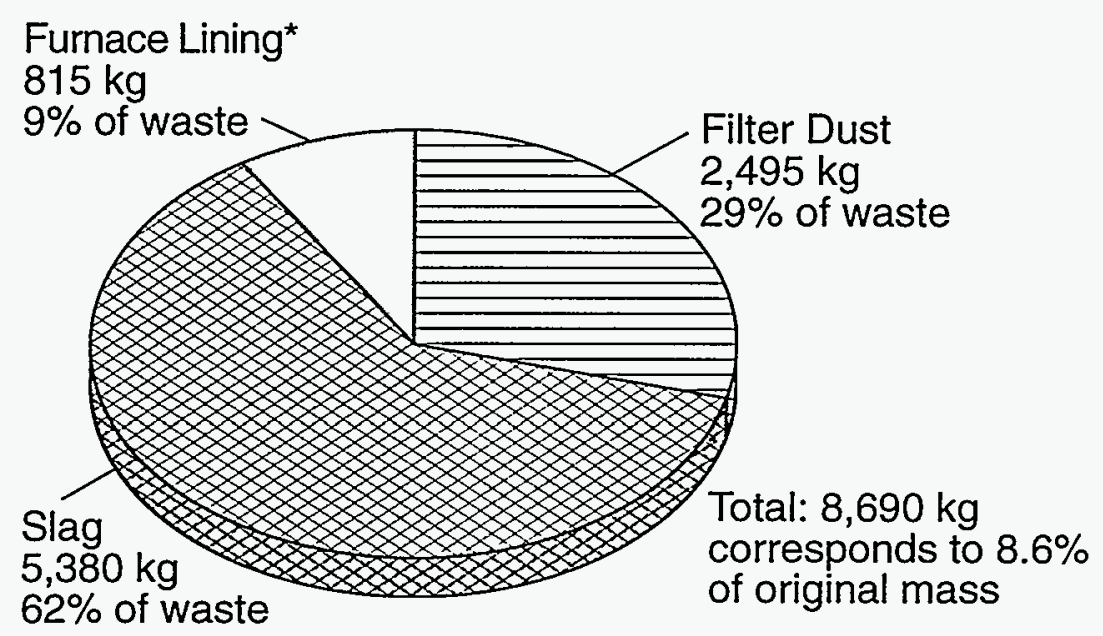

*Includes $25 \%$ of replaced furnace lining

LBA2603

FIGURE 1 Secondary Waste Mass Distribution from a Melting Program at the Siempelkamp Foundry in Germany (LBA2603-E)

The recycled material is then placed through a secondary melt. Metals are separated by composition and cast into blocks or waste containers. Currently, Siempelkamp has processed $80 \mathrm{t}$ of scrap contaminated metal from the Gundremmingen decommissioning project. A total of 7,000 t have been processed at Siempelkamp.

Figure 2 shows the distribution of materials after melting, while Figure 3 shows the distribution of radioactivity after melting. Information for Figures 2 and 3 was obtained from Bosse et al. (1993).

\subsubsection{Required Conditions and Characteristics of Waste}

The Siempelkamp foundry can process stainless steel, carbon steel, copper, brass, aluminum, and lead. Materials received by Siempelkamp are limited to $200 \mathrm{~Bq} / \mathrm{g}$ on average. The maximum length of material put into the primary melt is $80 \mathrm{~cm}$, and the maximum diameter is $50 \mathrm{~cm}$.

\subsubsection{Administrative and Training Requirements}

The first melt radiological limit for fissile material in the waste metal is $3 \mathrm{~g} / 100 \mathrm{~kg}$ and $2.4 \mathrm{~Bq} / \mathrm{g}$ for uranium-235. The limit per charge is $200 \mathrm{~Bq} / \mathrm{g}$. The maximum radioactivity limit per charge for the second melt is $200 \mathrm{~Bq} / \mathrm{g}$. 


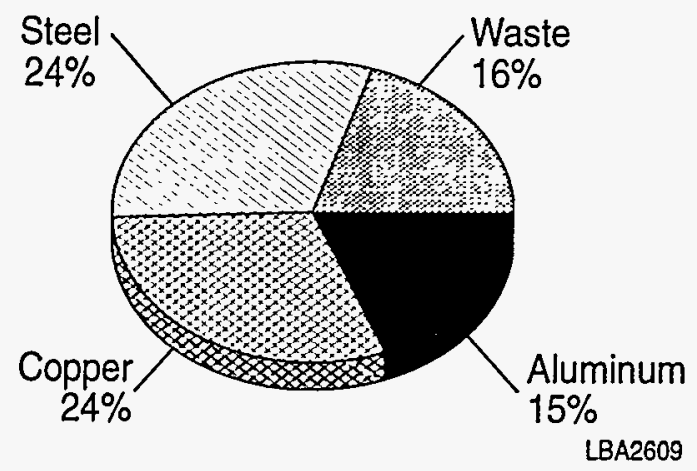

FIGURE 2 Distribution of Materials after Melting at the Siempelkamp Foundry in Germany (Source: adapted from Bosse et al. [1993]) (LBA2609-E)

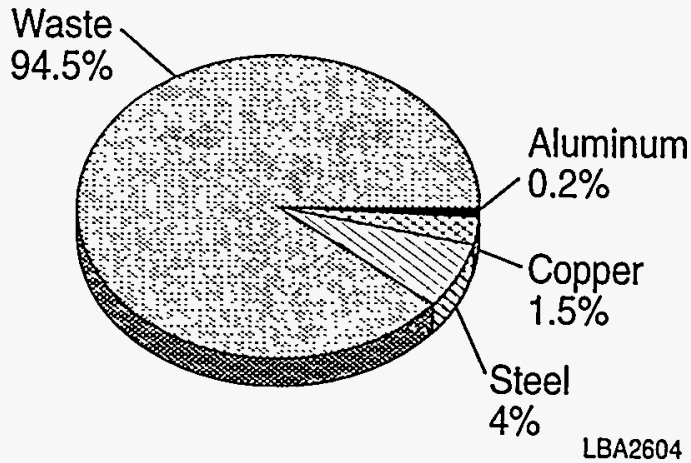

FIGURE 3 Distribution of Radioactivity after Melting at the Siempelkamp Foundry in Germany (Source: adapted from Bosse et al. [1993]) (LBA2604-E)

\subsubsection{Results}

- Costs. Costs concerning the melting facilities at Siempelkamp were not available.

- Volume reduction ratio and rates. The melting rate of the primary furnace is $2,000 \mathrm{~kg} / \mathrm{h}$. The decontamination factor for aluminum, brass, and copper is $100 \%$ and free release of the material. The total drum weight is $3,000 \mathrm{~kg}$. Liners are changed after each customer, and this operation takes two days to accomplish. The total metal processed to date is $7,000 \mathrm{t}$, of which $280 \mathrm{t}$ was returned to the supplier of the scrap as waste (slag, dust), giving an overall volume reduction factor of $25: 1$. The total waste generated by the first melt process is approximately $1.2 \%$ slag, $0.2 \%$ dust, and $0.6 \%$ for the crucible. The total waste including secondary waste is between 3.5 and $4 \%$ for the entire process.

- Recycle/reuse. The smelted metal is used to make storage containers and other materials. Components with the lowest radiological requirements (i.e., lowest decontamination factors) are shielding beams, plates, and cubes. The second level of applications are shielding doors and partitions, which have to be designed to meet certain static requirements. The third level of requirements are those for IP-2 Type A packages. The fourth level are Type B containers for high- and medium-level radioactive materials. The fifth and highest level requirements (i.e., metal with the highest decontamination factors) apply to CASTOR casks produced to transport and store fuel elements. The maximum limit for these shielding blocks and casks is $200 \mathrm{~Bq} / \mathrm{g}$. Approximately $125,000 \mathrm{t}$ of sand per year for molds and forms is 
used, with approximately $95 \%$ of the sand recycled. Siempelkamp currently makes 500 GNS Mosaik II casks per year, with $20 \%$ first melt material and $80 \%$ uncontaminated material. Type B casks use $30-40 \%$ of the first melt material. Shield walls use $50-100 \%$ of first melt material.

\subsubsection{Advantages, Disadvantages, and Problems}

The advantages of the Siempelkamp smelting methods include the homogenization of the radionuclides for representative sampling and separation of distinct radionuclides from the metal. These methods enable greater accuracy in identifying radionuclides. No disadvantages or problems associated with the Siempelkamp smelting process were identified.

\subsubsection{Contacts}

Dr. Manfred Sappok, Managing Director

Siempelkamp Giesserei GmbH

Siempelkampstrasse 45

D-4150 Krefeld, Germany

492151894205 Telephone

$49215189444 \quad$ Fax

\subsubsection{Smelting at the Scientific Ecology Group}

The SEG facility is designed to smelt metallic LLW and reprocess the decontaminated metal. The facility houses a 18,144-kg (20-ton), 7.2-MW, high-efficiency, hydraulically tilted induction furnace with a temperature range in excess of $1,650^{\circ} \mathrm{C}\left(3,000^{\circ} \mathrm{F}\right)$. The furnace is lined with refractory brick. Scrap metal is cut into sections $61 \times 61 \times 15.2 \mathrm{~cm}(2 \times 2 \times 0.5 \mathrm{ft})$ or less and sorted according to material type. Scrap metal is preheated to $\sim 1,182^{\circ} \mathrm{C}\left(1,200^{\circ} \mathrm{F}\right)$ to burn off the oils, rubber, and other combustibles; it is then melted. The melting temperature is $\sim 1,565^{\circ} \mathrm{C}\left(2,850^{\circ} \mathrm{F}\right)$, and the pouring temperature is $\sim 1,593-1,650^{\circ} \mathrm{C}\left(2,900-3,000^{\circ} \mathrm{F}\right)$. The radioactive slag is removed, and the decontaminated metal is molded into shielding blocks. The furnace is continually loaded to capacity after the slag is removed. Investigations are underway for developing special canisters for high-level radioactive waste storage and remotely handled transuranic (TRU) waste from the decontaminated metal.

The ventilation system in the smelting facility includes four separate baghouse and four HEPA filter sysiems with draft fans capable of processing $7,080 \mathrm{~m}^{3}\left(250,000 \mathrm{ft}^{3}\right)$ of air per minute. 
The radioactive slag is sampled (radionuclide content, toxicity characteristic leaching procedure [TCLP]) and stored for up to six months.

\subsubsection{Required Conditions and Characteristics of Waste}

Metals acceptable for smelting are stainless steel, carbon steel, iron, and galvanized metal. Nickel, chromium, and ferrous alloys with melting points at or less than $1,650^{\circ} \mathrm{C}\left(3,000^{\circ} \mathrm{F}\right)$ may also be acceptable. Small quantities (up to $1 \%$ of the total weight) of copper, aluminum, brass, bronze, and stellite are acceptable. Unacceptable materials are lead, tin, mercury, other heavy metals, pyrophorics, and refractory metals with melting points over $1,650^{\circ} \mathrm{C}$ (zirconium, tungsten, tantalum and molybdenum). Packages of waste material sent to SEG may not contain more than trace amounts of magnesium or asbestos. Nonfriable asbestos in insulation or valve packing material may be accepted with prior notice. Metals may not contain more than $1 \%$ burnable material. Tables 1 and 2 give SEG's criteria for metal recycling and metal volume reduction, respectively.

TABLE 1 SEG Radiological Criteria for Metal Recycling

\begin{tabular}{lr} 
Surface-contaminated or & $\begin{array}{r}\text { Radiation Levels } \\
\leq 0.5-\mathrm{mSv} / \mathrm{h} \text { average contact (unshielded) } \\
\leq 5 \mu \mathrm{Sv} / \mathrm{h} \text { average } \\
\text { activated metal }^{\mathrm{a}}\end{array}$ \\
$\begin{array}{l}\text { Radionuclide Limits } \\
\text { The average radionuclide concentration may not exceed the following limits } \\
\text { averaged over the package or component: }\end{array}$ \\
$\begin{array}{lr}\text { Radionuclide } & \text { Average Concentration } \\
\text { Total of all nuclides not listed below } & \leq 7.4 \mathrm{E}-2 \mathrm{kBq} / \mathrm{g} \\
\text { Hydrogen-3 } & \leq 3.7 \mathrm{E}-4 \mathrm{kBq} / \mathrm{g} \\
\text { Carbon-14 } & \leq 1.1 \mathrm{E}-3 \mathrm{kBq} / \mathrm{g} \\
\text { Iodine-129 } & \leq 3.7 \mathrm{E}-6 \mathrm{kBq} / \mathrm{g} \\
\text { Radium-226 (DOE only) } & \leq 370 \mathrm{~Bq} / \mathrm{g} \\
\text { Radium-226 (commercial) } & \text { Prior approval required } \\
\text { TRU } & \leq 37 \mathrm{~Bq} / \mathrm{g} \\
\text { Other special nuclear material } & \text { Prior approval required }\end{array}$ \\
\hline
\end{tabular}

a Average dose rates assume that additional metal will be available for blending to ensure the production of acceptable shield or container material.

b Includes uranium-233, uranium-235, or uranium enriched in the isotope uranium-233 or uranium-235. 
TABLE 2 SEG Radiological Criteria for Reducing the Volume of Metal

Surface-contaminated or activated metal

\section{Radiation Levels}

$\leq 2-\mathrm{mSv} / \mathrm{h}$ average contact (unshielded)

Radionuclide Limits

The average radionuclide concentration may not exceed the following limits averaged over the package or component:

\section{Radionuclide}

Total of all nuclides not listed below

Cobalt- 60

Cesium-137

Hydrogen-3

Carbon-14

Iodine-129

Radium-226 (DOE only)

Radium-226 (commercial)

TRU

Other special nuclear material $^{\mathrm{a}}$

$$
\begin{array}{r}
\text { Average Concentration } \\
\leq 3.7 \mathrm{kBq} / \mathrm{g} \\
\leq 1.85 \mathrm{kBq} / \mathrm{g} \\
\leq 7.4 \times 10^{-2} \mathrm{kBq} / \mathrm{g} \\
\leq 3.7 \times 10^{-4} \mathrm{kBq} / \mathrm{g} \\
\leq 1.1 \times 10^{-3} \mathrm{kBq} / \mathrm{g} \\
\leq 3.7 \times 10^{-6} \mathrm{kBq} / \mathrm{g} \\
\leq 37 \mathrm{~Bq} / \mathrm{g} \\
\text { Prior approval required } \\
\leq 3.7 \mathrm{~Bq} / \mathrm{g} \\
\text { Prior approval required }
\end{array}
$$

a Includes uranium-233, uranium-235, or uranium enriched in the isotope uranium-233 or uranium-235.

\subsubsection{Administrative and Training Requirements}

Waste generators must follow the requirements outlined in SEG (1995).

\subsubsection{Results}

- Costs. The average cost for a DOE contractor to melt metal at the facility is approximately $\$ 2.67 / \mathrm{kg}$.

- Volume reduction ratio and rates. The SEG metal processing facility is designed to process 22.7 million $\mathrm{kg}$ (25,000 ton) of metallic LLW per year. The melting rate of the primary furnace is $5,443 \mathrm{~kg}$ ( $6 \mathrm{ton})$ per hour. The radioactive slag is approximately $3 \%$ of the total weight. The volume reduction ratio is estimated at 20:1. The slag contains up to $99 \%$ of uranium contamination, with comparable percentages for other radionuclides. 
- Recycle/reuse. Two principal avenues for the beneficial reuse of the metals are the manufacture of custom-designed and engineered products with controlled release of the metals to the DOE, and unrestricted release based on surface contamination levels in accordance with the NRC. Currently, the recycled material is used to make customized shielding blocks out of processed, remolded LLW metal. These blocks are delivered to the DOE for use in high-energy physics testing programs. Shielded drum and box configurations, which are used as "overpacks" for LLW storage and/or burial, are also manufactured in the metal melt facility.

\subsubsection{Advantages, Disadvantages, and Problems}

No disadvantages or problems associated with the SEG smelting process were identified.

\subsubsection{Contacts}

Richard P. Williams, Product Line Sales

Scientific Ecology Group

1560 Bear Creek Road

P.O. Box 2530

Oak Ridge, TN 37831

(423) 376-8076 Telephone

(423) 376-8484 Fax

\subsubsection{Smelting at the Capenhurst Works Facility}

The Capenhurst Works Facility is performing small prototype testing of smelting processes for British Nuclear Fuels, plc (BNFL). A full-scale smelting facility is being installed. The three new furnaces include two induction furnaces made by Taylor and a reverberatory furnace manufactured by Thermal Technologies Company. Each of these furnaces will be extensively modified by BNFL. The furnace temperature will be varied to separate different types of metals. Aluminum, which has a low melting point, will be separated from steel and nickel, which have higher melting points. Metal will be partially decontaminated before it is sent to the melting facility. 


\subsubsection{Required Conditions and Characteristics of Waste}

The furnace is designed to smelt most metals. Material from the Capenhurst decommissioning project includes aluminum, steel, copper, brass, and nickel. Activity limits on the material were not mentioned.

\subsubsection{Administrative and Training Requirements}

All personnel using the furnace at the Capenhurst decommissioning project must be trained in applicable administrative and safety requirements.

\subsubsection{Results}

- Costs. Costs associated with smelting at the Capenhurst Works Facility were not available.

- Volume reduction ratio and rates. The smelting system is designed to process $1.12 \mathrm{t} / \mathrm{h}$. The slag is approximately $1 \%$ of the total weight. The smelting facility has been approved to process $3,750 \mathrm{t}$ of the 5,620 $\mathrm{t}$ of material originally intended for burial at the Drigg waste disposal facility. The scrap metal (before melting) cannot be monitored cost effectively.

- Recycle/reuse. The smelted material will be incorporated into other uses, such as disposal containers.

\subsubsection{Advantages, Disadvantages, and Problems}

In the limited trials performed to date, the results of Capenhurst Works do not agree with the results obtained at some other smelting facilities. The slag does not necessarily appear to contain most of the radioactive material. Capenhurst Works is currently checking for homogeneity. Capenhurst does have the same off-gas problems encountered at other smelting facilities, but has designed for a high-efficiency ventilation/entrainment system. 


\subsubsection{Contacts}

Dave Clements, Decommissioning Manager

British Nuclear Fuels, plc

Capenhurst Works

Chester, Cheshire, CH1 6ER

United Kingdom

$44513393759 \quad$ Telephone

$44513473797 \quad$ Fax

\subsection{PLASMA ARC CUTTING}

The plasma arc cutting system is used to dismantle contaminated metallic waste into more manageable sizes, resulting in higher disposal packaging efficiencies. Plasma arc cutting is based on a direct current arc between a tungsten electrode and any conducting metal. The arc is established in a gas or gas mixture that flows through a constricting orifice in the torch nozzle to the workpiece. The constricting effect of the orifice on both the gas and the arc results in very high current densities and high temperatures $(10,000-24,000 \mathrm{~K})$ in the stream.

The stream or plasma consists of positively charged ions and free electrons. The plasma is ejected from the torch nozzle at a very high velocity and, in combination with the arc, melts the contacted workpiece metal and blows the molten metal away from the cut. An automatic plasma arc cutting system includes torch positioning equipment; torch travel system; air, starting gas and plasma gas supply systems; pilot arc high-frequency power supply; plasma arc power supply; and associated gas flow, arc, and mechanical travel controls.

The following sections describe cases in which plasma arc cutting systems were successfully used to reduce the overall volume of metallic LLW.

\subsubsection{Plasma Arc Cutting at Los Alamos National Laboratory}

Plasma arc technology was used at LANL in the TRU Waste Size Reduction Facility (SRF). The facility is designed to remotely cut and repackage TRU-contaminated metallic wastes for eventual disposal at the Waste Isolation Pilot Plant (WIPP) in New Mexico. The metal objects are cut by using the plasma arc torch; either gas or water is used for fume reduction and cooling. The objects are cut into sizes that can be packaged more efficiently in disposal containers. 


\subsubsection{Required Conditions and Characteristics of Waste}

The SRF has successfully processed stainless steel gloveboxes (with and without lead shielding construction) and retention tanks. TRU contamination present in waste items is a mixture of radionuclides. The primary mixtures encountered are designated as material types plutonium-52 and -83 . The components of these material types are included in Table 3. A frequent contaminant is americium-241, with a specific alpha activity of $120 \mathrm{GBq} / \mathrm{g}$.

\subsubsection{Administrative and Training Requirements}

The total inventory of TRU material allowed at any one time at the SRF is $150 \mathrm{~g}$ of plutonium-52, $10 \mathrm{~g}$ of plutonium-83, or $15 \mathrm{~g}$ of americium-241. The average inventory in waste packages pending processing is approximately $47 \mathrm{~g}$ of plutonium-52, with a maximum TRU inventory of $51 \mathrm{~g}$ of plutonium-52. Waste must conform to size and weight limits. The SRF system requires implementation of safety precautions and thorough training of operators in system operations.

\subsubsection{Results}

- Costs. The savings will depend on the items being cut by the SRF. Substantial savings are associated with reducing the size of large contaminated metallic items.

TABLE 3 Composition of Plutonium-52 and Plutonium-83

\begin{tabular}{|c|c|c|c|}
\hline $\begin{array}{l}\text { Material } \\
\text { Type }\end{array}$ & Radionuclide & $\begin{array}{l}\text { Weight Fraction } \\
\text { for Each } \\
\text { Nuclide }\end{array}$ & $\begin{array}{c}\text { Total Specific } \\
\text { Alpha } \\
\text { Activity }\end{array}$ \\
\hline Plutonium-52 & $\begin{array}{l}\text { Plutonium-238 } \\
\text { Plutonium-239 } \\
\text { Plutonium-240 } \\
\text { Plutonium-241 } \\
\text { Plutonium-242 }\end{array}$ & $\begin{array}{l}1.00 \times 10^{-4} \\
9.39 \times 10^{-1} \\
5.75 \times 10^{-2} \\
3.40 \times 10^{-3} \\
2.00 \times 10^{-4}\end{array}$ & $2.6 \mathrm{GBq} / \mathrm{g}$ \\
\hline Plutonium-83 & $\begin{array}{l}\text { Plutonium-236 } \\
\text { Plutonium-238 } \\
\text { Plutonium-239 } \\
\text { Plutonium-240 } \\
\text { Plutonium-241 } \\
\text { Plutonium-242 }\end{array}$ & $\begin{array}{l}1.00 \times 10^{-6} \\
8.00 \times 10^{-1} \\
1.63 \times 10^{-2} \\
3.00 \times 10^{-2} \\
6.00 \times 10^{-3} \\
1.00 \times 10^{-3}\end{array}$ & 516 GBq/g \\
\hline
\end{tabular}


- Volume reduction ratio and rates. Throughput information, volume reduction, and decontamination rates were not available. Significant volume reduction factors are available through increased packing efficiency.

- Recycle/reuse. Consumables cannot be recycled or reused. Wastewater is collected and solidified with portland cement.

\subsubsection{Advantages, Disadvantages, and Problems}

The plasma arc system at the SRF has successfully reduced metallic waste volumes through material sectioning. Fume generation can be a problem because of (1) the increase in the need for prefilters and HEPA filters and the corresponding increase in secondary waste, and (2) the condensation of fumes on the interior metallic surface. The latter results in the need to decontaminate the metal. Fume generation is controlled through engineering techniques. The prefilters must be changed frequently.

\subsubsection{Contacts}

Information on this technique was obtained from Harper and Warren (1987). Additional information can be obtained from:

Tony Drypolcher, Manager of Waste Minimization

Los Alamos National Laboratory

HSE-7, MS E517

Los Alamos, NM 87545

(505) 667-8293 Telephone

\subsubsection{Plasma Arc Cutting at Capenhurst Works - British Nuclear Fuels, plc}

A plasma cutting system is used at the Capenhurst Works (Figure 4). All volatile and fine grains generated during cutting are contained within the component being cut or the cutting system's ventilation extraction. The surfaces of the cut material are smooth, which is a major factor if decontamination is going to be performed after cutting.

A robotics system manufactured by Cincinnati Milacron controls the plasma cutting of tanks and other large components. The plasma cutting system includes a rotary table that allows the system to obtain six degrees of freedom. The plasma torch cuts a very fine $0.64-\mathrm{cm}(0.25$-in.) groove 


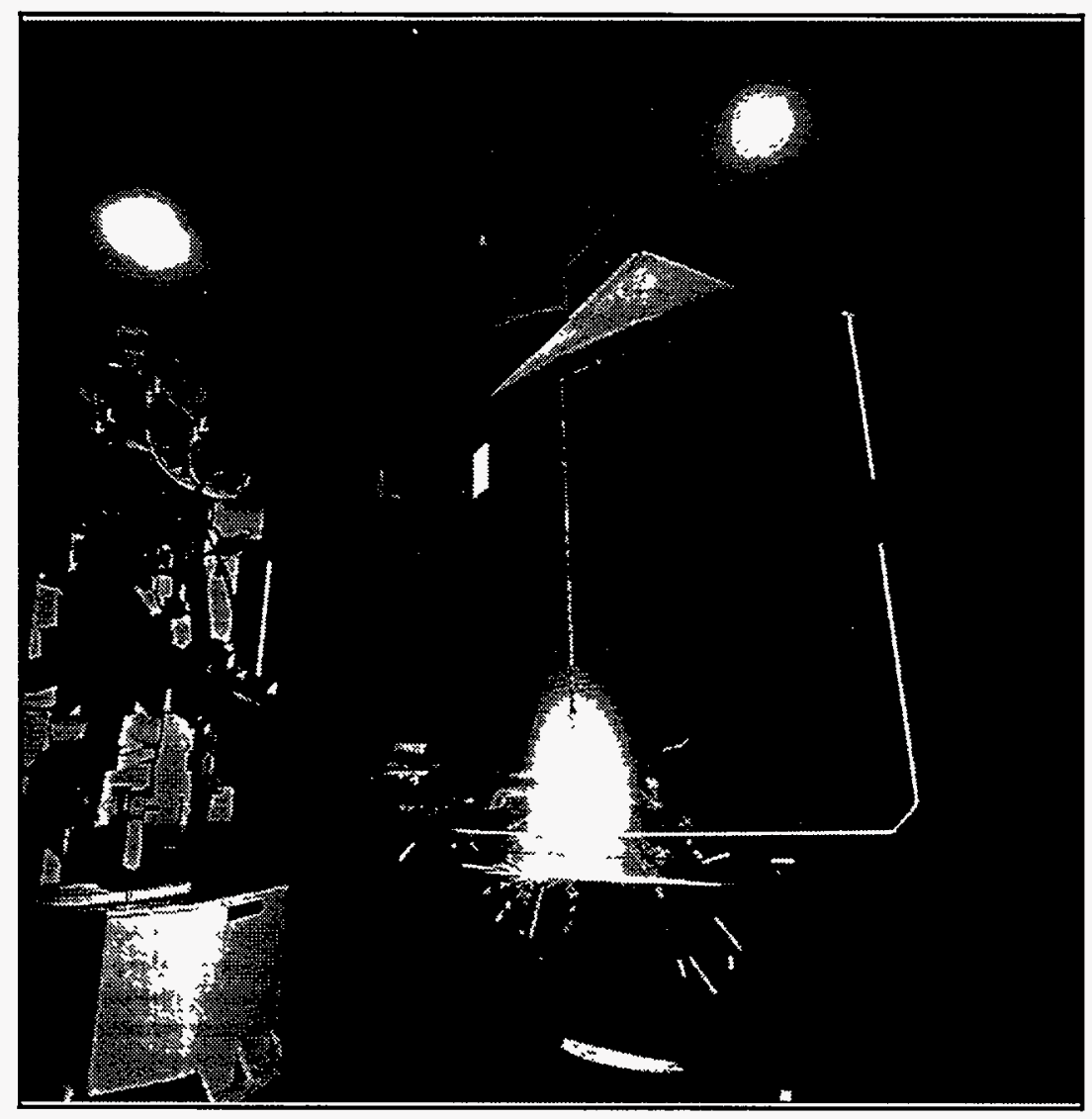

FIGURE 4 Plasma Arc Cutting at Capenhurst (courtesy of British Nuclear Fuels, plc)

into $12.7-\mathrm{cm}$ (5-in.)-thick wall by using a proprietary gas mixture. The plasma cutting system also contains a reverse-pulse roughing filter and HEPA filters for the fumes.

\subsubsection{Required Conditions and Characteristics of Waste}

The plasma cutting system is used on pipes and material with aluminum and steel walls up to $12.7 \mathrm{~cm}(5 \mathrm{in}$.) thick. Material waste is segregated into aluminum, steel, nickel, etc., when possible. Each type of metal waste is then processed separately.

\subsubsection{Administrative and Training Requirements}

The plasma cutting system requires implementation of safety precautions and thorough training of operators in system operations. 


\subsubsection{Results}

- Costs. Costs concerning the plasma arc cutting system at Capenhurst Works were not available.

- Volume reduction ratio and rates. The cutting speed of the torch is 0.3-4 $\mathrm{m} / \mathrm{min}$. Significant volume reduction factors are available through increased packing efficiency.

- Recycle/reuse. Recycle and reuse applications concerning the plasma arc cutting system at Capenhurst Works were not available. Material can be sent for decontamination and recycle.

\subsubsection{Advantages, Disadvantages, and Problems}

Limitations to the plasma arc cutting system at Capenhurst Works were not available.

\subsubsection{Contacts}

David Clements, Decommissioning Manager

British Nuclear Fuels, plc

Capenhurst Works

Chester, Cheshire, CH1 6ER

United Kingdom

44513393759 Telephone

$44513473797 \quad$ Fax

\subsection{SUPERCOMPACTION}

Supercompaction refers to the compaction of 200-L (55-gal) drums filled with compactible radioactive waste. The magnitude of force applied to the waste distinguishes supercompactors from conventional compactors. Supercompactors operate on hydraulic presses ranging from 27.6 to 151.7 $\mathrm{MPa}$ (4,000 to $22,000 \mathrm{psi}$ ). Material, such as wood, pipe, metallic scrap, glass, and concrete rubble, can be compacted to densities of about $2,403 \mathrm{~kg} / \mathrm{m}^{3}\left(150 \mathrm{lb} / \mathrm{ft}^{3}\right)$. Compacted plastic waste can reach a density of approximately $1,041 \mathrm{~kg} / \mathrm{m}^{3}\left(65 \mathrm{lb} / \mathrm{ft}^{3}\right)$, and mixtures of plastic, rubber, paper and cloth can approach $1,441 \mathrm{~kg} / \mathrm{m}^{3}\left(90 \mathrm{lb} / \mathrm{ft}^{3}\right)$. 
Supercompactors consist of three main components:

- The main upper and lower plates and columns. These apply the compaction stresses and comprise the main press structure.

- The hard-faced internal surface or replaceable liner (referred to as the mold assembly). The supercompactor mold assembly surrounds the waste package after it is loaded onto the press.

- The main cylinder. The main cylinder has a main piston that drives the ram plate that applies the force to the waste package.

Hydraulic fluid drives the main piston and ram down onto the package. The mold is withdrawn, stripping the compressed waste package (referred to as a puck) away from the mold's internal surface. The piston returns to its fully withdrawn position, and the puck is removed from the press. A collection system located below the supercompactor collects any dispelled liquid and routes it to a collection tank or processing system.

Hydraulic systems provide power to the press and peripheral equipment. The press is operated by the main pumping systems. Smaller motors drive the auxiliary pumping systems used to operate peripheral equipment. Filters remove particulates from the hydraulic fluid before delivery to the press and on return to the reservoir. Heat exchangers are used to limit the accumulation of heat that results from pumping. The scrap drums and their contents are compressed in the supercompactor and then overpacked into $2.5-\mathrm{m}^{3}$ steel boxes, which significantly reduces the overall disposal volume. General volume reduction results are provided in Table 4.

TABLE 4 Volume Reduction from Supercompaction

\begin{tabular}{lcc}
\hline \multicolumn{1}{c}{ Waste Material } & $\begin{array}{c}\text { Volume } \\
\text { Reduction Factor }\end{array}$ & $\begin{array}{c}\text { Puck Density } \\
\left(\mathrm{kg} / \mathrm{m}^{3}\right)\end{array}$ \\
\hline Scrap metal & $4-5$ & $3,200-4,000$ \\
Heavy mixture of waste & $3.5-5$ & $1,600-2,400$ \\
Plastic material & $2-3$ & $800-1,120$ \\
Light mixture of waste & $2.5-3.5$ & $800-1,280$ \\
\hline
\end{tabular}

a Volume reduction results do not include overpack inefficiencies. Plastic and light mixed waste results assume in-drum compaction by conventional compactors before supercompaction. 
Supercompaction techniques and results were compared and contrasted among six different facilities. Further, a commercial metallic waste baler was also included.

\subsubsection{Supercompaction at the Winfrith Technology Center}

The supercompaction of solid LLW has been carried out at the Winfrith Technology Center since 1989. This process for the treatment of drummed LLW was adopted because the volume reduction achieved produced significant savings in disposal costs at the national waste repository operated by British Nuclear Fuels, plc at Drigg, Cumbria.

The supercompactor located in the Winfrith Technology Center is manufactured by Hansa Projekt Anlagentechnik GmbH of Germany and was leased until its purchase in 1991. The plant consists of two units: the main unit, comprised of the compactor and control modules that are mounted on a specially constructed three-axle "low-boy" trailer, and a standard full-height ISO freight container into which is packed, for transport, the compactor input and output conveyors, bridge crane, and other miscellaneous equipment and spares. The supercompactor has a maximum operating force of $2,000 \mathrm{t}$.

\subsubsection{Required Conditions and Characteristics of Waste}

The LLW scheduled for compaction cannot have asbestos or polychlorinated biphenyls (PCBs). Incoming waste must weigh less than $330 \mathrm{~kg} / \mathrm{drum}$, with a maximum dose rate of $2 \mathrm{mSv} / \mathrm{h}$.

\subsubsection{Administrative and Training Requirements}

Disposal limits are $4 \mathrm{GBq} / \mathrm{t}$ for alpha and $12 \mathrm{GBq} / \mathrm{t}$ for beta-gamma. Radioactive monitoring equipment was set up around the facility.

\subsubsection{Results}

- Costs. The initial cost of the supercompactor is $\$ 1,600,000$. Annual maintenance costs are approximately $\$ 4,800$.

- Volume reduction ratio and rates. The Hansa supercompactor is currently getting a $4: 1$ volume reduction factor. Compaction rate is $4 \mathrm{~min} / \mathrm{drum}$ or $15 \mathrm{drum} / \mathrm{h}$. The facility can compact $90-100$ drums in a 12-h day. Figure 5 shows the daily throughput for a 44-d period in 1993. The supercompactor 


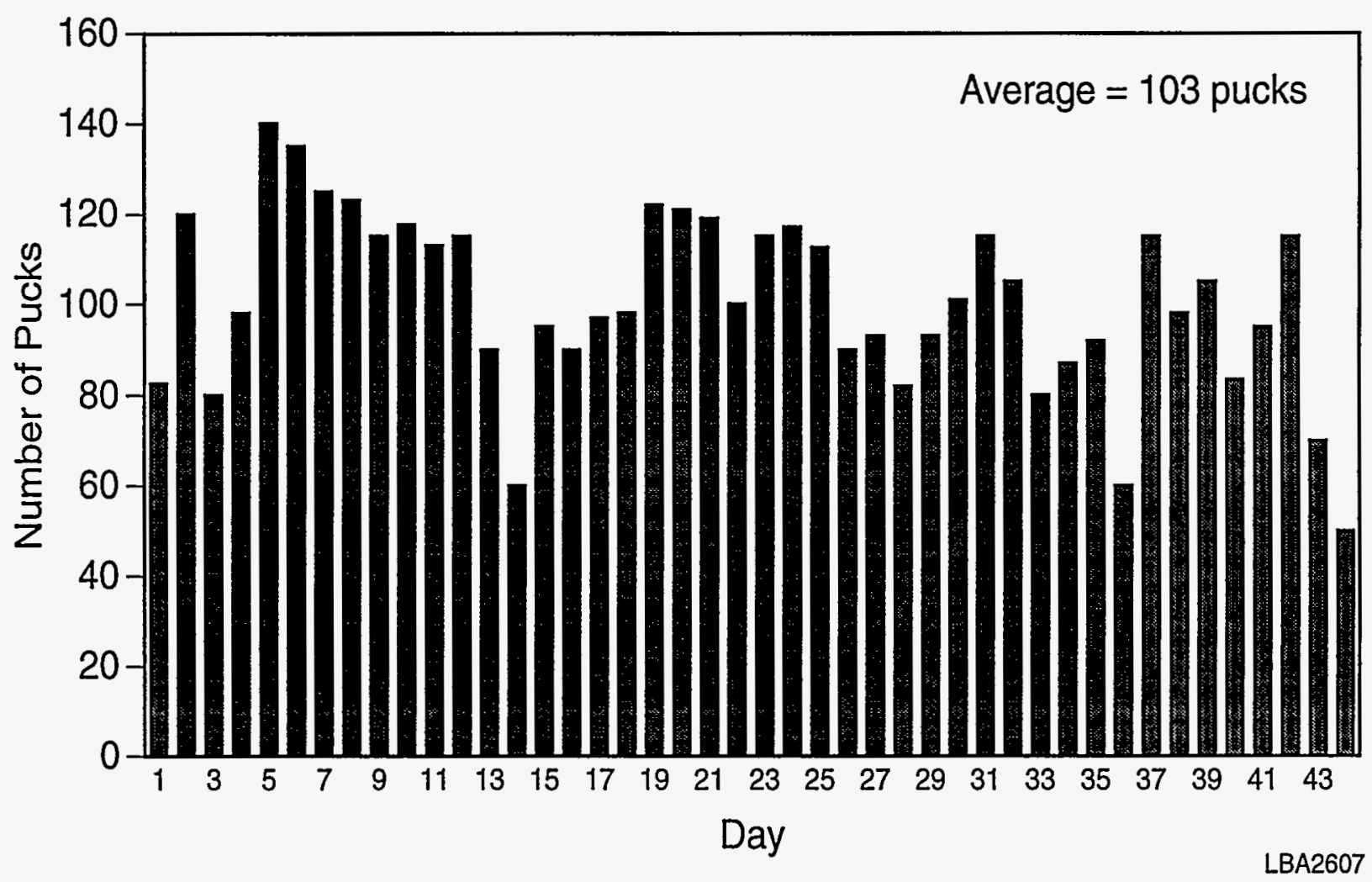

FIGURE 5 Daily Throughput of the Supercompactor at Winfrith for 1993 (LBA2607-E)

has processed more than 22,000 drums of solid, dry LLW. The system is designed for 125,000 cycles before major overhauls are required.

- Recycle/reuse. Recycle and reuse applications generally do not apply to supercompacted waste.

\subsubsection{Advantages, Disadvantages, and Problems}

The Winfrith supercompactor has shown continued success in reducing the volume of waste drums. Approximately $10 \%$ of the drums show some degree of springback, due primarily to plastics and rubber in the drums. Drums badly damaged during the compaction process may release contamination and free liquids. 


\subsubsection{Contacts}

Tim Boorman

AEA O'Donnell, Inc.

241 Curry Hollow Road

Pittsburgh, PA $15236-4696$

(412) $655-1200 \quad$ Telephone

(412) 655-2928 Fax

\subsubsection{Supercompaction at Scientific Ecology Group}

SEG has three types of compactors to handle generated LLW, including metals. The incoming waste is routed to a receiving area designed to sort the LLW according to the most effective means of managing it. Metallic waste that is not sent to the metal melting facilities is placed in containers that will undergo compaction.

The majority of LLW is sent to SEG's proprietary ultracompactor. The ultracompactor was designed and built by SEG. Metal drums and boxes are filled to capacity with previously separated nonburnable materials and then placed in the ultracompactor. A drum positioned by a conveyor belt, and the compactor mold is lowered over the drum or box. The weight of the press $(31,750 \mathrm{~kg})$ compresses the object; the hydraulic press is then activated. The ultracompactor has a 4,536 $\mathrm{t}$ (5,000 ton) force with a maximum of $34.5 \mathrm{MPa}(5,000 \mathrm{psi})$, with $10.3-138 \mathrm{MPa}(1,500-2,000 \mathrm{psi})$ used on average. The ultracompactor compacts the metal drums and boxes into pucks, which are repacked into containers called overpacks. The overpacks are monitored, identified, sealed, weighed, logged, and loaded for transport and delivery to a final designated burial site.

A second compactor, a totally enclosed TRU press, serves exclusively for compacting plutonium-contaminated and other TRU waste. The TRU press is housed in an area that has its own ventilation system to enable containment of all contaminants. The TRU compactor has a 902-t $(1,000$-ton) press. A third, transportable, compactor is used mainly at generators' sites for special projects.

\subsubsection{Required Conditions and Characteristics of Waste}

The SEG ultracompactor is designed to process dry, non-TRU compactible waste, including wood, metal, plastic, paper, cloth, concrete, soil, powdex resin, cartridge filters, vulcanized rubber, etc. Wet wastes are placed in a 113,400-kg, portable, compressive-force, vacuum-compression, dewatering system. SEG can process bead and powdered ion-exchange resins, filter sludges, liquid concentrates, sump sludges, and other specific wastes. Burial site license criteria, SEG license/permit 
limits, or physical and chemical hazards associated with compaction preclude the compaction of the following waste items:

RCRA/TSCA hazardous wastes

Explosives

Pyrophoric materials

Flammable solids

Liquid

Absorbed liquid
Smoke detectors

Gas containers

Gas sources

Aerosol cans (unless punctured)

Animal/biological waste

Krypton-85 electron tubes

Radiological criteria for dry active waste compaction at SEG are presented in Table 5.

\subsubsection{Administrative and Training Requirements}

Waste generators must follow the requirements outlined in SEG (1995).

\subsubsection{Results}

- Costs. The average cost to the DOE (ORNL Complex) is $\$ 4.37 / \mathrm{kg}(\$ 1.98 / \mathrm{lb})$. The initial start-up cost was $\$ 6$ million.

- Volume reduction ratio and rates. The SEG ultracompactor gives a 9:1 reduction ratio. The throughput is 20 drums or boxes per hour, or approximately 1 drum every 3 minutes.

- Recycle/reuse. Recycle and reuse applications generally do not apply to supercompacted waste.

\subsubsection{Advantages, Disadvantages, and Problems}

Springback of supercompacted drums is the greatest problem with the ultracompactor. Plastics and rubber have the largest amount of springback. Small metallic objects (tools, etc.) help to reduce springback by acting as bonding agents. 
TABLE 5 SEG Radiological Criteria for Dry Active Waste Compaction

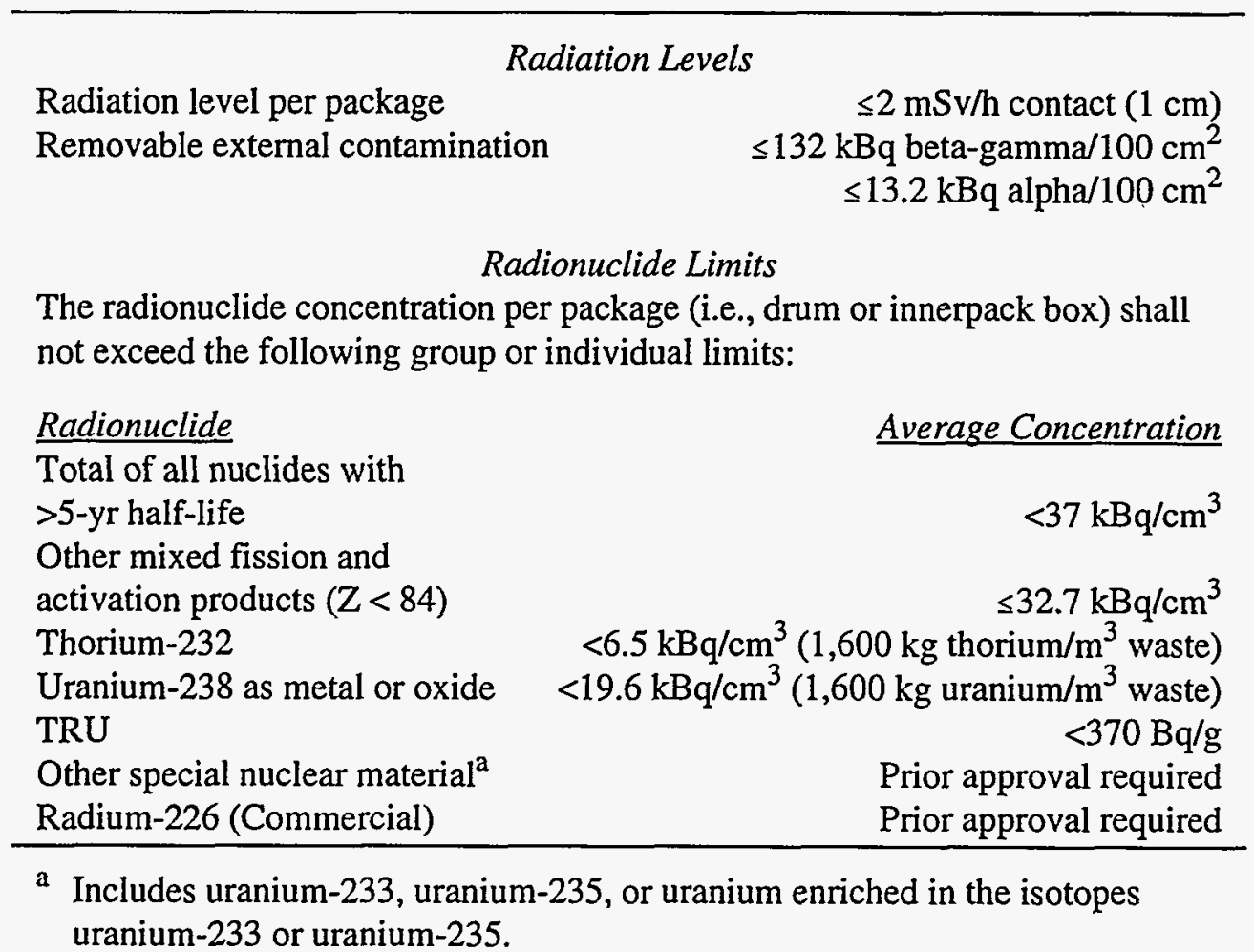

\subsubsection{Contacts}

Richard P. Williams, Product Line Sales

Scientific Ecology Group

1560 Bear Creek Road

P.O. Box 2530

Oak Ridge, TN 37831

(423) 376-8076 Telephone

(423) 376-8484 Fax

\subsubsection{Supercompaction at the Kernforschungszentrum Karlsruhe GmbH}

Nonburnable solid LLW materials and dismantled plant components are transported to the LLW scrapping plant in metal drums, casks, and containers. The waste is precompacted in the scrap press and then supercompacted. The parts to be scrapped are unpacked in a materials lock and brought into the scrapping caisson. The scrap press processes and bales the waste material. These scrap bales are placed in 180-L sheet metal drums and passed to the supercompactor. The scrap press is manually operated. 
The scrap bales are then supercompacted by means of a 15,000-kN (700-bar) press made by Fontijne. The Fontijne supercompactor concept was developed in conjunction with the national waste treatment facility at ECN in Petten, the Netherlands. All systems associated with the supercompactor, including the press, the conveyor belts, the height measuring system, and the lifting gear, are operated automatically by means of a programmable control system. The supercompacted drums can be packaged into 200-L drums.

\subsubsection{Required Conditions and Characteristics of Waste}

Compactible materials include metals, disposables, concrete, ash, and filters. These materials are decontaminated, if possible. If decontamination is ineffective or cost-prohibitive, the material is supercompacted. The LLW scheduled for compaction may need to undergo thermal or mechanical decomposition processes.

\subsubsection{Administrative and Training Requirements}

Administrative and training requirements for the use of the supercompactor at Kernforschungszentrum Karlsruhe (KfK) were not available.

\subsubsection{Results}

- Costs. The cost for compacting nonburnable materials is approximately $\$ 6 / \mathrm{kg}$.

- Volume reduction ratio and rates. The scrapping plant has a throughput of five drums per hour or $3,000 \mathrm{~m}^{3} / \mathrm{yr}$. The volume reduction ratio is $6: 1$.

- Recycle/reuse. Recycle and reuse applications generally do not apply to supercompacted waste.

\subsubsection{Advantages, Disadvantages, and Problems}

Limitations concerning the supercompactor at KfK were not available. 


\subsubsection{Contacts}

Reinhard Pfeiffer, Department Manager

Kernforschungszentrum Karlsruhe $\mathrm{GmbH}$

Postfach 3640

D-76021 Karlsruhe, Germany

$497247824388 \quad$ Telephone

$497247824272 \quad$ Fax

\subsubsection{Fontijne Holland/Stock Equipment Company Supercompactor}

The Fontijne supercompactor concept was developed in conjunction with the national waste treatment facility at ECN in the Netherlands. The overall design can be fully automated. Fontijne manufactures supercompactors with a pressforce of 1,500-2,000 t. Fontijne compactors have been installed at the Babcock \& Wilcox (B\&W) Waste Reduction Center (WRC), the KfK (see Section 2.3.3), and the Dounreay Nuclear Facility. The Dounreay facility has operated a 2,000-t compactor since 1991. A Fontijne compactor was also supplied to the nuclear power station in Philippsburg, Germany; it was expected to become operational in 1995 (Figure 6).

A Fontijne/stock equipment supercompactor was installed at the B\&W WRC in 1986. It is a second-generation design, 1,500-t, automatic, and remotely operated compaction press system. After staging drums for a press campaign, the system is microprocessor controlled to provide automatic and remote operation. The real-time graphics display in the control room provides the operator with system and container status, start-up and shut-down sequences, and error/fault analysis. The system can perform the following functions:

- Select drums in proper sequence from four feed conveyors.

- Feed drums to the press via an air lock in the press negative pressure environment chamber.

- Pierce the drum to control release of effluents during the press operation.

- Perform drum pressing, including the release of the compressed drum from the press mold.

- Transfer the compressed drum from the press to a six-station staging turntable.

- Measure the height of the compressed drum (puck). 


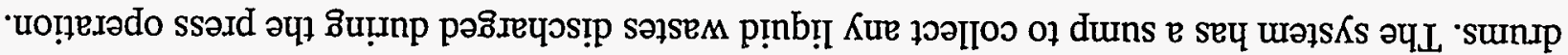

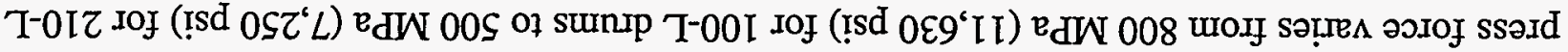

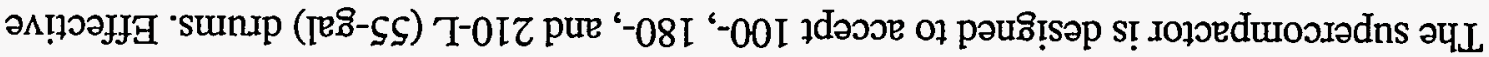

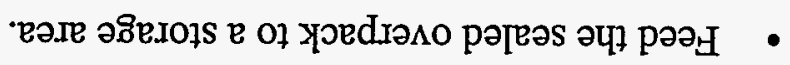

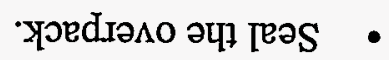

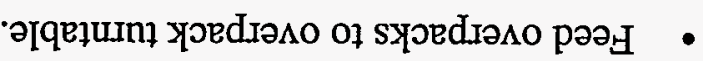

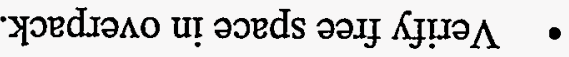

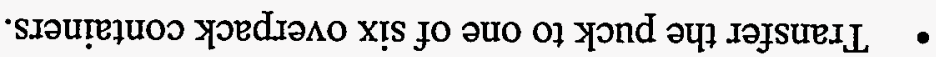

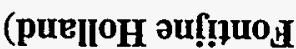

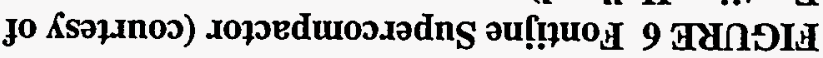

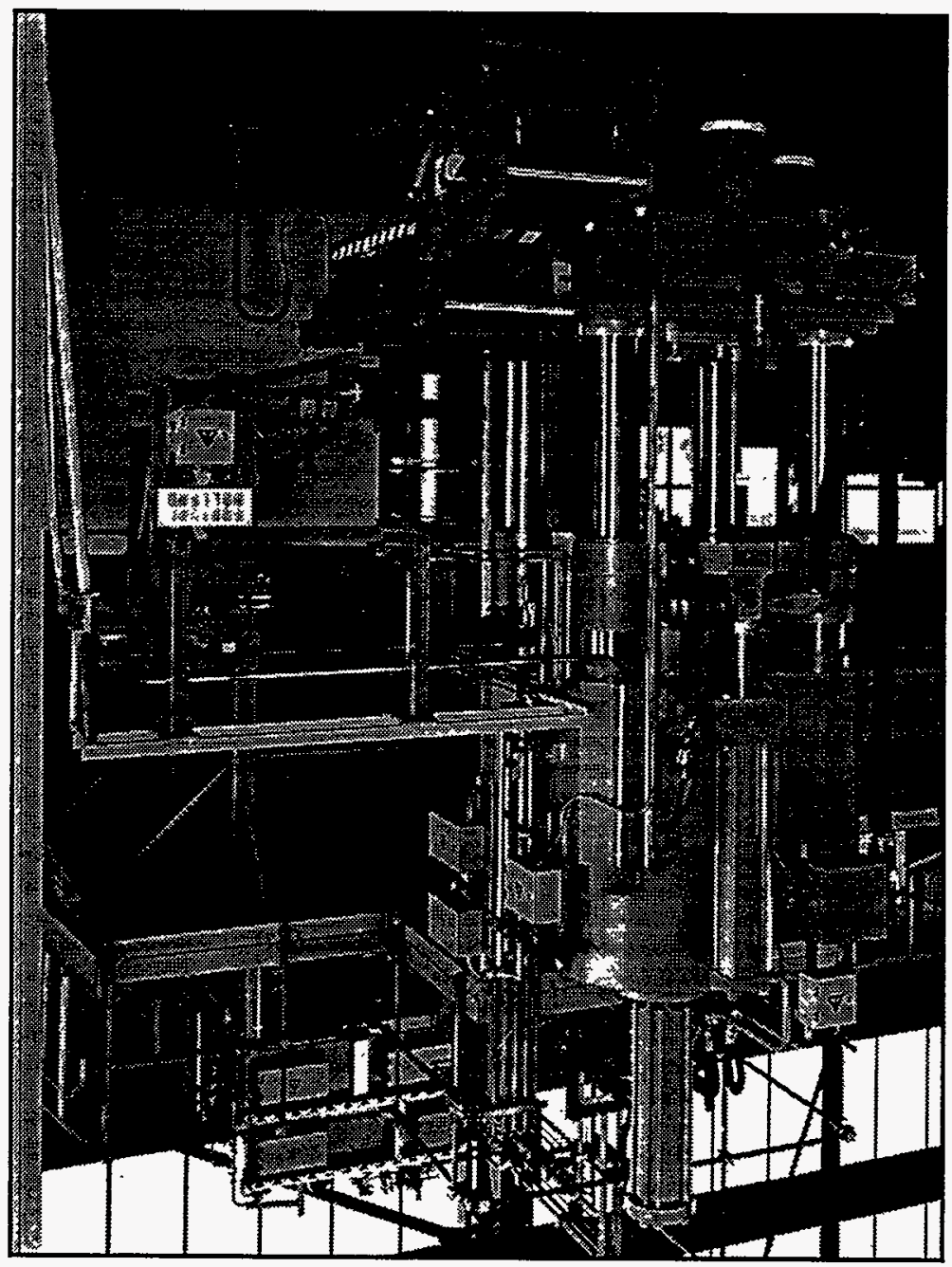


The overpacks can contain $0.26-\mathrm{m}^{3}$ pucks and were designed specifically for this operation. Eighteen-gauge drums, rather than thinner gauge containers, are used. The thicker gauge allows the drums to act as antispringback devices. The computer tracks available space in each overpack after loading each puck. The automated system, computer sensors, and the ability to alternately feed drums of different weight or content to the press ensure that each overpack is filled automatically. Equipment for disposal may be added to fill any void space in the overpacks.

\subsubsection{Administrative and Training Requirements}

Administrative and training requirements for the use of Fontijne supercompactors were not available.

\subsubsection{Required Conditions and Characteristics of Waste}

The LLW scheduled for compaction includes dry solids, contaminated oils, liquid scintillation vials, and biological waste generated by nuclear power plants, institutional facilities, and industrial plants. Waste compacted at WRC has included electric motors, hard wood, and concrete blocks.

\subsubsection{Results}

- Costs. The initial cost of the supercompactor at Dounreay was $\$ 1.2$ million to obtain and install. Maintenance and operational costs are approximately $\$ 1.6 \mathrm{million} / \mathrm{yr}$.

- Volume reduction ratio and rates. Throughputs are generally limited by the infrastructure of the facility. Fontijne supercompactors are designed to process approximately 40 drums per hour, with an average volume reduction ratio of $3: 1$.

The supercompactor at WRC can process 30 drums per hour. Typical drum heights after compaction are 4.44-40.6 cm (1.75-16 in.), averaging $15 \mathrm{~cm}$ (5.9 in.) with an initial uncompacted height of $91.4 \mathrm{~cm}$ (36 in.). The density of the compacted drums varies from 1,393 to $4,900 \mathrm{~kg} / \mathrm{m}^{3}$ ( 87 to $306 \mathrm{lb} / \mathrm{ft}^{3}$ ), with an average of $2,305 \mathrm{~kg} / \mathrm{m}^{3}\left(144 \mathrm{lb} / \mathrm{ft}^{3}\right)$. The 1,500 -ton presses have processed more than 200,000 drums. The supercompactor at Dounreay can compact approximately 20 drums per hour. The compactor is limited by the assay system (Canberra system with germanium detectors). 
- Recycle/reuse. Recycle and reuse applications generally do not apply to supercompacted waste.

\subsubsection{Advantages, Disadvantages, and Problems}

Limitations applicable to Fontijne supercompactors were not available.

\subsubsection{Contacts}

Dr. Doug Graham, Radwaste Operations

UKAEA Dounreay Thurso

Caithness

KW14 7TZ United Kingdom

44847802121 , Ext. 2811 Telephone

$44847802900 \quad$ Fax

R.C. de Lange, Engineer

Industrieweg 21

Fontijne-Holland

P.O. Box 149

3130 AC Vlaardingen, the Netherlands

$+31(0) 10-4348233 \quad$ Telephone

+31(0)10-4352655 Fax

\subsubsection{Supercompaction at the Cogema Reprocessing Plant}

A supercompactor is located within the AD2 Waste Treatment Plant at the Cogema Reprocessing Plant in France. The plant is designed to process solid, low-level secondary/technology waste. All waste is placed into $120-\mathrm{L}$ drums.

The supercompactor is a shroud and piston design with a 1,500-t press manufactured by ACB. Four to six compacted drums are placed in a secondary drum and then in an overpack. The overpack is filled with a mixture of concrete and cast iron fillings.

\subsubsection{Required Conditions and Characteristics of Waste}

The Cogema Supercompactor accepts solid, dry LLW. 


\subsubsection{Administrative and Training Requirements}

Administrative and training requirements for the use of the Cogema supercompactor were not available.

\subsubsection{Results}

- Costs. Costs concerning the supercompactor at Cogema were not available.

- Volume reduction ratio and rates. Throughput capacity is $50,000 \mathrm{drum} / \mathrm{year}$. Up to 100 drums can be processed per 8-h shift. The volume reduction ratio is $3: 1$, with the contents of five $120-\mathrm{L}$ drums compacted into $200 \mathrm{~L}$.

- Recycle/reuse. Recycle and reuse applications generally do not apply to supercompacted waste.

\subsubsection{Advantages, Disadvantages, and Problems}

Limitations concerning the supercompactor at Cogema were not available.

\subsubsection{Contacts}

Mrs. Edith Marie-Sainte, Service Communications

Cogema, Inc.

Establissement de La Hague

50444 Beaumont - Hague Cedex, France

$3333026108 \quad$ Telephone

$3333026611 \quad$ Fax

\subsubsection{Supercompaction at Kernkraftwerke Gundremmingen Betriebsgesellschaft mbH}

A GNS 1,500-t horizontal compactor is used for the supercompaction of secondary waste at the Gundremmingen Nuclear Power Plant. 


\subsubsection{Required Conditions and Characteristics of Waste}

The supercompactor at Gundremmingen is designed to supercompact dry LLW.

\subsubsection{Administrative and Training Requirements}

Administrative and training requirements for the use of the Gundremmingen supercompactor were not available.

\subsubsection{Results}

- Costs. Costs concerning the supercompactor at Gundremmingen were not available.

- Volume reduction ratio and rates. Approximately 20 drums are processed in an 8-h day.

- Recycle/reuse. Recycle and reuse generally do not apply to supercompacted waste.

\subsubsection{Advantages, Disadvantages, and Problems}

Limitations concerning the supercompactor at Gundremmingen were not available.

\subsubsection{Contacts}

Dr. Helmut Steiner, D\&D Manager

Kernkraftwerke Gundremmingen Betriebsgesellschaft $\mathrm{mbH}$

Postfach 89355

Gundremmingen, Germany

$498224783730 \quad$ Telephone

$498224782900 \quad$ Fax 


\subsubsection{Metallic Waste Baler at Harwell}

The Harwell site, located in the United Kingdom, is predominantly a research facility composed of research reactors, a cyclotron, hot cells, research laboratories, and a tank farm. A 100-t McIntyre 5025 baler is used for metallic waste at the Harwell site. Information concerning the operational specifics was not available.

\subsubsection{Required Conditions and Characteristics of Waste}

Compactible metallic items including duct work, pipes, filters, etc., can be placed inside the baler.

\subsubsection{Administrative and Training Requirements}

Administrative and training requirements for the use of the metallic waste baler at Harwell were not available.

\subsubsection{Results}

- Costs. Costs concerning the metallic waste baler at Harwell were not available.

- Volume reduction ratio and rates. The baler can process $5-10 \mathrm{~m}^{3} /$ shift. The volume reduction ratio is $4: 1$.

- Recycle/reuse. Recycle and reuse applications generally do not apply to baled waste.

\subsubsection{Advantages, Disadvantages, and Problems}

Limitations concerning the baler at Harwell were not available. 


\subsubsection{Contacts}

J. D. Neilson

UKAEA Government Division

B462 Harwell, Didcot

Oxfordshire, United Kingdom

44235821111

$44235824028 \quad$ Telephone

$44235823144 \quad$ Fax

\subsection{DECONTAMINATION TECHNIQUES}

Decontamination is defined as the process of removing radioactive contamination and materials from personnel, equipment, or areas. The objectives of decontamination include the reduction of personnel exposure, the salvage of equipment and materials, the reduction of waste volume disposal, and a reduction of the magnitude of the residual radioactive material.

Methods and techniques used to decontaminate metallic LLW fit into one of two primary categories: chemical and mechanical. Chemical decontamination uses concentrated or dilute solvents in contact with the contaminated item to dissolve either the base metal or the contamination film covering the base metal. Operating facilities generally use a solvent that dissolves the contamination film but does not harm the base metal. Decommissioning programs that do not reuse contaminated items may use destructive chemical decontamination methods (i.e., include the dissolution of the base metal). Chemical flushing is recommended for remote decontamination of intact piping systems.

Mechanical and manual decontamination are physical techniques. More recently, mechanical decontamination has included washing, swabbing, foaming agents, and latex-peelable coatings. Mechanical techniques may also include wet or dry abrasive blasting and grinding of surfaces. Additionally, technologies currently under development include hybrid technologies of chemical, electrochemical, biological, mechanical, or sonic methodology.

The reader is referred to the DOE Decommissioning Handbook for a more complete reference of decontamination techniques as they apply to D\&D projects. The methods described here have been successfully implemented at the respective facilities and have proved effective in significantly reducing the volume of metallic LLW. 


\subsubsection{Electropolishing at the Kernkraftwerke Gundremmingen Betriebsgesellschaft mbH}

The D\&D of the Gundremmingen Nuclear Facility began in 1983. The goal was to remove all equipment and material from inside the reactor building. To maximize the recycling of metallic scrap, an electrochemical decontamination method was developed by using a phosphoric acid bath as a reverse galvanization process. In this method, two pools are filled with the acid and a 6,000-amp (maximum) electrical current at $80^{\circ} \mathrm{C}\left(176^{\circ} \mathrm{F}\right)$ is applied. Oxalic acid is added, which allows the precipitation of cobalt- 60 in iron oxalate, minimizing the generation of secondary waste. The acid is periodically regenerated, with the liquid filtered through a bag in a patented process. The bags are vibrated to remove excessive moisture and then dried in an oven at $200^{\circ} \mathrm{C}\left(392^{\circ} \mathrm{F}\right)$, resulting in a dry powder (Figure 7).

The gas given off during the procedure passes through a catalytic converter, which prevents radioactive exhaust from escaping. Iron oxide is the only waste from this process.

The decontaminated scrap can be either free released or sent to Siempelkamp for melting/recycle.

\subsubsection{Required Conditions and Characteristics of Waste}

This process is applicable to surface radioactive contaminated metallic waste. The removal of grease, paint, and dirt is done with $\mathrm{NaOH}$. This process requires a separate bath.

\subsubsection{Administrative and Training Requirements}

The education program for workers answers all questions about their behavior at the plant.

\subsubsection{Results}

- Costs. The cost of the electropolishing process depends on the material and kind of contamination. The cost is in the range of $\$ 1-2 / \mathrm{kg}$. Start-up costs depend on the size of the system and the decontamination factors desired.

- Volume reduction ratio and rates. Average decontamination time is 4-6 h. Decontamination factors have reached 50,000, and most of the primary water system (pumps, pipes, etc.) could be decontaminated for free release. 


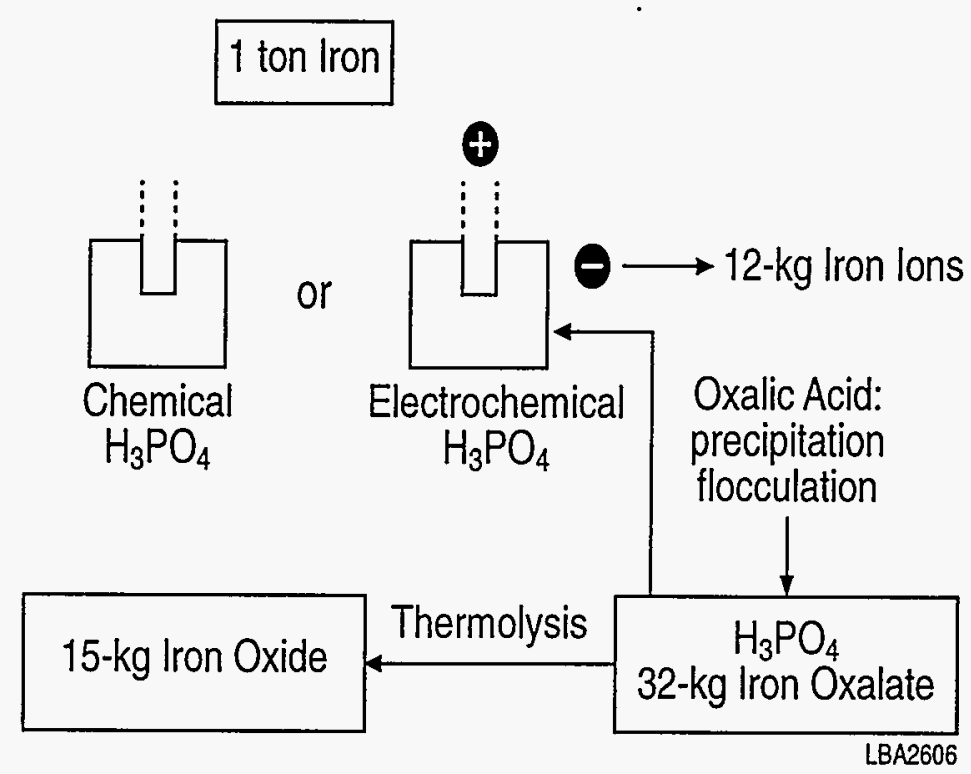

FIGURE 7 Material Balance of Decontamination (LBA2606-E)

- Recycle/reuse. Approximately $95 \%$ of the waste will be decontaminated, with $60 \%$ of the material free released and $33-35 \%$ recycled through melting. The phosphoric acid is reusable once oxalic acid has been added.

\subsubsection{Advantages, Disadvantages, and Problems}

Limitations concerning the electropolishing process at Gundremmingen were not available.

\subsubsection{Contacts}

Dr. Helmut Steiner, D\&D Manager

Dr. Manfried Lasch, Head of Chemical Department

Kernkraftwerke Gundremmingen Betriebsgesellschaft mbH

Postfach 89355

Gundremmingen, Germany

$498224783730 \quad$ Telephone

$498224782900 \quad$ Fax 


\subsubsection{Chemical Decontamination Methods at Capenhurst}

British Nuclear Fuels, plc, runs an elaborate chemical decontamination center at the Capenhurst Works facility. The general purpose is to (1) remove material from the work area; (2) store major components outside on plastic liners on a gravel base to collect water run-off; (3) reduce volume, as required; (4) separate materials according to composition; and (5) decontaminate components.

Metal components are decontaminated with a chemical bath. Heavy rust is removed from the contaminated material by means of a standard power grit blaster. The chemical process involves immersing the contaminated metal in solutions of citric acid, sulfuric acid, and disodium citrate combined with suitable additives in separate steps. The material is subjected to a water wash between each step. All contaminated surfaces of the component must be in contact with the decontamination solution.

Most chemically decontaminated waste was contaminated with uranium, neptunium, or technetium. Citric acid forms a precipitate with uranium, which can be recovered. Sulfuric acid removes oxides, and disodium citrate removes technetium.

\subsubsection{Required Conditions and Characteristics of Waste}

The chemical decontamination system has been used on uranium-, neptunium-, and technetium-contaminated waste. This system has been used to decontaminate large compressors, motors, tank sections, and other metallic objects.

\subsubsection{Administrative and Training Requirements}

Administrative and training requirements for chemical decontamination methods used at Capenhurst were not available.

\subsubsection{Results}

- Costs. Operational costs for the chemical decontamination system is approximately $\$ 2 / \mathrm{kg}$. An additional $\$ 2 / \mathrm{kg}$ is for capital costs associated with the purchase of the system, which will be written off in 5 years. 
- Volume reduction ratio and rates. The waste volume is about $0.4-0.5 \%$ of the total volume (waste and material). The decontamination factor is $300: 1$. The throughput is $100 \mathrm{t} /$ week.

- Recycle/reuse. The chemicals used during chemical decontamination are processed through ion exchangers and reused. A total of $160,000 \mathrm{t}$ of material has been decontaminated at Capenhurst Works; $99 \%$ has been released for unrestricted use.

\subsubsection{Advantages, Disadvantages, and Problems}

Limitations concerning the chemical decontamination process at Capenhurst were not available.

\subsubsection{Contacts}

David Clements, Decommissioning Manager

British Nuclear Fuels, plc

Capenhurst Works

Chester, Cheshire

CH1 6ER United Kingdom

44513393759 Telephone

$44513473797 \quad$ Fax

\subsubsection{Decontamination Methods Used at AEA Technology}

AEA Technology Engineering Services is one of four businesses constituting AEA Technology — the trade name of the U.K. Atomic Energy Authority. The Engineering Services headquarters is located at Winfrith, United Kingdom, with operating divisions at Winfrith, Harwell, Windscale, and Dounreay. The following are decontamination methods and techniques successfully implemented by AEA Technology at the various operating divisions.

\subsubsection{Decontamination by Vibratory Cleaning}

In vibratory cleaning, contaminated items are subjected to high-energy vibrations in a tank containing various media, including stainless steel or ceramics. The vibrating action of the tank causes an abrasive interaction between the media and the contaminated items. This abrasive action 
decontaminates the item by removing the contaminated surface layer. Vibratory cleaning is most suitable for decontaminating hard materials (including steel, contaminated tools, etc.) where the media have easy access to the contaminated surfaces. A water-based lubricant solution is continuously sprayed over the tank contents during the vibrating process, flushing material removed by the scrubbing action of the media. Chemical additives in the lubricant solution increase the effectiveness of decontamination and improve the surface finish of many metals, including stainless steel.

Both ceramic and stainless steel media have distinct advantages. Ceramic media have a higher surface removal rate. Stainless steel media have a longer media life, are self-cleaning, and generate very small quantities of solid waste. The lubricant effluent is filtered and recirculated, keeping waste to a minimum.

\subsubsection{Decontamination Using High-Pressure Water Jets}

High-pressure water jetting is an established decontamination method that has been used for many applications ranging from washing to removing autoclave deposits. The principal advantage lies in using only water, thereby making effluent treatment a simple process. Application may be manual or mechanical, including remote robotics control.

An AEA Technology facility is equipped to carry out high-pressure water jetting by using a wide range of available nozzles. Some are specifically designed for nuclear pipe cleaning and may combine scrubbing with water flushing. High-pressure water jets can be combined with filtration for the removal of particulate contamination and ion exchange for soluble contamination, with the added possibility of a recirculating system to minimize effluent arisings.

At pressures up to $396 \mathrm{MPa}(55,000 \mathrm{psi})$ and low volumes $(10 \mathrm{~L} / \mathrm{min})$, large areas can be quickly treated by using hand-held and remotely manipulated tools. High-pressure water jetting is also a useful cutting technique for reinforced concrete when an abrasive is fed into the water stream.

AEA Technology has used this technique successfully to remove (1) particulate and watersoluble contamination (e.g., decontamination of fuel skips), (2) grown-on oxide films (e.g., in reactor circuit decontamination), and (3) dried-on grout (e.g., from the outside of cemented waste encapsulation drums). 


\subsubsection{Concrete Decontamination — Various Methods}

AEA Technology has developed the following concrete decontamination techniques:

- Scabbling,

- Very high pressure water jetting,

- Microwave removal, and

- Explosive removal.

Scabbling has been developed to the stage where tools are available for industrial applications. The equipment is based on commercially available tools modified for nuclear application, in particular for collection and removal of the spoil and dust created. Equipment available from AEA Technology includes remote-controlled wall scabblers, pneumatic piston floor scabblers, rotating flail floor scabblers, and pneumatic hand tools.

Vacuum suction is usually used for collecting spoil, and a number of HEPA-filtered vacuum units are available. These will operate in dry or wet conditions.

\subsubsection{Chemical Decontamination - Various Methods}

Various chemical decontamination methods are used at AEA Technology. These methods include spray decontamination, foam decontamination, and gel decontamination.

A spray decontamination technique has been developed for large structures with high levels of internal contamination. Acidic reagents in the form of a very fine mist are applied to contaminated surfaces. Secondary wastes are collected and disposed of accordingly. This method has been successfully used to decontaminate the boiler of the Windscale Advanced Gas-Cooled Reactor.

Foam decontamination is useful for large surface areas. The foams can be particularly formulated for a particular application, so as to maximize the decontamination effect and facilitate easy removal of the collapsed, or partially collapsed, foam. The foam can be suctioned into a chamber containing an antifoaming agent where it will completely collapse. The collapsed foam (containing the radioactive contamination) is then collected. Foams have been successfully used for decontaminating painted outer surfaces of transport flasks and during the initial stages of decontaminating active facilities, including hot cells. Decontamination factors for foam range from 2 to 10 . 
Decontamination gels have also been developed. Similar to foams as a decontamination technique, these gels are extremely effective in situations where long contact times are required together with the need to minimize waste.

Secondary wastes that arise from chemical decontamination can be treated by filtration, cementation, and the destruction of organic material.

\subsubsection{Electrochemical Decontamination}

Anodic electropolishing of stainless steel in a phosphoric acid electrolyte is an established surface finishing technique in the metal finishing industry. The article to be treated is connected anodically in an electrolyte cell, and a direct current is passed through, causing dissolution at the surface of the article. AEA Technology has developed a full-scale anodic decontamination process by using a nitric acid electrolyte. The electrolyte operates at low current density and ambient temperature, which makes it possible to decontaminate complex structures. This also circumvents many problems associated with using phosphoric acid as the electrolyte, including gassing, high power requirements, and the inherent difficulty of making electric connections capable of carrying the high currents. In addition, the difficulty of down-stream waste treatment of phosphoric acid is avoided. The quantity of secondary waste effluent generated by using the nitric acid electrolyte compares favorably with other decontamination methods. A small decontamination probe is used to decontaminate hot spots. The probe head is located (manually or automatically) over the hot spot and held in place with vacuum suctions. The system can be linked by an automatic activity scanner.

Electrochemical decontamination techniques have been successfully used during the routine decontamination of components in the Sellafield THORP plant and the decontamination of fuel skips. Electrochemical decontamination of stainless steel in a nitric acid electrolyte has the following advantages:

- Speed and simplicity,

- Low-cost maintenance,

- Easy-to-handle secondary waste effluent, and

- Ability to reduce highly contaminated articles to background levels.

The rates of loss of metal thickness are low and controllable (typically in the range of 1-10 $\mu \mathrm{m} / \mathrm{h}$ ). The process is suitable for decontaminating metal parts before maintenance operations and for reducing the category of active waste (e.g., intermediate- to low-level waste) before disposal. 


\subsubsection{Decontamination by Particle Impact Cleaning}

Particle impact cleaning (shot blasting, grit blasting, or sand blasting) is a simple but highly effective method of surface decontamination. It is quick and uses low-cost equipment. The amount of surface erosion on the item to be decontaminated can be controlled by varying the pressure and media (which can range from iron shot to nut shells). The resulting dust is controlled with suitable containment and air filtration. The impact media can be used alone (dry) or be combined with water (wet). AEA Technology has an apparatus suitable for completing dry abrasive blasting trials and for meeting large-scale operational requirements.

Wet abrasive blasting is a more refined method highly suitable for radioactive decontamination. This system uses compressed air to blast the item to be cleaned with a slurry of media and water. The water acts as a buffer between the media and the component, giving a very controllable surface cleaning effect and prolonging the media life expectancy. Contaminants are dissolved or suspended by the wet media, and active aerosols are minimized while inside a closed cabinet. The water is recirculated after filtering. The media types most frequently used are aluminum oxide and glass beads. AEA Technology has also developed the use of other materials, which have much longer useful lifetimes.

Additional development work already carried out in this field includes a process for decontaminating the outside surface of stainless-steel waste encapsulation drums. A typical test program includes choice of equipment and media and optimization of process conditions, such as stand-off distance, pressure and exposure times, for a particular decontamination requirement. Options for effluent treatment can also be examined.

\subsubsection{Contacts}

Tim Boorman

AEA O'Donnell

241 Curry Hollow Road

Pittsburgh, PA 15236-4696

(412) 655-1200 Telephone

(412) 655-2928 Fax

\subsubsection{Carbon Dioxide Decontamination Methods Used at Rocky Flats Environmental Technology Site}

The Rocky Flats Environmental Technology Site is using an Alpheus Cleaning Technologies Carbon Dioxide $\left(\mathrm{CO}_{2}\right)$ Cleanblast System for decontaminating contaminated metal. 
In this system, $\mathrm{CO}_{2}$ pellets are inserted into a high-pressure 275- to $1,724-\mathrm{kPa}$ (40-250-psi) dried air stream and shot at a high velocity at the material to be cleaned. The pellets, upon impact, penetrate through the surface coating to the substrate, where they sublime into a $\mathrm{CO}_{2}$ gas expanding 400 times the pellet's original volume. This action acts as a "gas wedge," separating the surface coating from the substrate. After the pellets sublime, they become part of the atmosphere, and there is no secondary waste requiring deposal (i.e., grit or solvents). The system is used inside a containment structure to capture $\mathrm{CO}_{2}$ dispersion of the contamination.

Experience has shown there is an optimum height of about $46 \mathrm{~cm}$ (18 in.) from the surface for ideal blasting. Large quantities of air movement are recommended, which tends to control the contamination and dissipates the $\mathrm{CO}_{2}$.

\subsubsection{Required Conditions and Characteristics of Waste}

The $\mathrm{CO}_{2}$ unit is used to decontaminate metals including excess process equipment, maintenance strip out, vessels, gloveboxes, etc.

\subsubsection{Administrative and Training Requirements}

Administrative and training requirements for the use of $\mathrm{CO}_{2}$ decontamination methods are found in a report issued by Rocky Flats Environmental Technology Site (1993).

\subsubsection{Results}

- Costs. The unit initially cost $\$ 255,000$. It can be leased for $\$ 10,000 /$ week. Test results performed before the actual purchase of the unit were estimated at a cost of $\$ 297 / \mathrm{h}$ of use. The breakeven point with respect to offsetting transportation and burial costs is approximately $0.4 \mathrm{t}(0.44 \mathrm{ton}) / \mathrm{h}$ of material.

- Volume reduction ratio and rates. Rocky Flats has processed approximately $7.2 \mathrm{t}$ ( 8 tons) of stainless and mild steel. The estimated throughput is more than $0.4 \mathrm{t}$ of material/h. With more experience, the throughput can be doubled.

- Recycle/reuse. The decontaminated steel is released from radiological control and recycled. 


\subsubsection{Advantages, Disadvantages, and Problems}

Rocky Flats has found that the Alpheus unit has significant advantages over other systems used to decontaminate metals. The $\mathrm{CO}_{2}$ system replaced a solvent paint stripper (methylene chloride) method for decontaminating radioactive material. This method was inefficient (only one-third of the metal was releasable) and later outlawed by RCRA legislation.

Rocky Flats also found distinct advantages of the Alpheus unit over similar equipment. One system used $\mathrm{CO}_{2}$ pellets to create a thermal shock effect to the substrate. The substrate froze, contracted, and separated the radioactive material from the clean material. The unit uses two hoses to separate the pellets from the air, which has advantages over a similar one-hose pellet/dried air delivery system used by the thermal shock system. The one hose system is open, which causes a problem with foreign material entering the system, which eventually causes the $\mathrm{CO}_{2}$ pellets to sublime before leaving the unit. Further, other systems produced uneven pellet size. Overall, the other systems experienced more problems than the Alpheus unit, and this unit was eventually purchased.

\subsubsection{Contacts}

LaVelle Knight, Project Lead

Waste Minimization Program

EG\&G Rocky Flats

P.O. Box 464

Golden, CO 80402-0464

(303) 966-4293 Telephone

\subsubsection{Decontamination Center at the Dounreay Nuclear Establishment}

The Dounreay Decontamination Center has been operational since 1988 and consists of two cells. The primary decontamination cell is an alpha and beta-gamma room. Decontamination operations are performed in tents located in the cell. Each tent has a portable ventilation system, while the cell has a scrubber and HEPA ventilation system. A wash/decontamination system has been installed on the walls, and a 31.8-t (35-ton) crane is available.

A band saw and nibbler are the most common volume reduction equipment used in the cell. An electrochemical bath is also available in the primary cell. Material is put into titanium baskets and dipped in tanks containing nitric acid or a caustic solution.

The second decontamination cell is for low-level beta-gamma activity. 


\subsubsection{Required Conditions and Characteristics of Waste}

Waste conditions and characteristics were not identified.

\subsubsection{Administrative and Training Requirements}

Administrative and training requirements at the Dounreay Decontamination Center were not available.

\subsubsection{Results}

- Costs. Costs concerning the Dounreay Decontamination Center were not available.

- Volume reduction ratio and rates. Throughput capacity, volume reduction ratios, and decontamination ratios concerning the Dounreay Decontamination Center were not available.

- Recycle/reuse. Recycle/reuse applications concerning the Dounreay Decontamination Center were not identified.

\subsubsection{Advantages, Disadvantages, and Problems}

Soluble grit blasting was tried in the secondary cell; a baking soda medium was used. However, it was not very effective. Additional information concerning the Dounreay Decontamination Center was not available.

\subsubsection{Contacts}

Dr. Doug Graham, Radwaste Operations

U.K. Atomic Energy Authority

Dounreay, Thurso, Caithness

KW 147 TZ United Kingdom

44847802121 , Ext. $2811 \quad$ Telephone

$44847802900 \quad$ Fax 


\subsubsection{Decontamination Techniques at the Sellafield Nuclear Facility}

Various decontamination equipment and techniques are applied to minimize radioactive waste and reduce its volume. Scabbling, high-pressure water jetting, concrete shaving, vacuum cleaning, and other chemical techniques are routinely used for decontamination. The scabbling systems, deployed both manually or remotely, use a metal flail system to impact the concrete surface. The resulting debris is collected via a shrouded vacuum extraction and HEPA-filtered collection system.

Where remote dismantling is required, BNFL uses different manipulators. These manipulators can deploy shear cutters, drills, grinders, nibblers, a plasma arc torch, and a butterfly lifting device. The manipulators use either forced feedback or tool compliance and three-dimensional imaging to assist the operators. The plasma arc uses current backfeed to control the stand-off distance of the torch tip to the cutting surface. Automatic tool tip camera/lighting tracking systems ensure that the operator can constantly monitor the orientation of the manipulator tool/end effector.

British Nuclear Fuels, plc, has developed a diamond wire cutting system that can cut through Type 304L stainless-steel pipework and vessels without requiring a coolant or lubricant.

Explosive cutting of stainless-steel pipework within confined areas was made possible after developments in the optimization of explosive charge shape and weight and the development of blast wave attenuation techniques.

A reciprocating saw can be deployed either by a manipulator or by the CODRO (COntact Deployment Remote Operation) principle, whereby an operator can quickly clamp the saw to a pipe up to $10 \mathrm{~cm}$ ( $4 \mathrm{in}$.) in diameter, then move to an area of lower radiation to control the operation of the saw, thus reducing the operators radiation dose uptake.

British Nuclear Fuels has also developed a double-action crimp/shear tool that will eventually be made available for consumer purchase. The tool can completely crimp and then cut up to $3 \mathrm{~cm}$ (1.5 in.) Schedule 80 stainless-steel pipes in a single operation. The tool operates at a pressure of $70 \mathrm{MPa}$ and has demonstrated tool/anvil life in excess of 1,000 cuts during development trials.

The company has also developed a solvent jetting rig to remove plutonium contamination from the inside of glovebox facilities. The solvent complies with current aerial discharge requirements, unlike Freon (chlorofluorocarbon).

A glovebox-mounted vacuum cleaner has been developed that is critically safe by geometry to enable its use with plutonium-contaminated facilities. 
Closed-loop chemical decontamination systems are used, where appropriate. Radioactivity is precipitated out of the acid for disposal as a solid, and the acid is regenerated for reuse. Development of equipment that can be operated submerged within fuel storage ponds will enable decontamination/volume reduction of pond equipment in situ, deployed hands-on by divers.

A lead/adhesive spray has been developed that can apply a lead-loaded mixture to an area or component to reduce the intensity of the radiation that it is emitting. Future developments will include the replacement of lead with depleted uranium, which has a greater shielding effect.

\subsubsection{Required Conditions and Characteristics of Waste}

Required conditions and characteristics of the waste processed at the Sellafield Nuclear Facility were not available.

\subsubsection{Administrative and Training Requirements}

Administrative and training requirements for the Sellafield Nuclear Facility were not available.

\subsubsection{Results}

- Costs. Costs concerning the decontamination techniques used at Sellafield were not available.

- Volume reduction ratio and rates. Throughput capacity, volume reduction ratios, and decontamination ratios concerning the decontamination techniques used at Sellafield were not available.

- Recycle/reuse. Recycle/reuse applications concerning the decontamination techniques used at Sellafield were not identified.

\subsubsection{Advantages, Disadvantages, and Problems}

Limitations of processes used at the Sellafield Nuclear Facility were not available. 


\subsubsection{Contacts}

Richard Davage, Commercial Manager for Decommissioning

British Nuclear Fuels, plc

Risley, Warrington, Cheshire, United Kingdom WA3 6AS

$01044925835347 \quad$ Telephone

$01044925822773 \quad$ Fax

\subsubsection{Decontamination Methods Used at the Savannah River Site}

The Savannah River Site (SRS) currently uses or is evaluating various decontamination methods as part of an overall waste minimization program. A "Clean-Blast 250 " $\mathrm{CO}_{2}$ blasting unit has been purchased and demonstrated. Ice blasting is also being evaluated as an alternative method to $\mathrm{CO}_{2}$ blasting. The ice blast system uses ice pellets instead of $\mathrm{CO}_{2}$ pellets. This wet process generates minimal airborne activity. Moreover, ice blasting tends to be less expensive than $\mathrm{CO}_{2}$ blasting. Finally, a grit blasting process is being examined that uses glass grit in the form of an airinjected slurry.

SRS is evaluating lead decontamination methods. A Turco solution is used in lead decontamination. SRS is currently investigating the use of nitric acid to etch the surface layers of contaminated lead to a couple of millimeters. Also, a test has proved that clean bricks can be coated with a poly coat to prevent contamination. SRS has developed a lead bank program that involves the storage of contaminated and clean lead. The stored lead is available to other organizations on-site for reuse.

Various methods are used to decontaminate concrete. SRS has six Kelly Systems concrete decontamination systems. These systems decontaminate concrete at 1.86-1.93 MPa (270-280 psi) pressure and $124-247^{\circ} \mathrm{C}\left(255-265^{\circ} \mathrm{F}\right)$. An extraction process developed by EET, Inc., is also used for concrete decontamination (Section 3.1.1). Also, a model LTC Americas 1060PN vacuum blaster was purchased to use for decontaminating metal items and scrap.

Contaminated plastic suit hoses will be shredded to minimize void spaces during disposal. A vacuum unit is also being tested to minimize void space during the disposal of contaminated dry active waste. A vacuum machine is connected to a plastic bag containing material. The vacuum draws air from the plastic bag, allowing greater packing efficiencies. Acid digestion is also being investigated as a means of plastic disposal.

SRS currently uses three compactors for radioactive waste. Two compactors are for B-25 waste containers and one (known as the "box compactor") is for 61-cm (21-in.) cardboard boxes. One B-25 compactor is located in the $\mathrm{M}$ area and is used for uranium waste, and one B-25 compactor 
is located in a butler building and is used for very low level material. Container Products Corporation (CPC) and CGR Compacting, Inc. (CGR) each manufacture one of SRS's B-25 compactors. The box compactor is in the reactor area and is used for tritium waste. It is a CPC model B-20 compactor.

Some experiments have been performed with foam technology during the decontamination of metals. This technique involves adding an organic foam material to a decontamination solution, such as nitric acid. SRS has obtained a $70 \%$ volume reduction factor and has found that foam technology reduces the time for decontamination. A potential safety problem exists concerning the mixture of the solutions. The solutions must be compatible and must be mixed in the proper proportions.

Various additional decontamination and volume reduction practices are used at SRS. Strippable coatings are used to remove surface contamination from walls. These coatings also coat clean walls before decontamination to prevent the spread of contamination. Bioremediation has been found to be effective for sites contaminated with organics. Two types of cutting systems are used at SRS to assist in volume reduction. Plasma torch cutting is used to cut metal objects, and water jet abrasive cutting has been tested to section various materials. The latter method uses a grit and water slurry. Tank cleaners are very effective but generate large amounts of waste. Tank cleaners are generally recommended for small tanks. Polyester cloths dampened with nitric acid are a very effective decontamination method. These cloths are the same cloths used in clean rooms and are made by Scientific Textiles.

SRS has developed a robotics monitoring machine (Simon) used to survey floors automatically. Simon has two gas flow proportional monitors attached in front and uses side radar to maintain contact with the walls. The robot can either collect the data internally or transmit it back to a central station; it can also provide a color-coded map of the surveyed areas. The machine automatically starts at the end of the day and follows a preprogrammed route through the laboratory building. SRS has also developed special application robots for D\&D operations with good design and development capability.

\subsubsection{Required Conditions and Characteristics of Waste}

Required conditions and characteristics of the waste processed through decontamination methods at SRS were not available.

\subsubsection{Administrative and Training Requirements}

All personnel involved with decontamination techniques must be trained in all waste minimization procedures. 


\subsubsection{Results}

- Costs. Costs concerning the decontamination techniques used at SRS were not available.

- Volume reduction ratio and rates. Throughput capacity, volume reduction ratios, and decontamination ratios concerning decontamination techniques used at SRS were not available.

- Recycle/reuse. Recycle/reuse applications concerning decontamination techniques used at SRS were not identified.

\subsubsection{Advantages, Disadvantages, and Problems}

Limitations of processes used at SRS were not available.

\subsubsection{Contacts}

John P. Harley, Jr.

Savannah River Site

P.O. Box 616

Aiken, SC 29802

(803) $557-6332 \quad$ Telephone

(803) 557-6306 Fax Location 705-3C

\subsubsection{Decontamination Studies at Idàho National Engineering Laboratory}

\subsubsection{Liquid Abrasive Grit Blasting Literature Search and Decontamination Scoping Tests}

Westinghouse Idaho Nuclear Company, Inc., has performed a literature search and scoping tests on liquid abrasive grit blasting decontamination methods. Ferguson (1993) describes the technical specifications of liquid abrasive grit blasting and evaluates various systems (the KUE Engineering System 918; Bartlett Nuclear, Inc.; Westinghouse Electric Corporation; AEA Technology; and Kleiber and Schulz designs and studies) according to the following criteria: technical performance; waste considerations; environmental, safety, and health issues; additional costs; and remote applicability. Although these criteria were not evaluated according to a ranking scale, the report contains the results of the tests performed under these criteria. 
The purpose of the scoping test was to test the effectiveness of three different abrasives in removing simulated contamination from a stainless-steel coupon. The aggressiveness of liquid abrasive grit blasting can be varied by either changing the abrasive media or adjusting the air pressure to the blasting nozzle. Three different abrasives were used (in order from least to most aggressive): plastic beads, glass beads, and alumina oxide.

Results show plastic beads tended to wipe the contaminants off the surface, while glass beads used the impact of the abrasive to remove the contaminants. However, 500x surface photography shows no adverse damage to the metal substrate. Alumina oxide tended to grind away the contaminants. With some coupons, it was apparent some metal material had been removed. The reader should refer to the source literature for the complete evaluation of the literature search and the scoping test.

Required Conditions and Characteristics of Waste. Liquid abrasive grit blasting applies to a variety of materials. However, the blasting will damage electric components, such as motors. Mechanical equipment can be reused provided the correct abrasive is used.

Administrative and Training Requirements. All personnel involved with liquid abrasive grit blasting decontamination techniques must be trained in operational procedures. However, operation of the system is not complicated.

\section{Results.}

- Costs. The development costs will be low because this technique is well developed. The equipment costs for these systems vary depending on the added features, size, type of abrasive to be used, and additional design requirements. Depending on the company, the basic wet abrasive system will range from $\$ 50,000-\$ 300,000$. Labor costs should be investigated although only one or two operators will be required for this type of system.

- Volume reduction ratio and rates. Decontamination factors varied according to the material being decontaminated and the following criteria: grit composition, concentration, and size; angle and speed of impact; and distance to the surface. Westinghouse Electric Corporation obtained results in a study involving different abrasives (Table 6).

- Recycle/reuse. Decontaminated material can be free released for recycle or reuse. 
TABLE 6 Decontamination Factor Measurements for Various Abrasives

\begin{tabular}{lcc}
\hline & \multicolumn{2}{c}{$\begin{array}{c}\text { Decontamination Factor } \\
\text { Measurements }\end{array}$} \\
\cline { 2 - 3 } Abrasive & Laboratory & Field \\
\hline Boron oxide & $3-6$ & 4 \\
Magnetite & $50-200$ & $>6$ \\
Aluminum & $250-4,000$ & $200-300$ (nominal) \\
\hline
\end{tabular}

Advantages, Disadvantages, and Problems, The advantages of wet abrasive decontamination are as follows:

- High decontamination factors;

- Grit recycling;

- Abrasion depth variability (type of grit, system pressure);

- Liquid recirculation, which reduces the amount of secondary waste generated; and

- Effective removal of smearable, fixed, alpha, beta, and gamma contamination.

By changing abrasive grits, liquid abrasive grit blasting can be a flexible system for removing fixed and surface contamination.

The main drawback with liquid abrasive grit blasting is generation of secondary waste. When used within a glovebox or walk-in booth-type enclosure that has a closed-loop recirculatory system, the amount of secondary waste can be greatly reduced. Systems are currently being developed that would enable the use of liquid abrasive grit blasting outside a booth or enclosure. These systems use a small amount of liquid $(\sim 5 \%)$ and a vacuum recovery system to recover and then recycle the grit. 


\subsubsection{2 $\mathrm{CO}_{2}$ Pellet Blasting Literature Search and Decontamination Scoping Tests}

Westinghouse Idaho Nuclear Company, Inc., has performed a literature search and scoping tests on $\mathrm{CO}_{2}$ pellet blasting decontamination methods. Archibald (1993) describes the technical specifications of $\mathrm{CO}_{2}$ pellet blasting and evaluates two systems (the Cold Jet and Alpheus systems) according to the following criteria: technical performance; waste considerations; environmental, safety, and health issues; additional costs; and remote applicability. Although these criteria were not evaluated according to a ranking scale, the report contains the results of tests performed under these criteria.

INEL subcontracted the Environmental Control Division (ECD) to perform a demonstration. $\mathrm{ECD}$ uses $\mathrm{CO}_{2}$ pellet blasting equipment manufactured by Cold Jet. A scoping test was performed on this system, and the results were included as part of this report. The test was organized into three phases. The first phase concentrated on cold surrogate materials to verify the effectiveness of the containment, ventilation, and cleaning abilities, and to gather initial data of operating parameters before hot operation. The second phase involved testing, both for decontamination and debris treatment, of low-level radioactively contaminated materials and tools. The final phase of testing encompassed radioactively contaminated lead. The results of the first test showed conclusively the $\mathrm{CO}_{2}$ pellet blasting system is effective for every day type cleaning. The results for the second test showed the system is most effective on loose contamination, although it does remove large amounts of fixed contamination, and that the system is nondestructive. The final test results showed that while no lead bricks were cleaned to free release, alpha contamination levels were greatly reduced. The major concern with this type of system is the increased ventilation requirements.

Required Conditions and Characteristics of Waste. Carbon dioxide pellet systems have proved to be effective in removing loose contamination from stainless steel, carbon steel, concrete, glass, herculite, wood, plastic, weld slag, electric components, paints, lead, aluminum, rubber, hand tools, small parts, and pumps. $\mathrm{CO}_{2}$ pellet blasting does have a problem cleaning fixed contamination along with epoxy-coated concrete, carbon steel, rusted carbon steel, complex geometries, and inside pipes.

Administrative and Training Requirements. All personnel involved with $\mathrm{CO}_{2}$ decontamination techniques must be trained in operational procedures. 


\section{Results.}

- Costs. The development costs of using $\mathrm{CO}_{2}$ pellet blasting will be low because of the recent development of this technique throughout the industry. The full-scale equipment costs range from $\$ 250,000$ to $\$ 300,000$. Labor costs are low due to the simplicity of the system.

- Volume reduction ratio and rates. Decontamination factors range from 2 to 10. Pellet density, angle of impact, pressure changes, nozzle design, the material being decontaminated, and the stand-off distance are all factors in decontaminating material. The cleaning rate demonstrated by Rocky Flats on contaminated lead averaged $23.7 \mathrm{~kg}(52.3 \mathrm{lb}) / \mathrm{h}$. After the system had been onsite for a month, the rate of cleaning jumped to $32.7 \mathrm{~kg}(72 \mathrm{lb}) / \mathrm{h}$. Other companies have been able to process $70-90$ lead bricks per day, corresponding to an average of $4,717 \mathrm{~kg}(10,400 \mathrm{lb}) /$ week.

- Recycle/reuse. Decontaminated material can be free released for recycle or reuse.

Advantages, Disadvantages, and Problems. Advantages and disadvantages of the various systems were identified in the report. The source literature should be referred to for the complete evaluation.

\subsubsection{Decontamination Technique Evaluation}

Westinghouse Idaho Nuclear Company, Inc., has evaluated various decontamination technologies according to a Kepner/Tregoe paired analysis technique. The results were published in Tripp (1994). Three technologies (laser ablation, liquid abrasive blasting, and $\mathrm{CO}_{2}$ pellet blasting) were evaluated. Criteria are used to weight technologies according to their relative importance. Importance is determined by using a Kepner/Tregoe Problem Solving process rather than standard decontamination techniques (sodium-based chemical cleaning and water/steam jet) used at the INEL Idaho Chemical Processing Plant (ICPP).

Each decontamination technique was judged according to five criteria: technical performance; waste considerations; environmental, safety, and health; additional costs; and remote applicability. Each criterion was divided into different categories, which were further divided into subcategories. Each particular technology was ranked (1-100\%) on how well it fulfilled each criterion. Each category was given a weighting factor. The ranking was multiplied by the weighting factor to enable comparison of different decontamination technologies on a particular application. 
The weighting factors indicate the degree of importance of each category in determining the best decontamination technology for a particular application.

Table 7 condenses the results obtained during the evaluation of decontamination techniques. The evaluation criteria total $100 \%$, indicating the importance of each criterion in the overall evaluation. The categories under each criterion also total $100 \%$, indicating the importance of each category in the evaluation of each criterion. The categories were further divided into subcategories (not shown), which were used in determining the scores for the categories.

Scores for the criteria and categories are also presented in the table. Each score is based on a scale of 1-10 (10 highest). The category scores are the sum of the subcategory scores multiplied by the relative percentages. The evaluation criteria scores are the sum of the category scores multiplied by the relative percentages. The overall score for the decontamination technology is the sum of the criteria scores multiplied by the criteria relative percentages. The full results, including the criteria used to determine the relative percentages; criteria, category, and subcategory definitions; and complete evaluation criteria are included in the source literature.

Required Conditions and Characteristics of Waste. The decontamination techniques are intended to be used on waste generated at the ICPP and other facilities at INEL. Specific criteria concerning the radioactive waste were not identified.

Administrative and Training Requirements. All personnel involved with decontamination techniques must be trained in operational procedures.

\section{Results.}

- Costs. Costs concerning the decontamination techniques evaluated by INEL were not available.

- Volume reduction ratio and rates. Throughput capacity, volume reduction ratios, and decontamination ratios concerning decontamination techniques evaluated at INEL were not available.

- Recycle/reuse. Recycle and reuse applications concerning decontamination techniques evaluated at INEL were not identified. 
TABLE 7 Summary of Results Obtained When Judging a Decontamination Technique

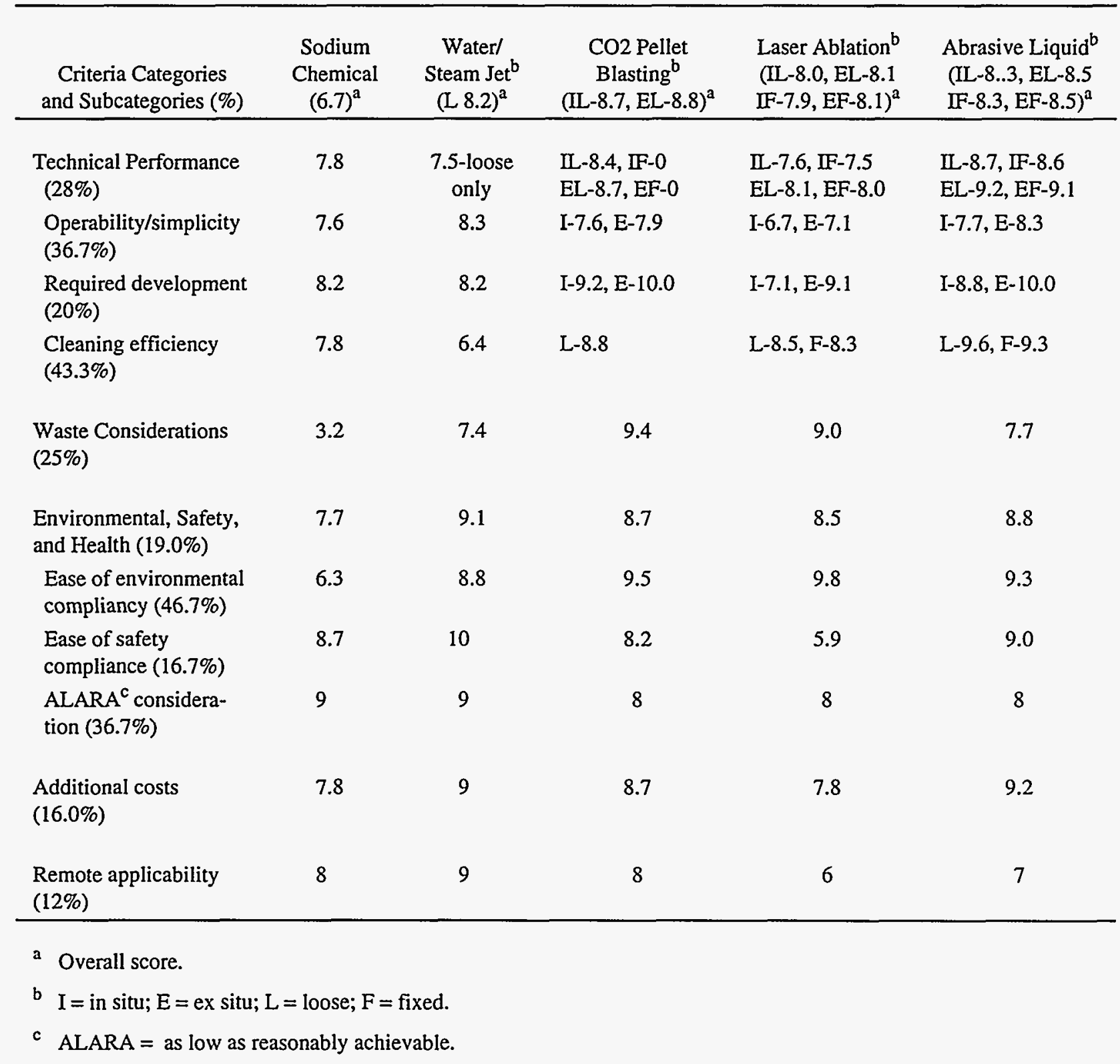

Advantages, Disadvantages, and Problems. The three decontamination techniques and the water jet ranked about the same overall (8-9 on a scale of 1-10). However, both the water jet and the $\mathrm{CO}_{2}$ pellet blasting are good only for loose contamination. For loose contamination removal, $\mathrm{CO}_{2}$ pellet blasting ranked the highest because it generates minimal waste and needs very little development. For fixed contamination removal, abrasive grit ranked slightly higher than light ablation, even though it does generate a secondary waste stream. Light ablation ranked slightly lower due to the amount of development still needed on this technique. All three decontamination 
techniques tested showed a significant advantage over decontamination with sodium-based chemicals.

\subsubsection{Testing and Evaluation of Eight Decontamination Chemicals}

WINCO performed laboratory scoping tests on novel chemical decontamination. The results were published in Demmer et al. (1994). This report describes the experimental work completed on eight different decontamination chemicals. Decontamination factors, waste generation values, and corrosion rates are tabulated for these chemicals. Recommendations are given for effective methods of non- or low-sodium decontamination.

The two most effective chemicals for decontamination found in these tests were a dilute hydrofluoric and nitric acid mixture and a fluoroboric acid solution. Concentration variables were optimized for these two solutions. Several oxidation/reduction chemical systems were also tested. These systems were similar to the Turco 4502 and Turco 4521 solutions used in the past. A lowsodium oxidation/reduction alternative, nitric acid/potassium permanganate was tested and optimized for use. A reductive chemical solution, oxalic acid/nitric acid, proved to have significant advantages.

Required Conditions and Characteristics of Waste. Chemical decontamination is applicable to a variety of materials. Where process equipment cannot be disassembled for cleaning, chemical flushing may be the only decontamination choice. Chemical decontamination can generate high volumes of liquid waste.

Administrative and Training Requirements. All personnel involved with chemical decontamination must be trained in operating procedures.

\section{Results.}

- Costs. The development costs will be low because chemicals are used throughout the industry. Equipment costs will vary on the basis of the systems available at the location. Labor costs should be investigated.

- Volume reduction ratio and rates. Decontamination factors for the various chemicals varied from 1.1 to 37.2 .

- Recycle/reuse. Decontaminated material can be free-released for recycle and reuse, if required. 
Advantages, Disadvantages, and Problems. Chemical decontamination can be done on systems in place or by removal of the systems to a decontamination location. Chemicals have been used for many years throughout the industry for decontamination. New, more effective chemicals can reduce the amount of secondary waste generated from decontamination activities. New techniques for recycling used chemicals are also being explored.

The major drawback with the use of chemicals is the amount of secondary waste generated. In addition, ES\&H concerns are an issue because the chemicals used can be highly corrosive.

\subsubsection{Testing and Evaluation of Light Ablation Decontamination}

WINCO has performed laboratory testing on laser light ablation of metals. Demmer et al. (1994) compares three different types of lasers for use in light ablation decontamination. Comparisons are made on the basis of speed, effectiveness, cost, and overall application to plant equipment. These evaluations were developed for the $\mathrm{CO}_{2}$ laser, Excimer laser, and the Neodymium:Yttrium Aluminum, Garnet (Nd:YAG) laser. The $\mathrm{CO}_{2}$ laser was eliminated at the early stages of ablation research because of apparent excessive metal melting. The tests completed on the other lasers included the suitability to remove coatings, examination of off-gas materials, and optical development.

These tests demonstrated that laser decontamination is a viable method. Lasers were used successfully to remove simulated contamination from coupons and real contamination from samples. Additional work is being completed to enable the use of a laser system with fiber optics for ease of delivery.

Required Conditions and Characteristics of Waste. The laser decontamination in this study focused on metals. Other research has used light ablation for concrete or other materials. Lasers have been used commercially to clean statues and to remove paint. Light ablation of metals does not create secondary waste. The ablated material is collected on HEPA filters of the particle collection system.

Administrative and Training Requirements. All personnel involved with laser decontamination must be trained in operating procedures. 


\section{Results.}

- Costs. Development is still underway at WINCO (now Lockheed Idaho Technologies Company [LITCO]) in conjunction with Ames Laboratory. The equipment costs will vary depending on the power of the laser to be used.

- Volume reduction ratio and rates. Decontamination factors are still being determined.

- Recycle/reuse. Decontaminated material can be free-released for recycle and reuse, if required.

Advantages, Disadvantages, and Problems. Light ablation decontamination is a viable decontamination tool that does not create additional waste. Practical, uncomplicated beam delivery systems that are integrated with robotics need to be developed.

\subsubsection{Contacts}

Julia Tripp, Technical Lead, Decontamination Development

LITCO

P.O. Box 1625

Idaho Falls, ID $83415-5218$ 


\section{CONCRETE}

Radioactive concrete waste is generated in most decommissioning projects, primarily from the dismantling of facility foundations and biological shields. While the total volume of waste concrete can be very large, the contaminated portion is usually limited to the exposed surface to a relatively shallow depth (typically $2 / 3 \mathrm{~cm}$ ). Treatment of the contaminated portion will allow the remaining concrete to be free-released, minimizing the total cost and volume of disposal for radioactively contaminated concrete. The two primary categories of decontamination equipment and techniques are chemical and mechanical. In addition, the decontamination process may either remove the contaminants from the concrete or remove the contaminated portion altogether.

\subsection{CHEMICAL DECONTAMINATION}

Radioactive concrete can be either activated or contaminated. Activated concrete is caused by penetrating radiation (gamma radiation) transmuting stable nuclides into radioactive nuclides throughout the entire volume of concrete. Contaminated concrete is concrete in which only the top layer is radioactive, with the remaining volume free of radioactive material. In general, the chemical decontamination process involves using concentrated or dilute solvents in contact with the contaminated concrete to loosen the contaminated top layer. However, chemical decontamination may not be fully effective on porous surfaces (such as concrete) and may require large amounts of potentially hazardous chemicals and solvents (with the possibility of generating mixed waste during radioactive decontamination) that pose significant safety concerns. Exceptions to this generalization are included in this handbook.

\subsubsection{EET, Inc., Chemical Extraction Technology (TechXtract ${ }^{\mathrm{TM}}$ )}

EET, Inc., has developed an extraction process to remove contaminants, such as radionuclides (including transuranics), from porous surfaces and substrates. Each project requires a custom-engineered application process for effective use of the extraction technology.

After completing the preliminary steps, which include removing gross contamination and establishing critical zones, a technician applies proprietary chemicals to the contaminated surface and then removes them in a multistep, multicycle sequence. After a preflush step, the first chemical blend (surface preparation) is applied to clean and prepare the surface. This blend is removed, and a second chemical blend (extraction) is applied. This blend extracts and removes the contaminants from the surface and substrate. The application calculation for each step is project specific. The sequence of applying, rinsing, and removing each of the chemical formulations constitutes one 
extraction cycle and takes one day. This cycle is repeated as needed until the desired residual contamination levels are achieved.

The chemicals must be scrubbed onto the surface manually or with automated machinery to ensure they make good contact with all surfaces. Decontamination results are approximately $90 \%$ or higher per cycle. After the final cycle and confirmation of acceptable results by doing a sample analysis, a chemical fixation formula can be applied as an optional step. The fixation formula immobilizes any trace amounts of remaining contaminants and simplifies future cleaning if recontamination from other sources occurs.

The chemicals are normally atomized and applied as a fine mist to minimize the volume of chemicals used and the resultant waste. The chemicals used in the extraction process do not exhibit any toxicity characteristics, and the blends do not contain components listed under TCLP testing or RCRA hazardous constituents. They also do not contain components on the "California List." The waste chemicals are not subject to regulation as hazardous waste.

\subsubsection{Required Conditions and Characteristics of Waste}

The EET TechXtract is most applicable in decontamination projects when one or more of the following conditions apply:

- The acceptable level for any residual contaminant is very low (e.g., 1,000 dpm/100 $\mathrm{cm}^{2}$ ) or background for beta-gamma radiation.

- Simple surface cleaning is ineffective because of leaching of subsurface contaminants or radiation for fixed radionuclides.

- Removal and disposal of the entire contaminated surface and substrate are not desirable.

- Significant safety concerns are raised (e.g., the generation of airborne radioactive contaminants).

- Decontamination is to be performed on surfaces that are not flat and horizontal, including equipment, walls, ceilings, structural beams, and internal piping.

- Equipment in the area to be cleaned needs to continue operating. 
The EET TechXtract is applicable to concrete, bricks, cinder blocks, tile, asphalt, transite, wood, cast iron, steel, and exotic metals. Extensive decontamination of fixed radionuclides is possible regardless of depth. A variety of nuclides can be removed, depending on the chemical used to decontaminate the material. The technique is effective for both activated and contaminated materials and for removal of PCBs, heavy metals, and other hazardous contaminants.

\subsubsection{Administrative and Training Requirements}

The EET extraction process must be performed by trained EET personnel.

\subsubsection{Results}

- Costs. Costs associated with EET's TechXtract are project specific and vary according to customer needs. Removal of low-level contaminants costs approximately $\$ 4 / \mathrm{ft}^{2}$.

- Volume reduction ratio and rates. In an operation performed for Martin Marietta Energy Systems (DOE), beta-gamma levels were reduced from 4,645 to less than $7 \mathrm{~Bq} / 100 \mathrm{~cm}^{2}\left(278,678\right.$ to less than $\left.424 \mathrm{dpm} / 100 \mathrm{~cm}^{2}\right)$. Alpha levels were reduced from 14 to $0.3 \mathrm{~Bq} / 100 \mathrm{~cm}^{2}$ (862 to less than $19 \mathrm{dpm} / 100 \mathrm{~cm}^{2}$ ). Uranium in the rinse fluid increased from 0 to $312,000 \mu \mathrm{g} / \mathrm{L}$. Similar results have been obtained in comparable radiological decontamination projects. Typical waste volumes are 7.5-30.3 L/9.3 $\mathrm{m}^{2}$ (2-8 gal/100 $\mathrm{ft}^{2}$ ) for the project, including chemical blends, rinsate, and contaminants from all cycles. Crew sizes usually range from three to five persons.

- Recycle/reuse. The decontaminated material can be released for unrestricted use.

\subsubsection{Advantages, Disadvantages, and Problems}

Advantages of the technique include (1) the applicability to nonhorizontal and irregular surfaces and (2) the nondestructive nature of the process. 


\subsubsection{Contacts}

Michael W. Bonem, Executive Vice President and Chief Operating Officer

EET, Inc.

4710 Bellaire Boulevard, Suite 300

Bellaire, TX 77401

(713) 662-0727 Telephone

(713) 662-2322 Fax

\subsection{MECHANICAL DECONTAMINATION}

Mechanical decontamination methods include surface cleaning (removing the contaminants from the top $[2 / 3 \mathrm{~cm}]$ level of concrete) and surface removal (removing the entire top level of concrete). In general, surface removal techniques are most effective for decontaminating concrete, especially for floors and walls. Examples of these techniques are grit blasting and scarifying. The depth of surface removal varies on the basis of the depth of contamination, which is generally greater for floors than for walls and ceilings. Surface preparation and safety precautions may be required before removal activities begin. Many systems are self-contained and do not generate significant dust or waste. Many leave a smooth finish after removing the contaminated surface. A smooth surface allows a protective cap and/or paint to be applied.

\subsubsection{Pentek ${ }^{\circledR}$ Dustless Decontamination System at Rocky Flats Environmental Technology Site}

Current decontamination procedures used on concrete surfaces at Rocky Flats Environmental Technology Site involve the dustless decontamination system (DDS). The DDS is composed of three main components: a manually controlled piston device known as a "scabbler," a manually controlled needle gun, and a vacuum system. The scabbler, which has three pistons, is used in large-scale decontamination operations in which coated floor and concrete substrates are pulverized. The hand-held needle gun, which has one piston, operates under the same principle and is used to decontaminate such areas as walls and smaller, difficult-to-reach surfaces. These two devices are operated with a third device-a high-velocity vacuum system. This system is equipped with a roughing filter and HEPA filtration to ensure that radioactive particles are not released into the atmosphere. The vacuum system directly deposits all of the removed waste into drums.

Both the scabbler and the needle gun are air operated and use pistons with tungsten-carbide tipped bits or needles to pulverize the concrete surface. Each scabbler decontaminates surfaces to a nominal depth of $1 / 2 \mathrm{~cm}$ ( $3 / 16 \mathrm{in}$.). The needle gun can be adapted to odd geometries by using Teflon shrouds. 


\subsubsection{Required Conditions and Characteristics of Waste}

For surface-contaminated concrete, initial testing of equipment was performed on concrete with 500-25,000 cpm of alpha (plutonium) contamination.

\subsubsection{Administrative and Training Requirements}

Administrative and training requirements for the use of the Pentek DDS were not available.

\subsubsection{Results}

- Costs. The initial cost was $\$ 35,300$. Operational cost is about $\$ 5 / \mathrm{d}$.

- Volume reduction ratio and rates. The DDS decontaminates approximately $2.8 \mathrm{~m}^{2} / \mathrm{h}\left(30 \mathrm{ft}^{2} / \mathrm{h}\right)$. The initial test on the alpha-contaminated concrete resulted in all areas measuring $<15 \mathrm{kBq}(250 \mathrm{dpm})$.

- Recycle/reuse. The decontaminated concrete surfaces are released for unrestricted use.

\subsubsection{Advantages, Disadvantages, and Problems}

Radon gas is released as the concrete surface is disturbed. No secondary media waste is generated, such as grit or sand used in vacuum blast or grit-blasted units. The scabbler can be used for PCB decontamination. The scabbled surface has excellent adhesion properties and is conducive for placing a topping compound.

\subsubsection{Contacts}

Michael Simmons, Project Lead

Manufacturing Sciences Corporation

Waste Minimization Program

P.O. Box 464, Building 883

Golden, CO 80402-0464

(303) 966-7574 Telephone

(303) 966-5713 Fax 


\subsubsection{Pentek Dustless Decontamination Systems}

Pentek, Inc., has developed a line of dustless decontamination equipment to remove hazardous and radiological surface contamination from concrete and steel. The Moose ${ }^{\mathrm{TM}}$ concrete scabbling robot cleans and prepares a 46-cm (18-in.) path to remove protective coatings, laitance, and concrete substrate in increments of 0.08-0.5 cm (1/32-3/16 in.) deep. All dust and debris are removed from the surface by the onboard, pneumatically driven vacuum system and deposited directly into the waste drum. The Moose can be equipped with optional teleoperated controls, including color television and lights. Production rates vary according to individual location conditions.

The Squirrel- $\mathrm{II}^{\circledR}$ is used for small decontamination jobs on concrete floors. The manually operated scabbler can maneuver in tight spaces near corners, wall/floor penetrations, equipment pedestals, and steps and under protruding equipment. The Squirrel-III is $15.2 \mathrm{~cm}$ (6 in.) wide with a $23-\mathrm{cm}$ (9-in.) clearance and incorporates a vacuum flow design that controls dust and debris. It is used primarily for trims, perimeters, and other tight spaces.

The Corner-Cutter ${ }^{\circledR}$ is a hand-held, pneumatic piston-driven needle gun with reciprocating needles for both concrete and steel. The vacuum shrouding system simultaneously collects airborne and particulate hazards generated by the scabbling process. Shrouds on the tool conform to the work surface to direct the vacuum flow and provide localized containment. The Corner Cutter has a $360^{\circ}$ rotating collar and disposable shrouds and weighs $5 \mathrm{~kg}(11 \mathrm{lb})$. Production rates depend on the hardness of the concrete, the condition of the coating, the contours encountered, worker experience, and other conditions.

The $\mathrm{Vac}-\mathrm{Pac}^{\circledR}$ is a HEPA filtration vacuum and waste drumming system that can simultaneously support three Corner Cutters, two Squirrel-IIIs, or a combination of the two up to $30.5 \mathrm{~m}$ (100 ft) away. The portable Vac-Pac features self-cleaning first-stage filters. The Vac-Pac incorporates a controlled-seal drum fill system that allows the operator to fill, seal, remove, and replace the waste drum under controlled vacuum conditions. Waste material is deposited directly into a waste drum. An intermediate emptying step is not necessary, which eliminates the possibility of releasing airborne contamination during drum changes.

\subsubsection{Required Conditions and Characteristics of Waste}

The Pentek decontamination system performs on surface-contaminated concrete or painted steel. 


\subsubsection{Administrative and Training Requirements}

All operators of the Pentek decontamination system should be thoroughly trained in administrative and safety procedures.

\subsubsection{Results}

- Costs. Pentek decontamination systems are available on a purchase, lease, or service contract basis. All prices are subject to change without notice. Current purchase prices are as follows:

$\begin{array}{lrl}\text { - Vac-Pac } & \$ 18,160-38,150 & \text { (air powered) } \\ & \$ 29,170-37,930 & \text { (electric powered) } \\ \text { - Corner Cutter } & \$ 2,895 & \\ \text { - Squirrel-III } & \$ 9,975 & \\ \text { - Moose } & \$ 155,000\end{array}$

Rental prices for the Moose are as follows:

- $\$ 1,925 / \mathrm{d}(8 \mathrm{~h})$, which includes an operator, Moose remote scabbler and hoses, transportation, and travel and living expenses

- \$7,800/week (40 h)

- \$600 flat charge clean construction work

- $\$ 2,300$ flat charge for contaminated work

- $\$ 66.25$ for each disposable 23-gal drum

- $\$ 1.60 / \mathrm{m}^{2}\left(\$ 0.15 / \mathrm{ft}^{2}\right)$ for bit wear.

Applicable surcharges and service charges apply. Other rental prices are listed below:

One-Time

\begin{tabular}{lcc}
\multicolumn{1}{c}{ Equipment } & Service Charge & Weekly Rate \\
\cline { 3 - 3 } Vac-Pac, Model 9 & $\$ 1,750$ & $\$ 1,081$ \\
Squirrel-III scabbler & $\$ 800$ & $\$ 813$ \\
Corner Cutter needle gun & $\$ 450$ & $\$ 234$
\end{tabular}

- Volume reduction ratio and rates. The Moose can remove approximately $78-97 \mathrm{~m}^{2}(800-1,000 \mathrm{ft})^{2}$ per day at a $0.16-\mathrm{cm}(1 / 16-\mathrm{in}$.) depth. The Squirrel-III can remove approximately $3-4.4 \mathrm{~m}^{2}\left(30-45 \mathrm{ft}^{2}\right)$ per hour at a 0.16-cm (1/16-in.) removal depth. The Corner Cutter can process 
approximately $2-3 \mathrm{~m}^{2}\left(20-30 \mathrm{ft}^{2}\right)$ per hour on flat surfaces and 9.1-18.3 m (30-60 ft) per hour linear at a 0.16-cm (1/16-in.) depth removal for each gun.

- Recycle/reuse. The decontaminated concrete is released without restriction.

\subsubsection{Advantages, Disadvantages, and Problems}

The self-cleaning features of the Vac-Pac extend filter life to at least one year, reducing the need for filter changes. The Vac-Pac system has few moving parts, so a minimal maintenance operations are required. All components of the Pentek system are designed to integrate with each other or stand alone.

\subsubsection{Contacts}

Eric Crivella

Pentek, Inc.

1026 Fourth Avenue

Coraopolis, PA 15108-1659

(412) 262-0725 Telephone

(412) 262-0731 Fax 


\section{LIQUIDS}

This section pertains to the decontamination and treatment of radioactive liquids and sludges. Liquids encountered during decommissioning are usually dilute solutions with little or no suspended materials. Often bulk liquids must be treated for unusual chemical and physical characteristics that require specialized waste treatment. The primary components in sludge are liquids and solids. To treat sludge, it is initially necessary to remove the liquid. This section examines techniques for removing contaminants from liquids and sludges so that any resultant water can be reused or recycled to the environment and the contaminants can be concentrated for volume reduction.

\subsection{EVAPORATION}

Low-temperature thermal treatments $\left(<149^{\circ} \mathrm{C}\right)$ evaporate water content. Drying encompasses chemical reactions other than water evaporation. This section primarily looks at evaporation, although chemical drying techniques are mentioned where applicable. Thermal evaporation removes all surface water present in sludge, as compared with mechanical drying, which is only about $50 \%$ effective. However, in sludges that contain more than $30 \%$ water, mechanical drying (such as a centrifuge) should precede thermal drying.

Chemical drying and water evaporation are effective and universally applicable methods for purifying contaminated liquid effluents that contain pollutants and various chemical substances. The substances and the activity contained in the liquid effluent are concentrated in the evaporator residue, while only a very small fraction is transferred into the distillate. Normally, when no organic derivatives are present, solids are brought to $100^{\circ} \mathrm{C}$, and the vapor reaches $127^{\circ} \mathrm{C}$. If the effluent contains water vapor only, a spray tower can be used to remove a large fraction of the water vapor. The cooling water enters the tower at approximately $32^{\circ} \mathrm{C}$, and the condensed effluent leaves at temperatures between 60 and $77^{\circ} \mathrm{C}$. A fraction of this water may be recirculated through an air cooler to achieve the desired temperature of $32-38^{\circ} \mathrm{C}$.

A second method for condensing the water vapor is the use of a chiller. Most of the water can be removed with a refrigerated chiller operating at $-40^{\circ} \mathrm{C}$. A Venturi scrubber removes particulates in front of a condenser. The scrubber should have an independent water supply so that the coils of the refrigerated chiller do not become contaminated.

\subsubsection{Evaporation of Liquids at Kernforschungszentrum Karlsruhe}

A flash evaporator design with forced circulation and vapor compression is used at $\mathrm{KfK}$ in Germany. The liquid effluent is accepted in a collection tank and fed to an evaporator through a 
countercurrent heat exchanger. The vapors are heated by a compressor and transported and condensed in the heater of the evaporator. The distillate produced is removed through the countercurrent heat exchanger into collection tanks. After activity checks and clearance, the distillate is discharged to a chemical treatment plant. The concentrate evaporates by expansion upon entering the vapor chamber.

Two LLW evaporators and one medium-level waste (MLW) evaporator are located at KfK. The MLW is a two-stage system. MLW passes through a separator, and the sodium nitrate/nitric acid solution in an aqueous phase is transferred to the MLW evaporator. Table 8 contains the statistics for the two types of evaporation plants found at $\mathrm{KfK}$.

The sludge from all the evaporators is sent to a cementation plant. A 200-L drum is filled with a mixture of $120 \mathrm{~L}$ of sludge and $80 \mathrm{~L}$ of cement. The plant can process 10 drums per 8 -h day.

\subsubsection{Required Conditions and Characteristics of Waste}

The evaporators are designed to accept contaminated liquid effluents loaded with pollutants and various chemical substances.

TABLE 8 Evaporation Plants at Kernforschungszentrum Karlsruhe

\begin{tabular}{lll}
\hline & \multicolumn{2}{c}{ Type of Waste Processed at Evaporation Plants at KfK } \\
\cline { 2 - 3 } \multicolumn{1}{c}{ Equipment } & \multicolumn{1}{c}{ LLW } & \multicolumn{1}{c}{ MLW } \\
\hline Tanks & & $2 \times 2 \mathrm{~m}^{3}$ \\
Receiving & $2 \times 150 \mathrm{~m}^{3}$ & $2 \times 2.5 \mathrm{~m}^{3}$ \\
Feeding & $2 \times 40 \mathrm{~m}^{3}$ & 1.5 and $13 \mathrm{~m}^{3}$ \\
Concentrate & $3 \times 9 \mathrm{~m}^{3}$ & - \\
Distillate & $4 \times 65 \mathrm{~m}^{3}$ & Vacuum, steam jets \\
Conveyance & Radial pumps & \\
Evaporators & & Natural circulation evaporator \\
Type of evaporator & Flash evaporator with forced convection & External tube bundle \\
Heat exchanger & Internal tube bundle & Steam, 250 kPa \\
Heating medium & Condensed vapors, $140 \mathrm{kPa}$ & Perforated trays \\
Vapor cleanup & Packings & \multicolumn{2}{c}{. }
\end{tabular}




\subsubsection{Administrative and Training Requirements}

Administrative and training requirements for using the evaporators at $\mathrm{KfK}$ were not available.

\subsubsection{Results}

- Costs. Costs of the evaporators at KfK were not available.

- Volume reduction ratio and rates. The flow rate of each LLW evaporator is $4 \mathrm{~m}^{3} / \mathrm{h}\left(6,000 \mathrm{~m}^{3} / \mathrm{yr}\right)$, with decontamination factors of $10^{3}$ and concentration factors of 100. The flow rate of the MLW evaporator is $1 \mathrm{~m}^{3} / \mathrm{h}\left(500 \mathrm{~m}^{3} / \mathrm{yr}\right)$, with a decontamination factor of $10^{3}$ and a concentration factor of 10 . All evaporators have a maximum solids content of $25 \%$ in weight.

- Recycle/reuse. After evaporation, the water is discharged to a local sewage plant, and the solids are buried.

\subsubsection{Advantages, Disadvantages, and Problems}

Limitations of the evaporators at $\mathrm{KfK}$ were not available.

\subsubsection{Contacts}

Reinhard Pfeiffer, Department Manager

Kernforschungszentrum Karlsruhe $\mathrm{GmbH}$

Postfach 3640

D-76021 Karlsruhe, Germany

$497247824388 \quad$ Telephone

$497247824272 \quad$ Fax

\subsubsection{Concentrated Waste Dryer System: Stock Equipment Company}

The concentrated waste dryer system (CWDS) processes liquid radioactive wastes typically produced by pressurized-water reactors (PWRs). This process is accomplished by removing the nonradioactive water portion of the liquid LLW and condensing the remaining radioactive material into a granular solid. The CWDS consists of a mechanical, rotary horizontal evaporator/concentrator 
(E/C); a chiller; several heat exchangers and pumps; a jet pump; and a condensate reservoir. The heat required to evaporate the wastewater is provided by an existing steam system. The CWDS components are skid mounted to facilitate installation. All pertinent data necessary to monitor the system are routed through a central portable control station.

The liquid waste is preheated by a preheat heat exchanger in the inlet line before being injected into the $\mathrm{E} / \mathrm{C}$. Once the preheated waste enters the $\mathrm{E} / \mathrm{C}$, the waste continues to heat and mix, while a jet pump reduces the pressure to a slight vacuum. Under these conditions, the liquid waste evaporates and is removed by the suction of the jet pump. A heat exchanger then condenses the saturated steam before it enters the jet pump. The pumps send the condensate and the motive water flow into the condensate reservoir. Excess condensate is returned to the plant wastewater processing system.

The waste concentration increases as water is removed. The material precipitates out of solution and gradually converts to a granular solid. The material is continually heated until no further significant evaporation occurs, as evidenced by a leveling of the waste product temperature. The waste drying system consists of a $0.71-\mathrm{m}^{3}\left(25-\mathrm{ft}^{3}\right)$ horizontal rotary dryer and vacuum system.

A television monitoring system allows the operator to visually monitor the internal operation and drying of the waste inside the CWDS rotary dryer. The entire process is a closed system to minimize airborne contamination and reduce exposure to the operator and surrounding personnel, thus satisfying as low as reasonably achievable (ALARA) concerns. The CWDS is automated and remotely controlled.

\subsubsection{Required Conditions and Characteristics of Waste}

The CWDS is designed primarily for liquid LLW generated at PWRs, including boric acid slurries and evaporator bottoms/sludges.

\subsubsection{Administrative and Training Requirements}

Administrative and training requirements for the use of the Stock CWDS were not available.

\subsubsection{Results}

- Costs. Costs for Stock CWDSs were not available. 
- Volume reduction ratio and rates. Volume reduction ratio and rates for Stock CWDSs were not available.

- Recycle/reuse. Residual solids can be disposed of as waste, and the water can be discharged to local sewage plants.

\subsubsection{Advantages, Disadvantages, and Problems}

Waste that is preheated before evaporation requires less time to initiate evaporation and complete processing, which improves the overall thermal efficiency of the system. Counterflow heat exchangers achieve maximum heat transfer in the system and are more efficient than parallel flow heat exchangers. The CWDS has operated-controlled fluid flow to the heat exchangers and vacuum pressure to the E/C to achieve the best overall system performance with minimal wear on components. This capability also allows increased flexibility in processing varying waste streams. In addition, the CWDS incorporates automatic level control of the condensate tank.

\subsubsection{Contacts}

William S. Phillips, Nuclear Projects Sales Manager

Stock Equipment Company

16490 Chillicothe Road

Chagrin Falls, $\mathrm{OH} 44022-4398$

(216) 543-6000 Telephone

(216) 543-6678 Fax

\subsubsection{Resources Conservation Company}

Resources Conservation Company (RCC) manufactures the brine concentrator, which has been used at fuel processing centers, nuclear power plants, and remediation sites to reduce the volume of LLW. The concentrator is a falling film evaporator design. In one application at a nuclear fuel processing plant, uranyl nitrate was extracted from solution. The condenser uses the latent heat in the evaporated process vapor as the energy source for evaporation. To provide the driving force for heat transfer and vapor condensation, the vapor temperature and pressure are increased by a single-stage centrifugal compressor. The energy consumed by the compressor is substantially less than the energy being transferred to the evaporating liquid. Also, because the vapors transfer their latent heat back to the liquid, no condenser is required. 
Figure 8 shows the process flow of the brine concentrator. Wastewater is pumped through an initial heat exchanger where the temperature is raised to the boiling point. The hot wastewater is deaerated and decarbonated, and sent to combine with brine slurry in the sump. The brine slurry continually circulates from the sump to a floodbox at the top of a bundle of heat transfer tubes. As the brine flows in a falling film through the heat bundles to the sump, a portion evaporates and passes through mist eliminators to the vapor compression chamber. Compressed vapor flows to the outside of the heat transfer tubes. The transfer of heat sustains the evaporation of brine in the tubes, while condensing the compressed vapor into distillate. The distillate is pumped back into the heat exchanger, where it heats the incoming wastewater. A small amount of waste brine is blown down from the sump to control the brine density.

\subsubsection{Required Conditions and Characteristics of Waste}

The evaporators have been used on various types of wastewater, including water contaminated with uranyl nitrate and LLW. The evaporators have been used on cooling tower blowdown, demineralizer regenerant waste, reverse osmosis reject, and ash system blowdown. The RCC also designed a forced-circulation evaporator to treat LLW at Hanford.

\subsubsection{Administrative and Training Requirements}

All personnel using the brine concentrator must be trained in applicable administrative and safety requirements.

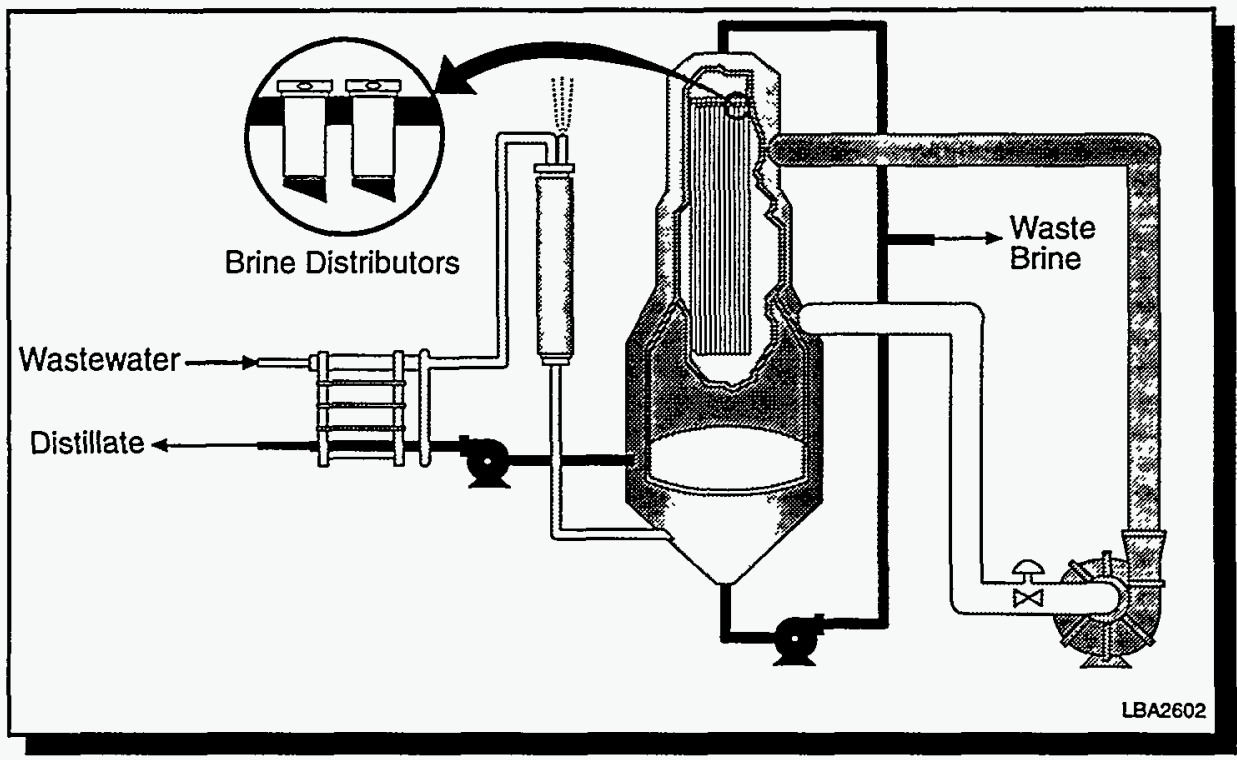

FIGURE 8 Process Flow of the Brine Concentrator (LBA2602-E) 


\subsubsection{Results}

- Costs. Prices for the brine concentrators range from $\$ 500,000$ for the smallest evaporator to about $\$ 4$ million for the largest single body. For the uranyl nitrate extraction application, the condenser initially (1980) provided a net savings of more than $\$ 45,000 /$ month in utility costs. By 1982 , the rising cost of energy increased the savings to $\$ 57,000 /$ month.

- Volume reduction ratio and rates. The brine concentrator recovers about $95 \%$ of the waste as distilled water ( $<10$ parts per million [ppm] total dissolved solids [TDS]). The remaining $5 \%$ is a concentrated slurry that can be reduced to solids in a crystallizer or similar process equipment. The brine concentrator is available in various sizes to handle flow rates ranging from approximately 1 to $38 \mathrm{~L} / \mathrm{s}$ ( 15 to $600 \mathrm{gal} / \mathrm{min}$ ) in a single body. Multiple brine concentrators can be coupled to handle very large flows.

- Recycle/reuse. Distilled water containing <10 mg/L TDS, excluding volatiles, can be recycled or discharged.

\subsubsection{Advantages, Disadvantages, and Problems}

The seeded slurry technology controls scale buildup within the system. The "twin spin" distributors ensure a smooth flow of brine, avoiding scale formation. The brine concentrator uses 0.019-0.023 kWh/kg (29-37 BTU/lb) of waste feed. This converts to $70-90 \mathrm{kWh} / 3,785 \mathrm{~L}(1,000 \mathrm{gal})$ of feed - 10 times more efficient than conventional single-effect steam-driven evaporators.

\subsubsection{Contacts}

Rodi Ludlum, Marketing Manager

Resources Conservation Company

3006 Northup Way

Bellevue, WA 98004-1407

(206) 828-2400 Telephone

(206) 828-0526 Fax 


\subsection{INCINERATION}

Liquid incineration refers to the process of burning contaminated liquid in a controlled environment. A liquid incinerator includes a burner housing mounted on the combustion chamber rather than on the in-line gas burner found on fume incinerators. Dual-fuel liquid incinerators are designed to burn both gas and liquids.

Three major specifications apply to a liquid fuel:

- A heat content greater than $2.585 \mathrm{kWh} / \mathrm{kg}(4,000 \mathrm{Btu} / \mathrm{lb})$,

- A viscosity less than 100 seconds saybolt universal (ssu) and

- A partial top size less than $0.04 \mathrm{~cm}(1 / 64 \mathrm{in}$.$) .$

The reason for this limited specification is that a liquid incinerator must discharge the liquid through a nozzle at a rate identical to the combustion rate. Most liquid waste streams at a decommissioning site will require pretreatment to fit these criteria. Liquid waste incinerators are in place in KfK in Germany, and the Scientific Ecology Group, Inc., Waste Processing Center in Oak Ridge, Tennessee.

\subsubsection{Incineration at Kernforschungszentrum Karlsruhe}

A system has been implemented for safely burning contaminated solvents and used oil from radioactive controlled areas. The liquid waste incinerator consists of a cylindrical refractory bricklined combustion chamber. The flue-gas cleanup system includes a jet scrubber, a Venturi scrubber, a HEPA filter, and a Dioxin filter. The flue gas is scrubbed in two stages and released through the filters by means of a blower. The incinerator was built in 1987 and designed by NuKem with HDB modifications. Residual material is filled in sheet metal drums and treated as nonburnable waste. This waste is compacted, if possible.

\subsubsection{Required Conditions and Characteristics of Waste}

The incinerator is designed to process contaminated oils and solvents. Specific activity limits were not available. 


\subsubsection{Administrative and Training Requirements}

All personnel using KfK incinerators must be trained in applicable administrative and safety requirements.

\subsubsection{Results}

- Costs. The initial cost of the incinerator was approximately $\$ 4.5$ million in 1987. Surveillance, maintenance, and building construction costs are incorporated with the solid waste incinerators at $\mathrm{KfK}$.

- Volume reduction ratio and rates. The throughput of the liquid waste incinerator is $30 \mathrm{~kg} / \mathrm{h}(40,000 \mathrm{~kg} / \mathrm{yr})$. The volume reduction factor is $10: 1$. The decontamination factor without a HEPA filter is 100 . The decontamination factor with the HEPA filter is $10^{3}$.

- Recycle/reuse. Recycle and reuse applications generally do not apply to incinerated waste.

\subsubsection{Advantages, Disadvantages, and Problems}

Limitations to the KfK liquid incinerator were not available.

\subsubsection{Contacts}

Friedrich Dirks, Department Manager

Kernforschungszentrum Karlsruhe $\mathrm{GmbH}$

Postfach 3640

D-76021 Karlsruhe, Germany

$497247822220 \quad$ Telephone

$497247824272 \quad$ Fax

\subsubsection{Incineration at Scientific Ecology Group - Liquid Waste}

The SEG can burn radioactively contaminated oils and fluids in the SEG oil incinerator (boiler). The boiler is a self-contained incineration package, complete with its own dedicated off-gas 
scrubbing and filtering system. Oils and aqueous liquids are consumed during the incineration process.

\subsubsection{Required Conditions and Characteristics of Waste}

"Oil" in this context refers to oils, fuels, solvents, or other similar fluids that meet incineration requirements. Petroleum-based lubricating and heating oils, including kerosene, hydraulic oil, diesel fluid, and other flammable oils, are acceptable for processing through the SEG oil burner provided they meet the following criteria:

- Viscosity

- Solids content

- Aqueous liquid content

- Nonhazardous by RCRA/TSCA $\leq 40$ weight $(<100 \mathrm{ssu})$

$<10 \%$ by volume

$<10 \%$ by volume

See Table 9

TABLE 9 RCRA/TSCA Radiological Limits for Both Burnable Oil and Aqueous Liquids

\section{Radiation Levels}

Radiation level per package

Removable external contamination $\leq 2 \mathrm{mSv} / \mathrm{h}$ contact $(1 \mathrm{~cm})$ $\leq 37 \mathrm{~Bq}$ beta-gamma $/ 100 \mathrm{~cm}^{2}$ $\leq 3.7 \mathrm{~Bq}$ alpha/ $100 \mathrm{~cm}^{2}$

\section{Radionuclide Limits $^{\mathrm{a}}$}

Radionuclide

Total of all nuclides not listed below

Hydrogen-3

Carbon-14

Iodine-129

Technetium-99

Radium-226

TRU

Other special nuclear material ${ }^{\mathrm{b}}$
Average Concentration

$\leq 1.85 \mathrm{kBq} / \mathrm{mL}$ $\leq 111 \mathrm{~Bq} / \mathrm{mL}$ $\leq 37 \mathrm{~Bq} / \mathrm{mL}$ $\leq 37 \mathrm{~Bq} / 100 \mathrm{~mL}$ $\leq 3.7 \mathrm{~Bq} / \mathrm{mL}$

Prior approval required $\leq 3.7 \mathrm{~Bq} / \mathrm{mL}$ Prior approval required

a The average radionuclide concentration shall not exceed the following limits when averaged over the truckload lot.

b Includes uranium-233, uranium-235, or uranium enriched in the isotope. 
Most synthetic fluids, including Fyrquel electrohydraulic control (EHC) fluid and Mobil lubricating fluids, are also acceptable. SEG will accept oil that has a viscosity of 100 ssu or less when diluted with kerosene in a ratio of one part kerosene to two parts oil. Surcharges may be applied if solidification of nonburnable oils is required.

SEG is also licensed to burn aqueous liquids. All aqueous liquids meeting the following criteria are acceptable for incineration:

- $\quad$ H range

- Solids content

- Oil content

- Chelating agents

- Nonhazardous by RCRA/TSCA

\section{$5-9$}

$<10 \%$ by volume

$<10 \%$ by volume

$<1 \%$ by volume

See Table 10

Generally, liquids exceeding the above criteria will still be accepted, although additional handling will be required. Oil and solid content is important because SEG burns the liquid in a specific burner. Aqueous liquids that contain significant percentages of oil or solids may require alternative processing. Aqueous liquids containing chelating agents will require an evaluation to determine decomposition products, the ability of the scrubber system to remove these products, and processing to ensure complete destruction of the chelantets.

\subsubsection{Administrative and Training Requirements}

Waste generators must follow the requirements outlined in SEG (1995).

\subsubsection{Results}

- Costs. The average price for DOE customers (Oak Ridge Complex) is $\$ 4.63 / \mathrm{kg}(\$ 2.10 / \mathrm{lb})$ for bulk incineration.

- Volume reduction ratio and rates. The oil burner can incinerate contaminated oil at the rate of 30-45 L (8-12 gal) per hour. Currently, the SEG oil burner processes about $227,100 \mathrm{~L}$ (60,000 gal) of oil each year. Incineration of oils and aqueous liquids does not result in discernable ash volume. Containers 
TABLE 10 SEG RCRA/TSCA Limits for the Incineration of Both Burnable Oil and Aqueous Liquids

Type of Analysis SEG Acceptance Criteria

1. Toxicity Characteristic

Leaching Procedure (TCLP)

Toxic Metals (40 CFR 261.24)

Arsenic

Barium

Cadmium

$<5.0 \mathrm{mg} / \mathrm{L}$

Chromium $<100.0 \mathrm{mg} / \mathrm{L}$

Lead $<1.0 \mathrm{mg} / \mathrm{L}$

Mercury $<5.0 \mathrm{mg} / \mathrm{L}$

Selenium $<5.0 \mathrm{mg} / \mathrm{L}$

Silver $<0.2 \mathrm{mg} / \mathrm{L}$ $<1.0 \mathrm{mg} / \mathrm{L}$ $<5.0 \mathrm{mg} / \mathrm{L}$

Organics

See the organic compounds and their respective regulatory levels listed under 40 CFR 261.24. Any compound that cannot be certified by the generator to be absent from the oil or liquid must be tested for under TCLP standards.

2. Total halogens - oils only $\leq 1,000 \mathrm{ppm}$ unless rebutted ${ }^{\mathrm{a}}$

3. $P C B s$

$$
<2.0 \mathrm{ppm}^{\mathrm{b}}
$$

4. Flashpoint $\geq 60^{\circ} \mathrm{C}$

a The EPA has specified a limit of $1,000 \mathrm{ppm}$ as the level at which they presume mixing with spent halogenated solvents has occurred. The oil can contain up to $4,000 \mathrm{ppm}$ total halogens if the presumption of mixing can be successfully rebutted. For successful rebuttal of the mixing presumption, an analysis must demonstrate that the oil contains $<100 \mathrm{ppm}$ of any individual halogenated solvent listed as an F001 or F002 waste and certify that no intentional mixing of hazardous constituents with the oil has occurred. Additional volatile organic analysis would be required to analyze for these individual compounds.

b Limits are based on request by the Tennessee Valley Authority and EPA regulations contained in 40 CFR 761 . 
used to ship the liquids or oils are processed or processed and returned to the generator.

- Recycle/reuse. Recycle and reuse applications concerning the SEG liquid incinerator were not identified and generally do not apply to incinerated waste.

\subsubsection{Advantages, Disadvantages, and Problems}

The benefits of oil burning over solidification and burial include reduced burial costs and reuse of the thermal energy produced from burning the oil.

\subsubsection{Contacts}

Richard P. Williams, Product Line Sales

Scientific Ecology Group

1560 Bear Creek Road

P.O. Box 2530

Oak Ridge, TN 37831

(423) 376-8076 Telephone

(423) $376-8484 \quad$ Fax

\subsection{MISCELLANEOUS TREATMENT OF LIQUID WASTE}

This section includes innovative methods of radioactive liquid waste treatment currently in practice at laboratories and research facilities. These technologies range from full-scale waste treatment plants to systems designed to handle smaller waste volumes. In general, these systems were designed for specific site waste streams and are unique. Two examples are included: the Waste Treatment Plant at ORNL and waste treatment at the Winfrith Technology Center.

Waste treatment plants collect and process large volumes of liquid waste generated throughout the site. Although the size of the plant corresponds to the total expected throughput of liquid waste, treatment plants are large and expensive, and are reserved for large-scale research sites and industrial complexes. However, specific aspects of waste treatment plants may be incorporated into smaller-scale liquid waste treatment systems. The techniques used at Winfrith Technology Center have been specifically implemented to process the wastes generated there. 


\subsubsection{Process Waste Treatment Plant and Collection System at Oak Ridge National Laboratory}

The Process Waste Treatment Plant (PWTP) and Collection System handles radioactive liquid waste from the main ORNL area, Melton Valley, and Bethel Valley. The process consists of three basic operations: precipitation, filtration, and ion-exchange. The first two use a static in-line pipe mixer, a sludge-blanket-type precipitator-clarifier, and pressure filters. The ion-exchange equipment is tailored to the process. The system introduces a zeolite column (TSM-300, consisting of natural chabosite) to increase radionuclide capture, especially cobalt- 60 .

Liquid waste is initially sorted according to radiological content. During the first two operations, a flocculent precipitate of calcium carbonate and magnesium hydroxide is formed by adjusting the $\mathrm{pH}$ of the waste stream to 11.5 by using $\mathrm{NaOH}$. At the same time, two flocculating agents - ferric sulfate in a $1 \%$ sulfuric acid solution and an organic polymer flocculating agent are added to the waste stream. Coagulation of the precipitates into larger particles occurs in the flocculator section of the precipitator-clarifier. Solid separation is achieved by upflowing the mixture through a sludge-blanket, which consists of fluidized particles that trap the floc and furnish additional nuclei to continue the precipitation reaction by crystal growth. As particles in the sludgeblanket agglomerate, they settle and form a slurry in the bottom of the vessel. It is this chemical and physical action that scavenges radionuclides, dirt particles, and algae from the waste stream and retains them in the slurry.

The slurry is periodically pumped from the bottom to a $22,710-\mathrm{L}(6,000$-gal) holding tank. The slurry, which averages $2-4 \%$ by weight solid, will be accumulated to a predetermined level and dewatered in a filter press. The dewatered sludge is removed from the filter press and placed in 208-L (55-gal) carbon steel drums lined with plastic bags for storage. The filtrate and the filter washes are eventually fed to the Bethel Valley storage tanks. Current development plans include proceeding to a more automated approach.

\subsubsection{Required Conditions and Characteristics of Waste} the PWTP.

All liquid waste passes monitors to determine radioactive content before being directed to

\subsubsection{Administrative and Training Requirements}

All personnel involved in the use of the PWTP must be trained in applicable administrative and safety requirements. 


\subsubsection{Results}

- Costs. The total cost was $\$ 3$ million for the collection system (1990 dollars), $\$ 12$ million for nonradiological components (1990 dollars), and \$1.3 million for the PWTP (1976 dollars).

- Volume reduction ratio and rates. The system has a maximum flow rate of $757 \mathrm{~L} / \mathrm{min}(200 \mathrm{gal} / \mathrm{min})$ and is clarifier limited. The system can process 265 million L/yr (70 million gal/yr). Approximately $80 \%$ of the strontium- 90 and $20 \%$ of the cesium-137 are removed from the incoming process waste feed stream by this process.

- Recycle/reuse. Water emerging from the PWTP is sent to the nonradiological wastewater treatment plant. Water emerging from the nonradiological wastewater treatment plant is eventually discharged to White Oak Creek.

\subsubsection{Advantages, Disadvantages, and Problems}

Limitations to the PWTP at the Oak Ridge Reservation were not available.

\subsubsection{Contacts}

Susan Michaud, Waste Management Waste Reduction Coordinator

Oak Ridge National Laboratory

Building 1054B, MS-6404

Oak Ridge, TN 37831

(423) 576-1562 Telephone

(423) $576-1050 \quad$ Fax

\subsubsection{Liquid Treatment at the Winfrith Technology Center}

\subsubsection{Chemical Processing of Organic-Containing Wastes}

The treatment of organic-containing radioactive waste by using a chemical processing system based on hydrogen peroxide (Wetox process) has been developed at the Winfrith Technology Center. Hydrogen peroxide, heated to $100^{\circ} \mathrm{C}$ and at atmospheric pressure, is added to the waste in the presence of a catalyst that decomposes the organic components. Both $\mathrm{CO}_{2}$ and water are given 
off, and an inorganic residue is formed. The residue can be cemented directly or dried and put into drums for disposal. Off-gases from the process pass through an off-gas scrubber and HEPA filter before discharge.

A mobile unit able to process $100 \mathrm{~kg}$ of ion-exchange resin per day will fit into one ISO container. A $1 \mathrm{t} / \mathrm{d}$ unit would require two ISO containers. These units work on either a batch process or a semicontinuous process.

A toxic waste unit could handle phenols, dyes, and pesticides and operate in a continuous processing mode. This unit can be attached up front to a sewer plant and can process up to $100 \mathrm{~m}^{3} / \mathrm{d}$ of toxic wastes that contain $1-5 \%$ organics.

Required Conditions and Characteristics of Waste. The unit can be used to decontaminate liquids and slurries, including ion-exchange resins, but cannot be used for solids, such as shredded plastics, rubber gloves, etc. The existing mobile plant is designed for material with activity up to $1 \mathrm{TBq} / \mathrm{m}^{3}$.

Administrative and Training Requirements. The mobile plant has been approved for active operation according to the requirements of the U.K. Nuclear Installation Inspectorate. Although the process is virtually all remote operation, some specific operation training is required.

Results.

- Costs. The initial cost for a unit that can process $100 \mathrm{~kg}$ of ion-exchange resin. per day is about $\$ 560,000$. Operational costs for this unit total $\$ 1,600-\$ 2,400$ per day plus the cost of the hydrogen peroxide.

- Volume reduction ratio and rates. The volume reduction factor for anion resin is $10: 1$. The volume reduction factor for cation resin is $8: 1$. Units are available to process $100 \mathrm{~kg}$ resin per day and $1 \mathrm{t}$ of resin per day.

- Recycle/reuse. Hydrogen peroxide is consumed in the process and is not recycled.

Advantages, Disadvantages, and Problems. Advantages of this system include the low operating temperatures and pressures, and the cost-effectiveness of the process. Disadvantages include the limitations on what type of organics can be treated. 


\subsubsection{Cross-Flow Filtration}

The Winfrith Technology Center has developed a cross-flow filtration system. This system uses 5- $\mu \mathrm{m}$ Pall Filters, Model No. CC23252. These are sintered metal powder filters and are effective for dewatering up to $50 \%$ solids depending on the materials being processed. The existing mobile unit consists of a 1.9- $\times 1.9-\times 1.9-\mathrm{m}$ filtration unit and a control console. It has a throughput of $200 \mathrm{~L} / \mathrm{h}(50 \mathrm{gal} / \mathrm{h})$ depending on the properties of the process liquids. AEA Technology produces other mobile cross-flow units with throughputs up to $3 \mathrm{~m}^{3} / \mathrm{h}(800 \mathrm{gal} / \mathrm{h})$.

Required Conditions and Characteristics of Waste. Prescreening of particles greater than $2 \mathrm{~mm}$ in diameter is required. For removal and soluble activity, small amounts of finely divided solid absorber can be added. This process is referred to as seeded cross-flow filtration.

Administrative and Training Requirements. No specialized training is required.

Results.

- Costs. The existing plant $(200 \mathrm{~L} / \mathrm{h})$ costs approximately $\$ 150,000$.

- Volume reduction ratio and rates. Sludges dewater up to $50 \%$ by weight. Volume reduction up to $5 \times 10^{3}$ can be achieved.

- Recycle/reuse. The filters are periodically back washed. A filter life of greater than $1 \mathrm{yr}$ is anticipated. Liquids can be discharged to a local water treatment plant.

Advantages, Disadvantages, and Problems. Advantages include flexible operation over a wide range of solid concentration, no waste filters, and high concentrations of recovered solids (high volume reduction).

\subsubsection{Contacts}

Tim Boorman

AEA O'Donnell

241 Curry Hollow Road

Pittsburgh, PA 15236-4696

(412) 655-1200 Telephone

(412) 655-2928 Fax 


\section{DISPOSABLES}

Decontamination and decommissioning activities generate disposable waste in the form of protective clothing, wipe cloths, miscellaneous paper products, and other items. Disposable waste is usually generated during decontamination or routine activities and not from the waste generated from the facility operation. The overall volume of disposable radioactive waste can be high, as many of these items can be used only once before they must be disposed of and replaced. However, simple administrative and effective housekeeping procedures can significantly reduce the volume of disposable items used, resulting in significant waste minimization and cost savings. These procedures are easy to implement, have minimal cost associated with them, are extremely effective, and should be designed and implemented before decontamination procedures are begun. Further information on administrative and housekeeping procedures is provided in Section 6.2.

Volume reduction techniques applicable to disposable radioactive waste include compaction, shredding, and incineration. Compaction, like supercompaction, involves compressing the total occupied space into a smaller volume, allowing the disposal of greater quantities of material in waste containers. Shredding allows increased packing efficiency by decreasing the void space within waste containers. This technique is accomplished by grating the material into small strips or sections. Incineration pertains to consuming the disposable waste, leaving only residual ash that can be compacted further. This section gives examples of the implementation of these three techniques.

\subsection{COMPACTION}

The mechanical compaction of waste is straightforward and based on hydraulic press technology. Conventional in-drum compactors can compact paper, cloth, glass, floor sweepings, and other dry LLW into steel drums or boxes, including 208-L (55-gal) drums. The hydraulic system operates in relatively low pressures of up to $11 \mathrm{MPa}(1,600 \mathrm{psi})$. The waste drum is placed on a support plate and positioned under the rim. Loose waste is placed in the drum. The ram plate, which connects to the main piston within the main cylinder, applies force to the package and compacts the loose waste in the drum. The piston then retracts and loose waste is added to the drum. The operator repeats this process until the drum is filled. Approximately $13,488 \mathrm{~N}(60,000 \mathrm{lb})$ of force is applied to the waste by using a $18-\mathrm{cm}$ (7-in.) compacting positioner.

An in-drum compactor design may incorporate an extension space above the drum to allow for loading of more material. In one design, the extension space adds $66 \mathrm{~cm}(26 \mathrm{in}$.) to the top of the drum. A built-in fan evacuates this space to prevent dust and contamination from escaping into the room and operates when the compactor operates. The fan draws the air through a series of filters, including HEPA filters. Used filters can automatically be dropped into the drum for compaction and disposal. A movable, locking, hinged worktable clamps the drum in place, thereby sealing the drum 
extension space. Loose waste is then loaded in the drum and drum extension space. The exterior space door is closed and waste compacted. Recycle and reuse applications are generally not applicable to compaction methods.

\subsubsection{Consolidated Baling Machine Company}

The Consolidated Baling Machine Company manufactures a series of compactors (see Figure 9 for an example) designed primarily to process wastes into 208-L (55-gal) drums and corrugated boxes. Compactors used for 208-L (55-gal) drums contain a two-column, open-side, downstroke hydraulic press with a frame and drum support. Bore cylinders range from 10 to $15 \mathrm{~cm}$ (4-6 in.), with a 89- to 97-cm (35 to 38-in.) stroke. The hydraulic pump motors range from 3.7 to $11 \mathrm{~kW}$ (5 to $15 \mathrm{hp}$ ). The pump motors require three-phase, $60-\mathrm{Hz}$, $440-\mathrm{V}$ electric output. Compression force ranges from 172 to $414 \mathrm{MPa}(25,000$ to $60,000 \mathrm{psi}$ ), with a corresponding compression pressure on the material ranging from 455 to $1,454 \mathrm{kPa}$ maximum (66 to $211 \mathrm{psi}$ ). Cycle time varies from $26 \mathrm{~s}$ for the smaller units to $41 \mathrm{~s}$ for the larger units. The air exhaust system consists of a hood, prefilter, absolute filter, impact tube and pressure gauge, and an exhaust fan. The exhaust fan has a 1/4-kW (1/3-hp) motor.

The compactors used for the corrugated boxes have $11.2-\mathrm{kW}$ (15-hp) motors that run at 1,800 revolutions per minute (rpm). The fan motor ranges from $2.2 \mathrm{~kW}(3 \mathrm{hp})$ at $3,450 \mathrm{rpm}$ (capacity of $1,190 \mathrm{ft}^{3} / \mathrm{min}$ ) to $4 \mathrm{~kW}$ (5 hp) at $1,800 \mathrm{rpm}\left(2,600 \mathrm{ft}^{3} / \mathrm{min}\right)$. Total compaction force ranges from 23 to $45 \mathrm{t}$ (25 to 50 ton), with operating pressures from 12.2 to $13.8 \mathrm{MPa}(1,770$ to $2,000 \mathrm{psi})$. The compression cycle is $37 \mathrm{~s}$ for the smaller unit and $29 \mathrm{~s}$ for the larger unit.

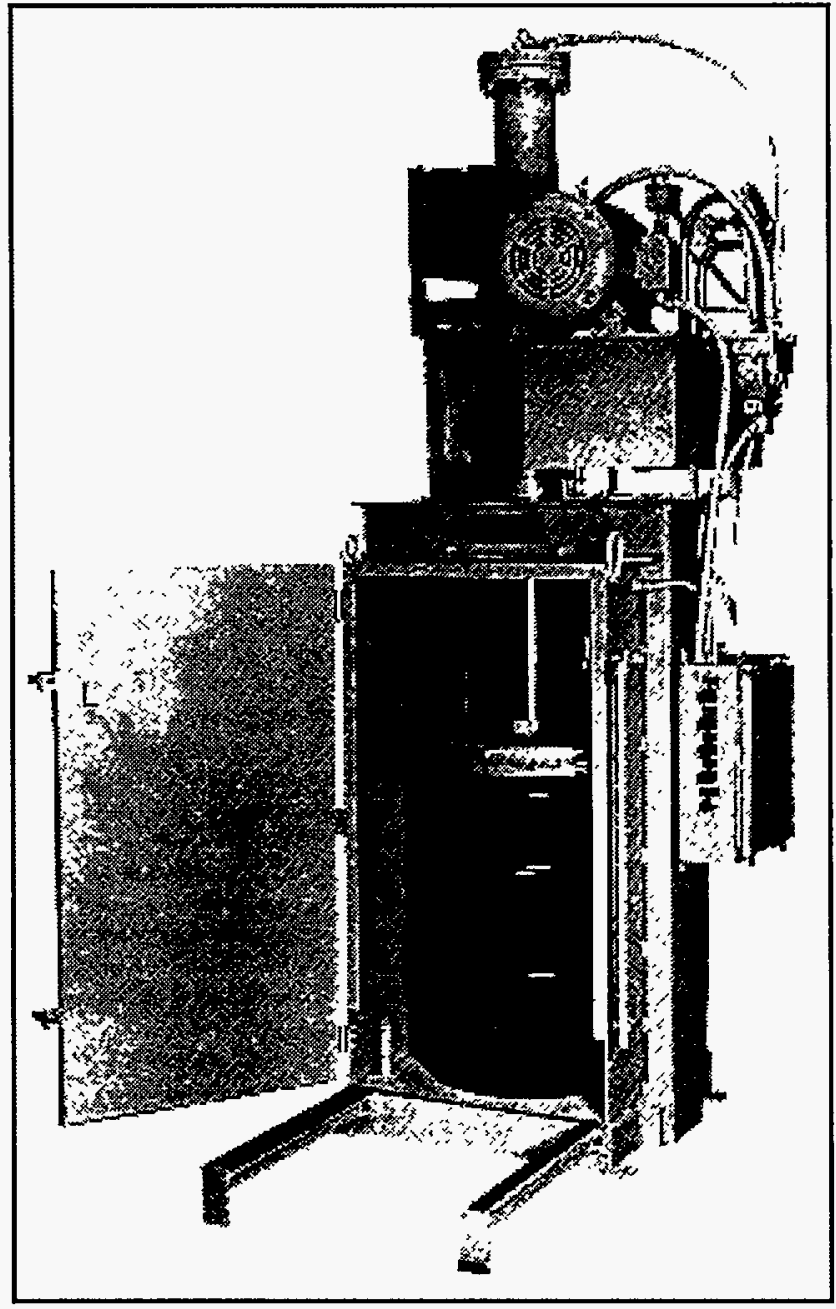

FIGURE 9 Consolidated Baling Machine Company Model DOS-RAW-W1 (used with permission) 


\subsubsection{Required Conditions and Characteristics of Waste}

Compactors are designed to process all compactible material up to specified limits for each unit. Bench tests should be performed before purchase.

\subsubsection{Administrative and Training Requirements}

All personnel using the Consolidated Baling Machine Company compactor must be trained in applicable administrative and safety requirements.

\subsubsection{Results}

- Costs. The cost of Consolidated Baling Machine Company compactors ranges from approximately $\$ 17,000$ to $\$ 85,000$, depending on the total compression force and overall power of the unit. Additional charges will be incurred for drum clamps and drum press collars. Costs are reduced if units are ordered without a drum support plate, front extensions, or a ventilation system.

- Volume reduction ratio and rates. The drum loading mechanism is manually operated. Drum throughput will vary according to operator ability. Normal throughput is one drum every $30 \mathrm{~s}-2 \mathrm{~min}$. The volume reduction ratio depends on the material placed in the drum and springback factors. Normal volume reduction is approximately 5:1 to $9: 1$.

- Recycle/reuse. Recycle and reuse applications generally do not apply to compacted waste.

\subsubsection{Advantages, Disadvantages, and Problems}

The Consolidated Baling Machine Company does not have appreciable limitations when applied to compactible waste. The material placed in the compactor must be able to fit into the waste drum. Large items and metallic items do not compact well. 


\subsubsection{Contacts}

Glenn Hoberg, General Sales Manager

Consolidated Baling Machine Company

P.O. Box 6922

Jacksonville, FL 32236

(800) 231-9286 or (904) 358-3812

Telephone

(904) 358-7013

Fax

\subsubsection{Compacting Equipment from Stock Equipment Company}

\subsubsection{55-Gallon Drum Dry Active Waste Hydraulic Compactor}

The Stock dry waste hydraulic compactor (Figure 10) handles disposable materials typically generated at nuclear facilities. Operators can vary the compaction force from 9 to $27 \mathrm{t}$ (10 to 30 ton) for specialized compacting requirements. The hydraulic system operates at the relatively low pressure of $10.8 \mathrm{MPa}(1,560 \mathrm{psi})$. The compacting piston is $18 \mathrm{~cm}$ (7 in.) in diameter, for a total compacting force of $27 \mathrm{t}$ (30 ton). A piston rod $12.7 \mathrm{~cm}(5 \mathrm{in}$.) in diameter and a 33-cm (13-in.) stop tube prevent damage to the cylinder and ram components under eccentric loads. The compactor frame is designed to withstand stall-out loads, both on-center and eccentric. The handling system is capable of withstanding the maximum compacting force plus $27,211 \mathrm{~kg}(60,000 \mathrm{lb})$.

The loaded drum rests on a contoured plate that supports the drum bottom during compaction. This plate can be extended outside the main body of the compactor by a small hydraulic cylinder in the base to ease hoist or lift truck pickup. The unit can compact up to $152 \mathrm{~cm}$

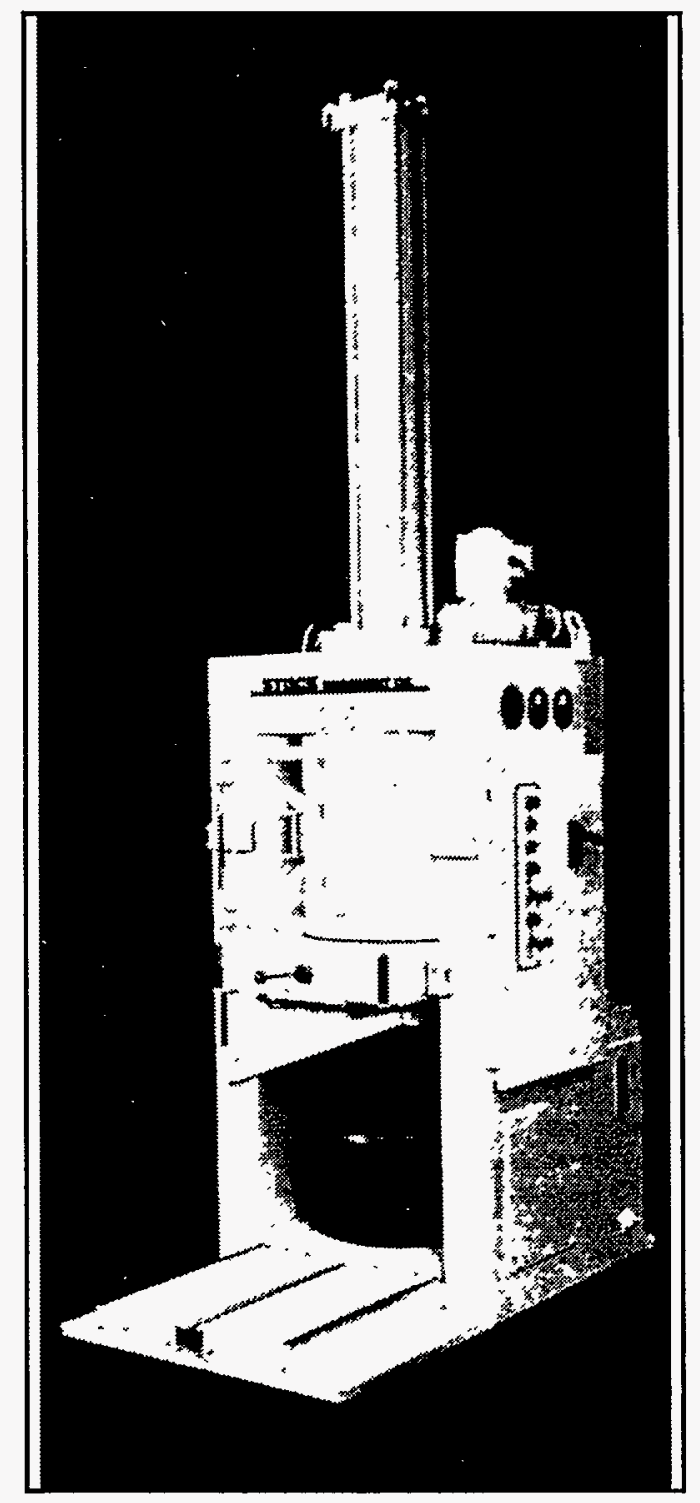

FIGURE 10 Dry Waste Hydraulic Compactor (courtesy of Stock Equipment Company) 
(60 in.) vertical of waste. The net compression stroke is $119 \mathrm{~cm}$ (47 in.). The unit has a built-in fan to prevent airborne contaminants from escaping during compaction. The fan draws air through a roughing filter followed by HEPA filters. Used filters are dropped into the compactor drum without being touched by hand.

Antispringback devices are used in the compactor. One method is compacting a steel disk with a slightly larger diameter than the drum. When the force is removed, the disk locks into place. The use of threaded rods or metal locking strips inserted into the drum also serve as antispringback devices. The average weight of a drum after compaction is $183 \mathrm{~kg}(404 \mathrm{lb})$, with some more than $227 \mathrm{~kg}(500 \mathrm{lb})$. The maximum compression stroke at no load was $10.2 \mathrm{~cm}$ (4 in.) per second, and the minimum compression stroke at full load was $2.54 \mathrm{~cm}$ (1 in.) per second.

These compactors have been installed in DOE laboratories and commercial power plants and are fully implemented.

Required Conditions and Characteristics of Waste. The compactors are designed to compact paper, cloth, glass, floor sweepings, and other low-level dry waste into standard 55-gal drums or 52-gal soda ash or fiber drums.

Administrative and Training Requirements. All personnel using the 55-gallon drum dry active waste hydraulic compactor must be trained in applicable administrative and safety requirements.

\section{Results.}

- Costs. The Stock 55-Gallon Drum Dry Active Waste Hydraulic Compactor costs approximately $\$ 80,000$, including delivery and one day field service.

- Volume reduction ratio and rates. Throughput capacity, volume reduction ratios, and rates concerning the 55-gal drum dry active waste hydraulic compactor were not available.

- Recycle/reuse. Recycle and reuse applications generally do not apply to compacted waste. 
Advantages, Disadvantages, and Problems. Stock uses a 12.7-cm (5-in.) piston rod, which is less likely to break at 27-t (30-ton) compacting force than are the smaller rods used by other manufacturers. The material placed in the compactor must be able to fit into the waste drum. Large items and metallic items do not compact well.

\subsubsection{Shredder/Box Compactor}

The Stock shredder/box compactor primarily processes wastes into box containers of various sizes. A forklift places the waste box container into the compacting chamber. The chamber doors and the containment door are closed. The compacting chamber accepts, with adjustments, various sized box containers. The upper loading chamber is then lowered into position. This chamber significantly enhances total waste loading by permitting the box container to be filled beyond the box height before compaction. A wheeled cart transports the dry activated waste to the shredder/box compactor. The LLW is shredded and evenly distributed within the box container. When the waste compaction level is reached, as indicated on the control console, the shredding cycle is stopped, and the box is positioned for ram compaction. The box is repositioned to achieve a uniform compaction height. This operation is observed through the use of a closed-circuit television camera installed in the containment unit. The operator can continue to add waste or install an antispringback device.

The Stock shredder/box compactor has a 15.2-MPa (2,200-psi) hydraulic system pressure applied to a 36-cm (14-in.) bore hydraulic cylinder, resulting in an overall force of $2.2 \mathrm{MPa}$ (314 psi) at the plate face. Nonshreddable objects can be manually loaded into the box, bypassing the shredders. Antispringback devices are loaded onto support tracks and released into the box guide at appropriate operational sequences (usually at $1 / 3$ and $2 / 3$ of total box height).

These compactors have been installed in DOE laboratories and commercial power plants and are fully implemented.

Required Conditions and Characteristics of Waste. The compactors are designed to compact paper, cloth, glass, floor sweepings, and other dry LLW into waste box containers.

Administrative and Training Requirements. All personnel using the shredder/box compactor must be trained in applicable administrative and safety requirements. 


\section{Results.}

- Costs. The Stock shredder/box compactor costs between $\$ 700,000$ and $\$ 800,000$, depending on the shredding requirements. Shredders are customerspecific and are based on an evaluation of the waste type.

- Volume reduction ratio and rates. Throughput capacity, volume reduction ratios, and rates concerning the shredder/box compactor were not available.

- Recycle/reuse. Recycle and reuse applications generally do not apply to compacted waste.

Advantages, Disadvantages, and Problems. The Stock shredder/box compactor does not have any appreciable limitations when applied to compactible waste. The material placed in the shredder/compactor must be shreddable and compactible and must be able to fit into the waste box container. Large items and metallic items do not shred or compact well.

\subsubsection{Contacts}

William S. Phillips, Nuclear Projects Sales Manager

Stock Equipment Company

16490 Chillicothe Road

Chagrin Falls, OH 44022-4398

(216) 543-6000 Telephone

(216) 543-6678 Fax

\subsubsection{CGR Compacting, Inc.}

CGR compactors (see example in Figure 11) are designed to compact dry LLW into suitable waste containers, such as the $2.54-\mathrm{m}^{3}\left(90-\mathrm{ft}^{3}\right) \mathrm{B}-25$ box or a similar container. CGR compactors are rated at 226-t (500,000-lb) compaction force, which results in $1.4 \mathrm{MPa}$ (200 psi) at the platen face on a compactor designed for a $2.54-\mathrm{m}^{3}\left(90-\mathrm{ft}^{3}\right)$ container, or $2.8 \mathrm{MPa}$ (400 psi) for a 1.4- $\mathrm{m}^{3}\left(50-\mathrm{ft}^{3}\right)$ container. The compaction force is uniform over the entire platen face, and the compactor cylinders work on the pull stroke. Typically, the compactor is batch loaded and requires two operators. The container removal system consists of four lifters that raise the container $7.62 \mathrm{~cm}$ ( 3 in.), making it possible to insert and remove the forklift. During compaction, the lifters retract into the floor, which means the floor is available to support the container base and punctures are eliminated. 


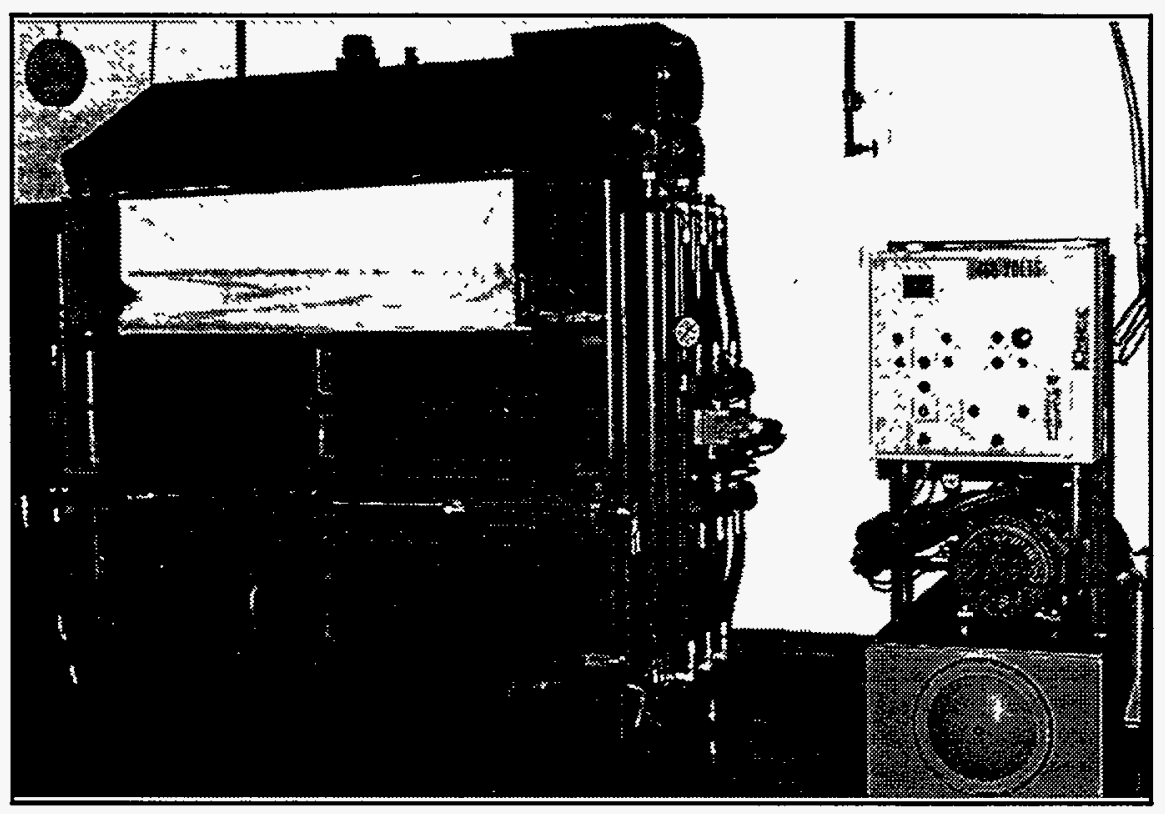

FIGURE 11 CGR 6-50-400 Compactor (courtesy of CGR Compacting, Inc.)

The containers are supported by hydraulically controlled walls and doors during compaction, which eliminates distortion. The hydraulic system includes a 454-L (120-gal) reservoir with cleanout covers, filter breather assembly, oil site-temperature gauge, temperature switch, lowlevel switch, drain plug, and suction strainer. The air filter system contains a $28.32 \mathrm{~m}^{3} / \mathrm{min}$ $\left(1,000 \mathrm{ft}^{3} / \mathrm{min}\right)$ fan assembly and HEPA filters.

As the waste is compacted, air is drawn into the compaction chamber, which is located at the edge of the ram. Negative pressure is created inside the box. The evacuated air is drawn through a HEPA filter and released to the ambient atmosphere. An optional "fully enclosed" compaction chamber is available. Compactor operations are controlled from a remote control panel.

\subsubsection{Required Conditions and Characteristics of Waste}

The compactors process compactible material into the $2.54-\mathrm{m}^{3}\left(90-\mathrm{ft}^{3}\right)$ waste containers. Materials include paper, plastic, wood, sheet metal, drums and other incidental contaminated objects.

\subsubsection{Administrative and Training Requirements}

The waste must meet the radiological criteria for the specific type of waste container (Low Specific Activity, Type A waste, etc.). 


\subsubsection{Results}

- Costs. Costs associated with the operation of the CGR compactor include the price of the waste container (about \$600) and HEPA filters (about \$200). Current prices for three models are:

$\begin{array}{ll}\text { Model No. } & \frac{\text { Cost }(\$)}{275,000} \\ 6-50-400 & 285,000 \\ 6-90-200 & 295,000\end{array}$

- Volume reduction ratio and rates. Compaction densities range from $641-801 \mathrm{~kg} / \mathrm{m}^{3}\left(40-50 \mathrm{lb} / \mathrm{ft}^{3}\right)$, for waste consisting predominately of paper and plastic, to $961-1,121 \mathrm{~kg} / \mathrm{m}^{3}\left(60-70 \mathrm{lb} / \mathrm{ft}^{3}\right)$ for waste, including primarily compactible metallic waste. Volume reduction ratios depend on the initial loose density of the material. For a loose density of $128 \mathrm{~kg} / \mathrm{m}^{3}\left(8 \mathrm{lb} / \mathrm{ft}^{3}\right)$, the volume-reduction ratio is $6-7: 1$. A $2.54-\mathrm{m}^{3}\left(90-\mathrm{ft}^{3}\right)$ waste container can be filled in $2-4 \mathrm{~h}$.

- Recycle/reuse. Recycle and reuse applications generally do not apply to compacted waste.

\subsubsection{Advantages, Disadvantages, and Problems}

Some models have been installed in-line with shredders that help to increase compaction densities. CGR designs waste containers to complement the compactors that require less burial space while incorporating a higher payload. These come in 1.42-, 2.54-, and 2.83- $\mathrm{m}^{3}(50-, 90-$, and $100-\mathrm{ft}^{3}$ ) sizes. Type A containers and IP-2 containers are also available.

\subsubsection{Contacts}

Bill R. Lyons, President

CGR Compacting, Inc.

7 Roberts Drive

North Adams, MA 01247

(413) 664-1076 Telephone

(413) 664-1079 Fax 


\subsection{SHREDDING}

Shredding refers to the sectioning of material (shredding) to minimize the void spaces in disposal containers. A typical shredder consists of counter-rotating shafts with numerous cutter wheels separated by spacers. The counter-rotating shafts draw material through the shredder generally at speeds $<60 \mathrm{rpm}$. The low shaft speed maximizes cutting force by using minimal energy. The shafts do not rotate at the same speed. The differential shaft speeds continually clear the sides of the cutter wheels from the loaded material. Because cutting takes place on the entire circumference of all wheels, the differential shaft speeds also ensure even cutting-edge wear on each wheel. The tooth of one wheel passes a different point on the opposite wheel during each pass until the rpm-cycle ratio repeats. This action distributes the wear and heat evenly on the cutter wheel edges. The cutting shafts automatically reverse normal rotation when unshreddable material is encountered in the waste. The shafts automatically reverse again to normal rotation and resume shredding. The reversing action sometimes positions the material differently, allowing the cutter's teeth to grab and eventually shred it; otherwise, the unshreddable material must be removed from the shredder.

The shaft and cutter wheels precisely align to ensure the cutter wheels intermesh, which allows shredding of the feedstock. Cutter wheels are removable for replacement or rearrangement. Narrow cutter wheels (close spacing) and/or adding additional teeth (hooks or knives) on each cutter wheel will produce smaller particles. Electrically or hydraulically driven units are available. Control panels provide automatic control of the shredding process and may require special operator training. Although the shredder may need to be located in a contaminated area, the shredder shafts, hydraulic hoses, and control panel can be located in a clean area. Shredders can also be adapted for use in underwater applications.

General shredder limits vary on the basis of cutter width, waste configuration, and the way that waste hits the cutter teeth (i.e., vertically/horizontally or perpendicular/parallel to the cutter shaft). In general, the heaviest materials that can be shredded are $0.64-\mathrm{cm}(0.25$-in.) plate steel, 3.2-cm (1.25-in.) rebar, 3.2-cm (1.25-in.) steel cable, and 10.2-cm (4-in.) Schedule 40 pipe. The largest shredders can accept a 1.27-m (50-in.) container. Multistage units can shred material to a particle size of $1.3-2.54 \mathrm{~cm}(0.5-1$ in.).

Pipes and bars can drop through the shredder if aligned vertically to the cutter teeth. Single drums can be aligned parallel to the cutter shafts and may not be caught by the cutters. Unless the drum is realigned, it will lay in the valley until the cutters wear through the side wall (estimated to occur in 3-10 $\mathrm{min}$ ). Wood lying flat on the cutters does not shred until it is repositioned or something heavy presses on it. A hydraulic tamper can force feed drums, wood, and waste material through the shredder. Shredded material cannot be decontaminated. However, further volume reduction is possible when used with a compactor. Darnell and Aldrich (1983) provide an overview of how 
commercially manufactured shredders performed with feedstock most likely to be generated at decommissioning sites.

\subsubsection{SSI Shredding Systems, Inc.}

SSI Shredding Systems, Inc., designs shredders to meet specific waste reduction needs (Figure 12). SSI manufactures high-torque, low-speed, rotary-shear-type shredders in both electric and hydraulic drive configurations. In-feed openings are up to $2.54 \mathrm{~m}$ (100 in.) long $\times 1.32 \mathrm{~m}$ (52 in.) wide. Counter-rotating drives with steel alloy shafts include load-sensing auto reverse. Electric drive configurations feature patented Severe Shock Protection torque couplings, which reduce the likelihood of shaft damage when encountering unshreddables in the system. Material is meter fed or batch fed into the shredder hopper. Optional patented Ram Assist pushes stubborn or oversize materials into the cutters for faster throughput. Electric systems range from $3.75-\mathrm{kW}$ (5-hp) single direct/in-line to $300-\mathrm{kW}(400-\mathrm{hp})$ dual direct/in-line drives. Hydraulic systems range from $75-\mathrm{kW}$ (100-hp) single direct/couple to $375-\mathrm{kW}$ (500-hp) dual direct/couple drives. Shredded material is discharged from the bottom of the system.

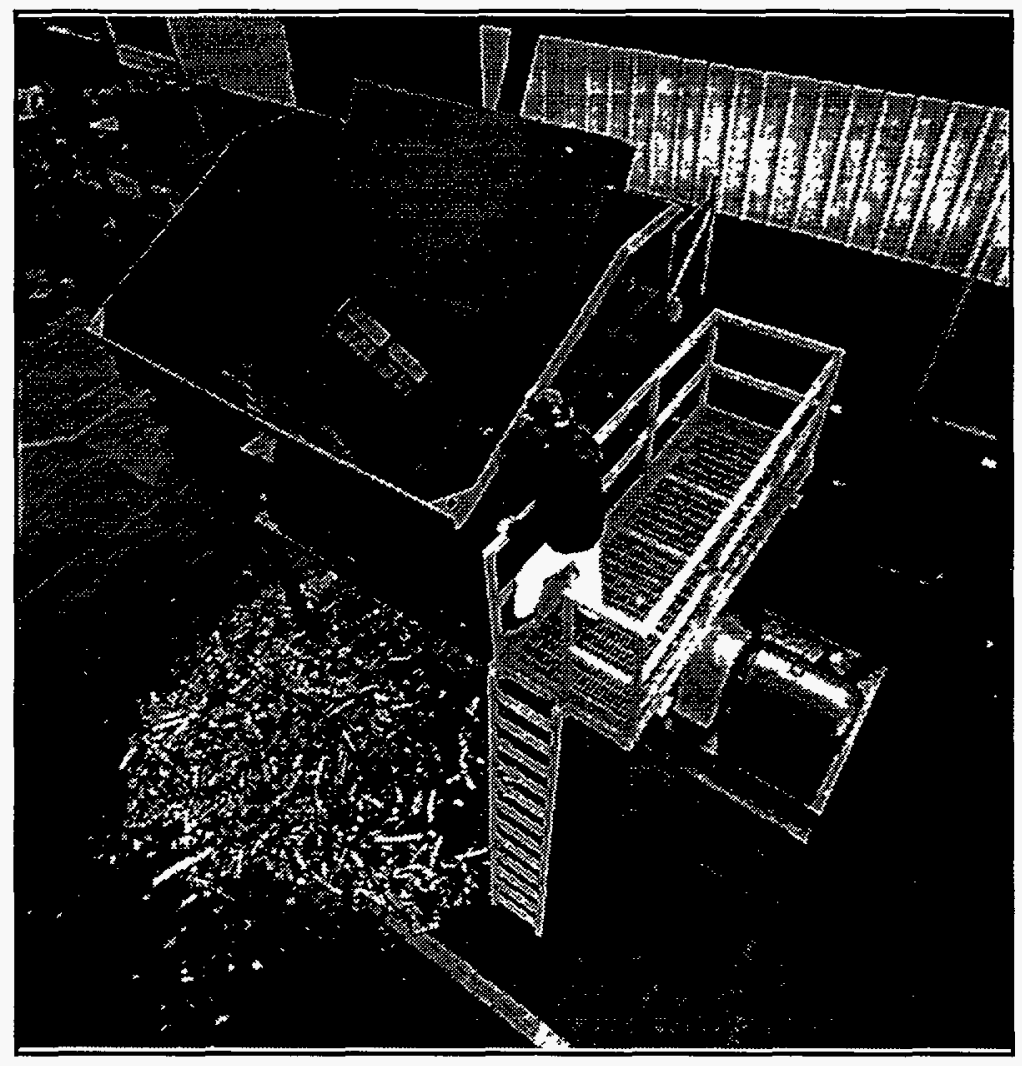

FIGURE 12 Shredder Made by SSI Shredding Systems, Inc. (used with permission) 


\subsubsection{Required Conditions and Characteristics of Waste}

These shredders can be designed to accept most disposable, metal, and solid wastes.

\subsubsection{Administrative and Training Requirements}

All personnel using SSI equipment must be trained in applicable administrative and safety requirements.

\subsubsection{Results}

- Costs. The cost of shredding equipment varies according to customer needs. Processing requirements, such as waste material, desired throughput, and particle size, are considered in the cost.

- Volume reduction ratio and rates. The throughput capacities are provided by SSI as estimates in Table 11.

TABLE 11 Throughput Capacities from SSI

\begin{tabular}{lll}
\hline & \multicolumn{2}{c}{ Capacity } \\
\cline { 2 - 3 } \multicolumn{1}{c}{ Item } & \multicolumn{1}{c}{$\mathrm{kg} / \mathrm{h}$} & \multicolumn{1}{c}{$\mathrm{lb} / \mathrm{h}$} \\
\hline & & \\
Aluminum scrap & $227-10,884$ & $500-24,000$ \\
Paper/cardboard & $340-12,6798$ & $750-28,000$ \\
Copper wire/ACSR & $227-10,884$ & $500-24,000$ \\
Pharmaceuticals & $454-6,803$ & $1,000-15,000$ \\
Plastic & $181-7,256$ & $400-16,000$ \\
Ferrous, light gauge & $1,134-13,605$ & $2,500-30,000$ \\
Solid waste & $680-45,400$ & $1,500-100,000$ \\
Foam rubber & $272-5,442$ & $600-12,000$ \\
Tires & $2,270-9,977$ & $5,000-22,000$ \\
In-plant waste & $680-27,211$ & $1,500-60,000$ \\
Wood & $340-10,884$ & $750-24,000$ \\
Pallets & $340-10,884$ & $750-24,000$ \\
55-gal drums ${ }^{\mathrm{a}}$ & $2-100$ & \\
\hline
\end{tabular}

a Measured in drums per hour. 
- Recycle/reuse. Hazardous/nuclear waste recycle and reuse applications were not identified by SSI and generally do not apply to shredded waste.

\subsubsection{Advantages, Disadvantages, and Problems}

High-torque, low-speed shredder technology provides such advantages as low dust and low noise over higher-speed shredders. SSI shredders do not have any appreciable limitations when applied to shreddable waste.

\subsubsection{Contacts}

Joyce Beasley, Technical Sales, Hazardous Waste

SSI Shredding Systems, Inc.

9760 SW Freeman Drive

Wilsonville, OR 97070-9286

(503) 682-3633 Telephone

(503) 682-1704 Fax

\subsection{INCINERATION}

Incineration of disposables is a high-temperature treatment designed to destroy waste. The incinerator design requirements depend primarily on the type of feedstock to be incinerated (i.e., solids require more combustion volume than liquids). To ensure a $99.99 \%$ or greater destruction removal efficiency, all combustion systems are designed to burn the waste for a minimum of $2 \mathrm{~s}$. Excess air is also an important combustion parameter, and requirements vary with feedstock characteristics. Excess air is the quantity of air, greater than the stoichiometric air requirements, present in the combustion chamber. The minimum excess air for solid feedstock is $50 \%$.

Incinerators defined for solid disposables usually contain a rotary kiln. Rotary kilns are capable of consistently removing organic constituents from solid particles $>2.54 \mathrm{~cm}$ ( $1 \mathrm{in}$.) in diameter. However, further treatment may be required if hazardous inorganic materials are present.

\subsubsection{Incineration at Kernforschungszentrum Karlsruhe}

Solid waste at $\mathrm{KfK}$ is separated into alpha waste and beta-gamma waste. Each type of waste has a separate incinerator. The two incinerators were developed by NuKem with HDB (Hauptabteilung Dekontaminationsbetriebe) modifications. In all incineration processes, the 
radioactive materials bound to the burnable waste are almost completely retained in the ash and filters. These residues are placed in sheet metal drums and treated as nonburnable waste, which is further compacted to reduce the overall volume.

Burnable solid residues to be disposed of as radioactive waste are collected in foil bags or cardboard drums in the controlled areas of $\mathrm{KfK}$ and carried to the incinerator shaft in tightly closed metal drums. The solid waste incinerators contain a cylindrical shaft, refractory brick-lined furnace, and afterburning chamber. The furnace is fed manually through a lock. Downstream from the afterburning chamber, a flue-gas purification system is installed. It consists of the ceramic hot gas filter for dust separation, a two-stage scrubbing system, HEPA filters, and a filter for dioxin adsorption. By means of a sliding vane rotary compressor, the off-gas is passed to a stack.

\subsubsection{Required Conditions and Characteristics of Waste}

The solid LLW consists of paper, wood, plastic, and carcasses separated into alpha and beta-gamma waste. Wastes with an alpha activity of up to $5 \times 10^{10} \mathrm{~Bq} / \mathrm{m}^{3}$ and a beta activity of up to $5 \times 10^{12} \mathrm{~Bq} / \mathrm{m}^{3}$ can be processed without limitations. Figure 13 presents a breakdown of a representative sample of waste.

\subsubsection{Administrative and Training Requirements}

All personnel using the $\mathrm{KfK}$ incinerators must be trained in applicable administrative and safety requirements.

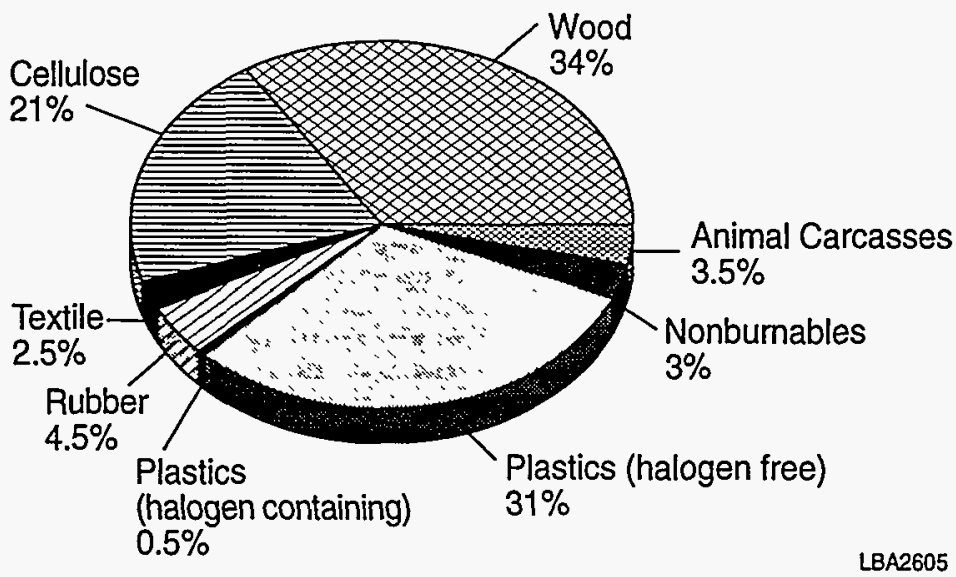

FIGURE 13 Mean Waste Composition (LBA2605-E) 


\subsubsection{Results}

- Costs. The initial cost of the alpha solid waste incinerator was $\$ 5,313,000$ in 1989. The initial cost of the beta-gamma incinerator was $\$ 4,375,000$ in 1971 . Surveillance and maintenance of the two solid waste incinerators are combined with a third, liquid waste/solvents incinerator. The total cost for surveillance and maintenance of all three incinerators is $\$ 625,000 / \mathrm{yr}$. The building cost $\$ 25$ million.

- Volume reduction ratio and rates. The throughput of the alpha incinerator is $60 \mathrm{~kg} / \mathrm{h}$. The throughput of the beta-gamma incinerator is $50 \mathrm{~kg} / \mathrm{h}$. Each incinerator has a decontamination factor of $10^{5}$ and a volume reduction factor of 100:1.

- Recycle/reuse. Recycle and reuse applications generally do not apply to incinerated waste.

\subsubsection{Advantages, Disadvantages, and Problems}

The KfK incinerators do not have any appreciable limitations when applied to compactible waste.

\subsubsection{Contacts}

Friedrich Dirks, Department Manager

Kernforschungszentrum Karlsruhe $\mathrm{GmbH}$

Postfach 3640

D-76021 Karlsruhe, Germany

$497247822220 \quad$ Telephone

$497247824272 \quad$ Fax

\subsubsection{Incineration at the Dounreay Nuclear Facility}

The incinerator at the Dounreay Nuclear Facility was installed in the late 1950s. The sole source of fuel is the combustible material placed in the incinerator within a glovebox at the top of a chute leading to the combustion chamber. The material falls into the combustion chamber and is incinerated. The system has a water scrubber, venturi scrubber, and HEPA filter system. The residual waste includes ash, filter media, and liquids. The ash cannot be compacted. 


\subsubsection{Required Conditions and Characteristics of Waste}

Incinerable solid LLW consists of cardboard, paper, gloves, and disposable clothing. Waste containing PVCs cannot be burned.

\subsubsection{Administrative and Training Requirements}

All personnel involved in the use of the Dounreay Nuclear Facility must be trained in applicable administrative and safety requirements.

\subsubsection{Results}

- Costs. Costs were not available.

- Volume reduction ratio and rates. The volume reduction ratio is $80: 1$.

- Recycle/reuse. Recycle and reuse applications generally do not apply to incinerated waste.

\subsubsection{Advantages, Disadvantages, and Problems}

The Dounreay incinerator should not burn waste containing PVC because it leads to corrosion problems.

\subsubsection{Contacts}

Dr. Doug Graham, Radwaste Operations

U.K. Atomic Energy Authority

Dounreay, Thurso, Caithness

KW14 7TZ United Kingdom

44847802121 , Ext. 2811 Telephone

44847802900

Fax 


\subsubsection{Incineration at Scientific Ecology Group - Solid Waste}

The incinerator at SEG was manufactured by Envikraft Incinerator, Type EK 980 NC, Paurhold Engineering Company (Denmark). Low-level waste sent to SEG is first sorted according to material to be incinerated, compacted, or decontaminated. Waste is then transported by conveyor belt to bomb-bay doors, which lead to the incineration chamber. The incineration chamber is initially propane fed, with the waste sustaining the continued burn in an oxygen-starved atmosphere at approximately $1,054^{\circ} \mathrm{C}$. Burn time lasts $8-10 \mathrm{~h}$. Two auger screws turning in a forward/backward manner ensure the waste is thoroughly burned. Residual ash ("hearth ash") is collected and returned to the generator. The residual hearth ash weighs $181-227 \mathrm{~kg}(400-500 \mathrm{lb})$. Any remaining waste is processed and sent for disposal. The SEG waste is processed and sent to Barnwell for disposal. The incinerator is cleaned between customers to reduce the possibility of cross-contamination. SEG intends to install a second incinerator to double the total output.

A separate evaporator concentrates and solidifies disposable solids suspended in the liquid effluent from the boiler and the scrubber. The resultant cleansed water is recycled back to the scrubber, which minimizes liquid effluents from the incineration process.

\subsubsection{Required Conditions and Characteristics of Waste}

Incinerable solid waste is classified as bulk, nonbulk, and animal/biological waste. Bulk material is defined as materials received in bulk containers (i.e., B-25 boxes, sea/land containers). Table 12 gives the radiological limits for bulk water. Nonbulk materials are materials received in nonbulk containers (small cardboard/fiber boxes or drums). These small-volume shipments contain only incinerable wastes that do not require routine sorting. Animal/biological waste pertains to animal carcasses, by-products, fluids, tissues, cultures, and similar materials. Table 13 gives the radiological limits for nonbulk waste, and Table 14 the limits for animal/biological waste. Table 15 lists materials acceptable for incineration in any combination (applies to both bulk and nonbulk dry solid waste).

Other materials may be deemed acceptable for incineration with prior SEG approval. Table 16 shows materials that are not acceptable for incineration.

Biohazard pretreatment is waste that contains pathogenic or infectious material. It is treated (i.e., autoclaved) to reduce the potential hazard associated with handling these materials before being shipped to SEG. 
TABLE 12 Radiological Limits for Bulk Dry Active Waste

\section{Radiation Levels}
Radiation level per package
Radiation level on waste
$\leq 2 \mathrm{mSv} / \mathrm{h}$ contact $(1 \mathrm{~cm})$
$\leq 4 \mathrm{mSv} / \mathrm{h}$ contact $(1 \mathrm{~cm})$

Radionuclide Limits $^{\mathrm{a}}$
Radionuclide
Total of all nuclides with $>5$-yr half-life
Total of all nuclides with $<5$-yr half-life
Hydrogen-3
Carbon-14
Iodine-129
Strontium-90
Radium-226
TRU
Other special nuclear material ${ }^{\mathrm{b}}$

$$
\begin{array}{r}
\text { Average Concentration } \\
\leq 0.26 \mathrm{kBq} / \mathrm{cm}^{3} \\
\leq 32.6 \mathrm{kBq} / \mathrm{cm}^{3} \\
\leq 0.026 \mathrm{kBq} / \mathrm{cm}^{3} \\
\leq 0.013 \mathrm{kBq} / \mathrm{cm}^{3} \\
\leq 6.5 \times 10^{-5} \mathrm{kBq} / \mathrm{cm}^{3} \\
\leq 1.3 \times 10^{-3} \mathrm{kBq} / \mathrm{cm}^{3} \\
\text { Prior approval required } \\
\leq 3.7 \mathrm{~Bq} / \mathrm{g} \\
\text { Prior approval required }
\end{array}
$$

a The average radionuclide concentration shall not exceed the above group or individual limits when averaged over the entire waste volume of the package or shipment.

b Includes uranium-233, uranium-235, or uranium enriched in the isotope uranium-233 or uranium-235.

\subsubsection{Administrative and Training Requirements}

Waste generators must follow the requirements outlined in SEG (1995).

\subsubsection{Results}

- Costs. The average cost for DOE customers (Oak Ridge Complex) is $\$ 4.63 / \mathrm{kg}(\$ 2.10 / \mathrm{lb})$.

- Volume reduction ratio and rates. Volume reduction ratios are approximately 150:1 after the incineration process. Hearth ash can be further compressed by an additional factor of 2, giving an overall volume reduction factor of 300:1. Throughput is approximately $454 \mathrm{~kg} / \mathrm{h}(1,000 \mathrm{lb} / \mathrm{h})$ or $11,338-13,605 \mathrm{~kg} / \mathrm{d}$ $(25,000-30,000 \mathrm{lb} / \mathrm{d})$. 
- Recycle/reuse. Recycle and reuse applications generally do not apply to incinerated waste.

\subsubsection{Advantages, Disadvantages, and Problems}

The SEG incinerators do not have any appreciable limitations when applied to incinerable waste.

\subsubsection{Contacts}

Richard P. Williams, Product Line Sales

Scientific Ecology Group

1560 Bear Creek Road

P.O. Box 2530

Oak Ridge, TN 37831

(423) 376-8076 Telephone

(423) $376-8484 \quad$ Fax

TABLE 13 Radiological Limits for Nonbulk Dry Active Waste

\begin{tabular}{|c|c|}
\hline \multicolumn{2}{|c|}{ Radiation Levels } \\
\hline Radiation level per package & $\leq 2 \mathrm{mSv} / \mathrm{h}$ contact $(1 \mathrm{~cm})$ \\
\hline \multicolumn{2}{|c|}{ Radionuclide Limits ${ }^{\mathrm{a}}$} \\
\hline Radionuclide & Average Concentration \\
\hline Total of all nuclides with $>5-\mathrm{yr}$ half-life & $\leq 0.26 \mathrm{kBq} / \mathrm{cm}^{3}(1.6 \mathrm{MBq} / \mathrm{kg})$ \\
\hline Total of all nuclides with $<5$-yr half-life & $\leq 32.6 \mathrm{kBq} / \mathrm{cm}^{3}(42 \mathrm{MBq} / \mathrm{kg})$ \\
\hline Hydrogen-3 & $\leq 0.026 \mathrm{kBq} / \mathrm{cm}^{3}(33.6 \mathrm{MBq} / \mathrm{kg})$ \\
\hline Carbo & $\leq 0.013 \mathrm{kBq} / \mathrm{cm}^{3}(16.8 \mathrm{MBq} / \mathrm{kg})$ \\
\hline Iodine- 129 & $\leq 6.5 \times 10^{-5} \mathrm{kBq} / \mathrm{cm}^{3}\left(8.4 \times 10^{-2} \mathrm{MBq} / \mathrm{kg}\right)$ \\
\hline Strontium-90 & $\leq 1.3 \times 10^{-3} \mathrm{kBq} / \mathrm{cm}^{3}(1.6 \mathrm{MBq} / \mathrm{kg})$ \\
\hline Radium-226 & Prior approval required \\
\hline TRU & $\leq 3.7 \mathrm{Bg} / \mathrm{g}$ \\
\hline Other special nuclear material ${ }^{\mathrm{b}}$ & Prior approval required \\
\hline
\end{tabular}

a The average radionuclide concentration shall not exceed the following group or individual limits when averaged over the entire waste volume of the package or shipment.

b Includes uranium-233, uranium-235, or uranium enriched in the isotope uranium-233 or uranium-235. 
TABLE 14 Radiological Limits for Animal/Biological Waste

Radiation Levels

Radiation level per package ${ }^{b}$

$\leq 2 \mathrm{mSv} / \mathrm{h}$ contact $(1 \mathrm{~cm})$

\section{Radionuclide Limits ${ }^{\mathrm{a}}$}

Radionuclide

Total of all nuclides with $>5$-yr half-life

Total of all nuclides with

$<5$-yr half-life

Hydrogen-3

Carbon-14

Iodine-129

Strontium-90

Radium-226

TRU

Other special nuclear material $^{\mathrm{b}}$
Average Concentration

Total of all nuclides with $\leq 0.26 \mathrm{kBq} / \mathrm{cm}^{3}(244 \mathrm{kBq} / \mathrm{kg})$

$\leq 32.6 \mathrm{kBq} / \mathrm{cm}^{3}\left(6.7 \times 10^{3} \mathrm{MBq} / \mathrm{kg}\right)$ $\leq 1.3 \mathrm{kBq} / \mathrm{cm}^{3}(336 \mathrm{MBq} / \mathrm{kg})$ $\leq 0.65 \mathrm{kBq} / \mathrm{cm}^{3}(168 \mathrm{MBq} / \mathrm{kg})$ $\leq 6.5 \times 10^{-5} \mathrm{kBq} / \mathrm{cm}^{3}\left(1.6 \times 10^{-2} \mathrm{MBq} / \mathrm{kg}\right)$ $\leq 1.3 \times 10^{-3} \mathrm{kBq} / \mathrm{cm}^{3}\left(3.4 \times 10^{-1} \mathrm{MBq} / \mathrm{kg}\right)$

Prior approval required $\leq 3.7 \mathrm{~Bq} / \mathrm{g}$

Prior approval required

a The average radionuclide concentration shall not exceed the following group or individual limits when averaged over the entire waste volume of the package or shipment.

b Includes uranium-233, uranium-235, or uranium enriched in the isotope uranium-233 or uranium-235.

TABLE 15 Materials Acceptable for Incineration

\begin{tabular}{ll} 
Animal carcasses/tissue $^{\mathrm{a}}$ & Polycarbonate \\
Bedding material (sawdust, & Polyester \\
cedar chips, corn cob) & Polyethylene \\
$100 \%$ cotton cloth & Polypropylene \\
$65 \%$ polyester $35 \%$ cotton cloth & Polystyrene \\
High-density polyethylene & Polyurethane \\
Latex & Natural rubber \\
Leather & Spun bonded polyolefin \\
Nitrile or nitrile rubber & Transparent thermoplastic \\
Nylon & Ultra-high molecular polyethylene \\
Paper & Urethane \\
& Wood \\
\hline
\end{tabular}

a Animal/biological waste designation only. 
TABLE 16 Materials Unacceptable for Incineration

\begin{tabular}{ll}
\hline Sharps & Asbestos \\
Metal & RCRA/TSCA hazardous wastes \\
Glass & Explosives \\
PVC & Pyrophorics \\
\hline
\end{tabular}

\subsubsection{Incineration at Los Alamos National Laboratory}

The incinerator at LANL is a modified Joy/Environmental Control Products (ECP 500T) dual-chamber, controlled-air incinerator. Initial combustion takes place in the primary combustion chamber at approximately $760-1,093^{\circ} \mathrm{C}\left(1,400-2,000^{\circ} \mathrm{F}\right)$. The incinerator accepts solids via a ram feeder mechanism and liquids via a liquid-injection mechanism. The burn chamber is capable of firing on natural gas, fuel oil, or liquid waste feed blends. Off-gases from the primary chamber enter the secondary chamber, which burns off any remaining volatiles at $1,982-2,182^{\circ} \mathrm{C}\left(2,000-2,200^{\circ} \mathrm{F}\right)$. The burner in the secondary chamber is fired on natural gas only. The off-gases from this chamber pass through an extensive air filter system that includes a water-spray quench column, scrubbers, primary and secondary HEPA units, and other air cleaning equipment. Waste from this process includes a scrub solution, which is treated at an industrial waste treatment facility, and the ash, which is discharged from the primary chamber of the incinerator through a gravity drop-out system into 208-L (55-gal) drums.

\subsubsection{Required Conditions and Characteristics of Waste}

The incinerator can process burnable TRU waste, LLW hazardous waste, and mixed waste. Solids include trash, packing material, rags, etc. Liquids include solvents and chemical reagents. The following definitions apply:

- TRU waste. Materials contaminated with long-lived radionuclides at levels $>3.7 \mathrm{kBq}(100 \mathrm{nCi})$ of alpha/gamma waste. TRU waste makes up approximately $10 \%$ of the radioactive waste generated at LANL.

- $L L W$. Materials that contain $<3.7 \mathrm{kBq}(100 \mathrm{nCi})$ of alpha/gamma waste and/or fission or activation products. 
- Hazardous waste. Materials that contain toxic or hazardous materials as defined by RCRA legislation, as well as chemicals that have hazardous characteristics, including corrosiveness or combustibility.

- Mixed waste. Materials contaminated with both hazardous (as defined by RCRA legislation) and radioactive materials.

\subsubsection{Administrative and Training Requirements}

All personnel using the LANL incinerator must be trained in applicable administrative and safety requirements.

\subsubsection{Results}

- Costs. Specific costs for process materials were not given. However, the initial and operating costs are offset by the savings in volume reduction and reduced disposal costs.

- Volume reduction ratio and rates. The incinerator can process approximately $86.16 \mathrm{~kg}(190 \mathrm{lb})$ of liquid per hour, with a volume reduction factor of 120:1. Also in $1 \mathrm{~h}$, the incinerator can process $56.7 \mathrm{~kg}(125 \mathrm{lb})$ of solid waste, with a volume reduction factor of 40:1. The overall volume reduction factor, including all side products (cradle to grave), is approximately 4:1 for solid mass, 20:1 for solid volume, 5:1 for liquid mass, and 3:1 for liquid volume. The incinerator was scheduled for batch processing by the end of 1993 .

- Recycle/reuse. Recycle and reuse applications generally do not apply to incinerated waste.

\subsubsection{Advantages, Disadvantages, and Problems}

The incinerator at LANL does not have any appreciable limitations when applied to incinerated waste. 


\subsubsection{Contacts}

Tony Drypolcher, Manager of Waste Management

Los Alamos National Laboratory

HSE-7

MS E517

Los Alamos, NM 87545

(505) 667-8293 Telephone

\subsubsection{Incineration at the Savannah River Site}

The SRS is currently building a John Zinc rotary kiln incinerator for disposal of solid and liquid LLW. This incinerator will be fuel-oil fired and operate at $5,275 \mathrm{~kW}$ (18 million Btu/h). The operating temperature of the primary chamber is $870^{\circ} \mathrm{C}\left(1,800^{\circ} \mathrm{F}\right)$, and the secondary chamber operates at $980^{\circ} \mathrm{C}\left(2,000^{\circ} \mathrm{F}\right)$. The incinerator was expected to begin trial burns in December 1995.

All solid waste is fed into the incinerator in 53-cm (21-in.) cardboard boxes. Each box is screened with a portal monitor, $x$-rayed for metals, and sent through a gamma spectroscopy system. Liquids are pumped directly into the incinerator from a local tank farm. Generators of waste must certify that their waste meets the incinerator acceptance criteria for both chemical and radiological components. The generator must identify all radiological isotopes and quantities of each isotope.

Waste products from the incinerator operation are filters, ash, and off-gas scrubber blowdown. Used filters are sent for compaction; the ash and scrubber blowdown are mixed with concrete and buried.

\subsubsection{Required Conditions and Characteristics of Waste}

The incinerator is designed to process hazardous and radioactive wastes in both liquid and solid form. The incinerator can accept only small amounts of metals and soil. The maximum dose rate of any box to be incinerated is $100 \mu \mathrm{Sv}(10 \mathrm{mrem}) / \mathrm{h}$.

\subsubsection{Administrative and Training Requirements}

All waste scheduled to be incinerated must meet SRS waste criteria. All personnel must be trained in appropriate waste minimization procedures. 


\subsubsection{Results}

- Costs. Total start-up cost for the incinerator, including construction and operational expenses, is $\$ 135$ million. The annual operating cost will be approximately $\$ 10$ million.

- Volume reduction ratio and rates. The volume reduction factor is expected to be 20:1, including the disposal of the waste products. Throughput capacity is $136 \mathrm{~kg}(300 \mathrm{lb}) / \mathrm{h}$ for liquids and $317 \mathrm{~kg}(700 \mathrm{lb}) / \mathrm{h}$ for solids. The system can handle approximately 45 box/h.

- Recycle/reuse. Recycle and reuse applications generally do not apply to incinerated waste.

\subsubsection{Advantages, Disadvantages, and Problems}

The incinerator at SRS does not have any appreciable limitations when applied to permitted waste.

\subsubsection{Contacts}

John P. Harley, Jr.

Savannah River Site

P.O. Box 616

Aiken, SC 29802

(803) 557-6332 Telephone

\subsubsection{Harper Electric Furnace Corporation Furnaces and Kilns}

Harper Electric Furnace Corporation provides furnaces and kilns with equipment configurations and related specifications designed to meet the needs of each individual customer. The normal temperature range in the incinerator's furnace and kiln is $149-2,200^{\circ} \mathrm{C}\left(300-3,992^{\circ} \mathrm{F}\right)$. Standard features included on the furnaces and kilns are as follows:

- An alloy or ceramic furnace tube;

- Single-fuel, dual-fuel, or electric heating; 
- A feed hopper designed to match the production rate;

- A vent assembly to handle volatiles;

- A variable-speed feeder, tube drive, and tube tilt designed to match the required process;

- Hardened ball-bearing trunions with a lubrication system;

- A power supply system with silicon-controlled rectifiers and shunt-trip circuit breakers;

- A temperature control package for single- or multizone regulation of temperature;

- An over-temperature alarm and shutdown; and

- Complete installation and start-up instructions plus a replacement part list.

Harper has incorporated designs for use in hot-cell, glovebox, and manipulator environments. Harper also has equipment for processing LLW and sophisticated pusher furnace equipment for sintering fuel pellets. These rotary calciners work on the principle of a sloped and rotating horizontal cylinder surrounded by a heating chamber. The cylinder's inner diameter is the material transport system. This design is energy-efficient because individual product carriers are not needed to convey the material through the furnace. This concept transfers all furnace heat directly into the product, rather than to the product and additional product carriers. The product feeds into the cylinder through a metering screw feeder. This entire concept is cost-effective - both in initial capital outlay and the operating cost.

A representative furnace used in treating radioactive material is shown in Figure 14. Harper furnaces and kilns are available with custom features to meet specific needs of the LLW generator. Oxidizing or special burn atmospheres are available. Harper equips their furnaces and kilns with standard dust-tight seals and can provide gas-tight seals, as needed. Harper can also furnish recuperators that reduce energy requirements on fuel-heated furnaces. The furnaces include either screw- or vibratory-type feeder mechanisms. Many additional features and options are available to maximize efficiency and throughput while minimizing cost and energy consumption. 


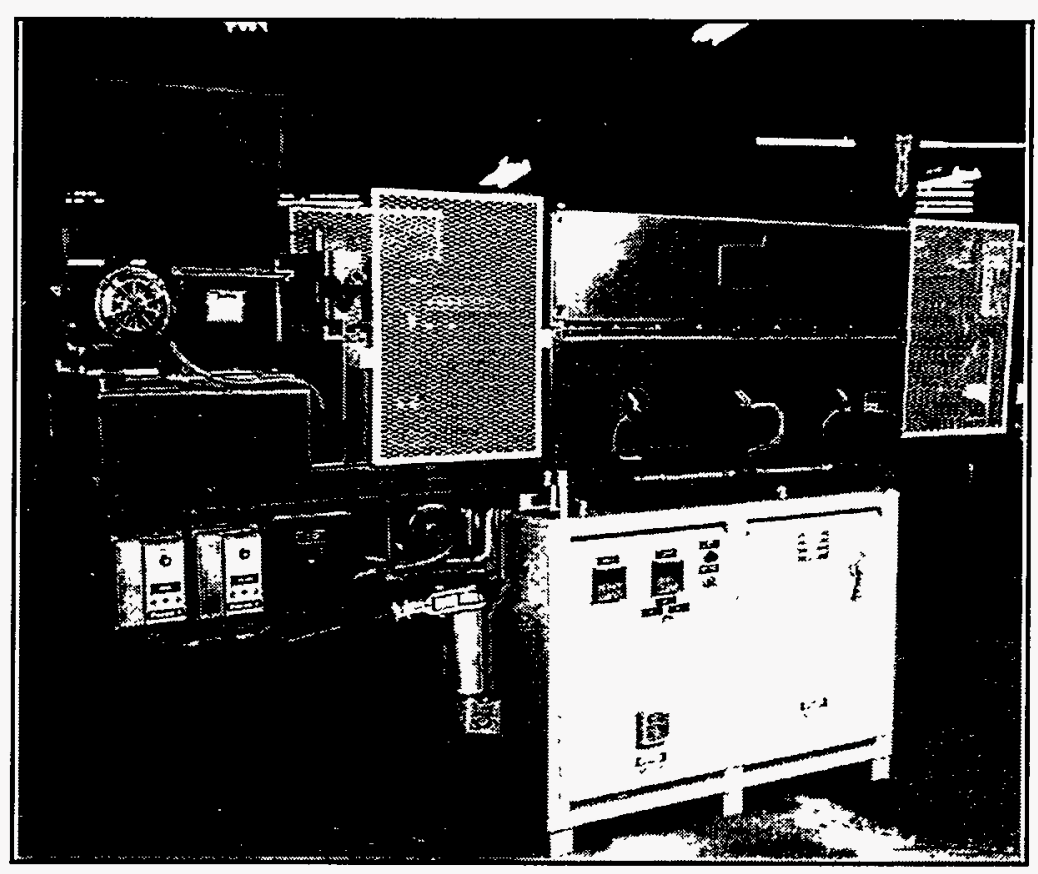

FIGURE 14 An Example of a Harper Furnace (courtesy of Harper Electric Furnace Corporation)

\subsubsection{Required Conditions and Characteristics of Waste}

Harper should be contacted to determine the optimum design features for the furnace according to the feedstock anticipated by the waste generator.

\subsubsection{Administrative and Training Requirements}

All personnel using Harper furnaces must be trained in applicable administrative and safety requirements.

\subsubsection{Results}

- Costs. The initial cost of the furnace and the required maintenance costs depend on the requirements designed to meet the needs of each individual customer. Costs are based on the required throughput capacity, the material to be incinerated, and the necessary residence (i.e., burn) time. 
- Volume reduction ratio and rates. Volume reduction rates depend on the desired feedstock and throughput.

- Recycle/reuse. Recycle and reuse applications generally do not apply to incinerated waste.

\subsubsection{Advantages, Disadvantages, and Problems}

Harper furnaces do not have appreciable limitations when applied to incinerated waste.

\subsubsection{Contacts}

Daniel J. Markiewicz, General Sales Manager

Harper Electric Furnace Corporation

West Drullard Avenue

Lancaster, NY 14086-1698

(716) 684-7400 Telephone

(716) 684-7405 Fax 


\section{OTHER WASTE MINIMIZATION PRACTICES}

The waste minimization practices discussed in this section do not pertain exclusively to waste streams identified earlier in this report. These examples include practices used to remove radioactive contaminants from TRU and mixed waste, including lead. Many of the entries also describe innovative new ways of minimizing waste by administrative practices or work procedures. Finally, technical advancements that involve different waste streams are described.

\subsection{LEAD DECONTAMINATION}

Many industrial complexes and national laboratories contacted during the preparation of this report expressed concern over lead decontamination and its release criteria. In the United States, lead is classified as a hazardous material under RCRA legislation, and lead contaminated with radiological material may be defined as mixed waste. No mixed waste disposal facilities currently operate in the United States, and all mixed waste must be stored on-site. Lead decontamination allows waste generators to release lead and minimize the amount of mixed waste that must be stored on-site. However, release criteria for decontaminated lead have not been established in the United States, and waste generators must continue to store decontaminated lead on-site. In the United Kingdom and elsewhere in Europe, radioactive material takes precedence over hazardous material, and contaminated lead is treated as radioactive waste.

The decontamination methods included in this section effectively removed surface contamination from lead bricks. Oak Ridge National Laboratory has "green-tag" release limits that allow decontaminated lead to be reused on-site.

\subsubsection{Lead Decontamination at the Scientific Ecology Group}

Lead is decontaminated at the SEG central volume reduction facility by means of various techniques and is released for reuse by the nuclear industry after surveying. SEG's primary decontamination technique is hydraulic jetting. Hydraulic jetting decontamination is performed in a large steel isolation compartment and features a $240-\mathrm{MPa}(35,000$-psi) hydrolaser capable of operating with or without abrasives.

The second SEG decontamination technique uses many water pressure washing and chemical cleaning steps. The pressure wash removes bulk grit and loose surface contamination before the alkaline and acidic chemical cleaning steps. The alkaline step is corrosive to the thin oxide layer on lead surfaces, whereas the acidic step dissolves the remaining loosened film. The water spray and chemical decontamination system features process tanks with circulation pumps, heaters, 
and a filtration system. The waste stream from the process solutions is ultimately concentrated to wet sludge.

The resultant waste is tested as a characteristic hazardous waste because of the presence of lead. SEG treats the waste by solidification within 90 days of accumulation in accordance with EPA and Tennessee regulations. The solidification process encapsulates the lead particles and subsequently removes the hazardous characteristic. Once the material is rendered nonhazardous, as determined by the TCLP test, the material is authorized for disposal at a commercial radioactive waste disposal site.

\subsubsection{Required Conditions and Characteristics of Waste}

Surface decontamination can be performed on a number of materials, including but not limited to stainless steel, carbon steel, iron, aluminum, copper, nickel, chromium, lead, concrete, and brass. Each material is evaluated on a case-by-case basis, involving material type, radiation and contamination levels, size, weight, geometry, etc. Specific radiological criteria are not available.

\subsubsection{Administrative and Training Requirements}

Waste generators must follow the requirements outlined in SEG (1995).

\subsubsection{Results}

- Costs. Costs for decontaminating lead at SEG were not available.

- Volume reduction ratio and rates. Specific volume reduction rates and ratios were not available. The lead is completely decontaminated for unrestricted use. The secondary waste stream consists primarily of grit and wet sludge and becomes the property of SEG.

- Recycle/reuse. The decontaminated lead is released for unrestricted use in full compliance with all applicable requirements of the State of Tennessee (an NRC agreement state) and other applicable rules and regulations.

\subsubsection{Advantages, Disadvantages, and Problems}

Limitations to the lead decontamination techniques used at SEG were not available. 


\subsubsection{Contacts}

Richard P. Williams, Product Line Sales

Scientific Ecology Group

1560 Bear Creek Road

P.O. Box 2530

Oak Ridge, TN 37831

(423) 376-8076 Telephone

(423) 376-8484 Fax

\subsubsection{Lead Decontamination Techniques at Oak Ridge National Laboratory}

Oak Ridge National Laboratory is developing technology for lead decontamination. The laboratory has tested decontamination of lead by using ice blasting and $\mathrm{CO}_{2}$ pellets. The ice blasting technique produced radioactively contaminated liquid water but no contaminated lead (total lead remaining in the wastewater was below RCRA levels). A HEPA unit was connected at the end unit to prevent the airborne release of contamination. Lead particles were detected in the roughing and HEPA filters. Lead was decontaminated to green-tag levels and stored on-site.

The $\mathrm{CO}_{2}$ pellet cleaning system involves a centrifuge-based cryogenic pellet accelerator. The cryogenic pellet is ejected at speeds $>450 \mathrm{~m} / \mathrm{s}$ with an acceleration efficiency of $65 \%$ (an $11-\mathrm{kW}$ [15-hp] electric motor can do the same job as a 110-kW [150-hp] compressed air system). The acceleration is a dry process, which eliminates potential oil contamination from the compressed air. The pellets impact with low velocity, causing a large impact pressure because the contact area is very small. The potential for a stationary radioactive decontamination device was investigated. Solid $\mathrm{CO}_{2}$ pellets were sent through a $22-\mathrm{kW}$ (30-hp) centrifuge accelerator with a throughput of $364 \mathrm{~kg} / \mathrm{h}$ $(800 \mathrm{lb} / \mathrm{h})$ at $414 \mathrm{~m} / \mathrm{s}(1,500 \mathrm{ft} / \mathrm{s})$. The target chamber was a glovebox/vacuum housing. The test was designed to determine (1) the feasibility of using the $\mathrm{CO}_{2}$ pellet system to remove oxide deposits from uranium castings and (2) its use in radium decontamination applications.

\subsubsection{Required Conditions and Characteristics of Waste}

The ice blast and $\mathrm{CO}_{2}$ tests were performed on surface-contaminated lead. Previous tests for the $\mathrm{CO}_{2}$ method included removing oxide deposits from uranium castings. Potential applications include cleaning uranium castings and aggressive cleaning and etching to remove surface coatings. Both the $\mathrm{CO}_{2}$ and the ice blast techniques apply only to surface contamination removal. 


\subsubsection{Administrative and Training Requirements}

All personnel using lead decontamination techniques at ORNL must be trained in applicable administrative and safety requirements.

\subsubsection{Results}

- Costs. As these tests were bench tests, costs were not specifically evaluated. However, the basic equipment cost is higher for the $\mathrm{CO}_{2}$ Cleanblast ${ }^{\mathrm{TM}}$ technique than for the Crystalline Ice Blast unit technique. This cost is in addition to the cost of compressed gas.

- Volume reduction ratio and rates. The two systems have essentially the same decontamination factors and application time. The surface contamination was removed to levels below release criteria. The decontamination factor would be directly related to the level of contamination removed and the history of the lead.

- Recycle/reuse. The decontaminated lead was green tagged for unrestricted reuse. The waste from both processes must be treated as radioactive and/or hazardous waste.

\subsubsection{Advantages, Disadvantages, and Problems}

The decontamination effectiveness of each system is similar, if not the same. The basic difference is the secondary waste generated. The main factor in determining the system operating cost is identifying the secondary waste and handling it on the basis of the decontamination method used. If liquid waste can be handled, the ice blast technique is less expensive. The amount of lead removed during the decontamination process (which entraps lead in the roughing and HEPA filters) is typically above the RCRA limits and must be disposed of as mixed waste. However, the liquid waste generated in the ORNL demonstration was not identified as a RCRA waste and was discharged to the liquid LLW system as a facility radioactive waste - a significant factor. The $\mathrm{CO}_{2}$ blasting technique was found to be better for manipulator parts and delicate instrumentation, especially for electric components. The decontamination effectiveness is similar, but one must evaluate the effects on the material to be cleaned and the secondary waste generated. 


\subsubsection{Contacts}

Susan Michaud, Waste Reduction Coordinator

Martin Marietta Energy Systems

Bldg. 1054B, MS-6404

Oak Ridge, TN 37831

(423) 576-1562 Telephone

(423) 576-0105 Fax

\subsection{ADMINISTRATIVE PHILOSOPHY}

Administrative philosophy is a loose term used to describe routine procedures or methods that reduce the generation of radioactive material. This section examines innovative approaches to waste management and disposal that reduce volume and save costs. These philosophies are nontechnical and incur minimal, if any, added expense. Many of the sites discussed in this section have a waste minimization plan incorporated into site manuals, including organizational/ responsibility structures and quality assurance controls. Waste minimization procedures are also incorporated into lesser order manuals, such as project work plans and job descriptions. These manuals pertain primarily to housekeeping procedures that minimize cross-contamination, reuse of contaminated materials, and use of other job- or facility-specific waste minimization practices. Administrative and housekeeping procedures should be implemented before D\&D activities are initiated. The following sections describe various administrative and housekeeping techniques used to minimize the generation of unnecessary waste.

\subsubsection{Pollution Prevention Waste Minimization Philosophy at Idaho National Engineering Laboratory}

Idaho National Engineering Laboratory has developed an awareness and training plan for pollution prevention (P2) waste minimization. The awareness program is composed of training, a newsletter, brochures, and community involvement. Currently, video tapes of the six training lessons are being developed, which should save time and money. INEL personnel are continuously exposed to P2 waste minimization. Each major program and facility has a waste minimization coordinator. A waste minimization plan has been written for each program or major activity. Work procedures are reviewed to ensure that waste minimization practices are included. Waste minimization is also part of the annual evaluation for managers. The following waste reduction activities are routinely used during decommissioning projects:

- Maximize separation of radioactive materials from clean materials through concrete scabbling and cutting/disassembly of equipment, 
- Reuse personal protective equipment when possible,

- Maximize the recycling of noncontaminated steel,

- Fill voids in waste boxes with contaminated soil,

- Use HEPA-filtered ventilation units and wetting agents to prevent the spread of contamination during decommissioning activities,

- Specify task sequences to remove contaminated items first to minimize the amount of cross-contamination,

- Scabble localized hot spots from the concrete floor so that most of the concrete can be disposed of as uncontaminated waste,

- Mechanically remove localized radioactive contamination on equipment, and

- Specify a nonhazardous decontamination solution to prevent the generation of a hazardous or mixed waste.

Also, checklists and quality assurance checks ensure waste minimization practices are performed during, and serve as the basis for, all decommissioning activities.

Pollution prevention opportunity assessments (PPOAs) are the first step in waste minimization. A PPOA is prepared for each major project or task to identify source reduction opportunities. A PPOA quantitatively identifies the input/output chemicals and the process steps that will be used. PPOAs also are used to evaluate any new or unique process steps that can minimize the waste generated. PPOAs attempt to reduce the waste generated in the previous year by such methods as solvent substitution.

The pollution prevention unit (PPU) produces a quarterly waste minimization report, reports on the progress of the waste minimization program, provides for technology transfer, and assists in implementing PPOAs. The PPU provides training on the PPOA process, helps to implement the PPOA system, and interfaces with the various groups involved with P2 waste minimization matters.

\subsubsection{Required Conditions and Characteristics of Waste}

The INEL P2 waste minimization philosophy applies to all generated waste types. 


\subsubsection{Administrative and Training Requirements}

All personnel involved in the generation and processing of waste at INEL must be trained in applicable P2 waste minimization procedures.

\subsubsection{Results}

- Costs. A cost analysis of the INEL waste minimization program was not available.

- Volume reduction ratio and rates. Although the waste minimization philosophy at INEL reduces the overall volume of generated waste, specific data were not available.

- Recycle/reuse. Recycle and reuse applications are incorporated into the INEL waste minimization philosophy where possible.

\subsubsection{Advantages, Disadvantages, and Problems}

The waste philosophy at INEL does not have any appreciable limitations.

\subsubsection{Contacts}

Christopher Ischay, Program Engineer

Idaho National Engineering Laboratory

P.O. Box 1625 , M/S 3950

Idaho Falls, ID $83415^{\circ}$

(208) 526-4382 Telephone

\subsubsection{Waste Minimization Philosophy at Westinghouse Hanford Company}

Each major facility at the Westinghouse Hanford Company (WHC) has its own waste minimization program. The programs include employee training and awareness, material life-cycle planning, preplanning, and process waste assessment. The process waste assessment looks at the input and output chemicals. Each individual facility program has a Pollution Prevention Council, ALARA Council, and an Accident Prevention Council. These three organizations work together to promote ALARA philosophy and minimize waste and accidents. Quality teams are set up to review 
the waste minimization effort. The first step is to prepare a process description matrix. The next step is to perform a value engineering and develop a criteria screening sheet. The third step is to prepare a process improvement plan checklist. A waste prevention logbook is developed, and engineering controls, such as separate tool cribs for clean and contaminated tools, are implemented.

Westinghouse Hanford Company is developing a concept known as "co-disposal." The co-disposal concept uses solidification agents (such as cements, polymers, or other materials) in conjunction with contaminated or hazardous wastes (such as soils, demolition rubble, well cuttings or other materials) to form a product called "wasterock." Wasterock can be used in several applications; the two major uses are stabilization of burial boxes that are in a state of imminent collapse or void fill in waste trenches. Currently, WHC is prequalifying two types of wastes to be used in wasterock; at the same time, they are procuring equipment to perform a full-scale demonstration of the co-disposal concept, using one or both of the prequalified wasterock formulations.

\subsubsection{Required Conditions and Characteristics of Waste}

At this time, WHC is only considering the use of co-disposal with LLW or hazardous wastes, but will pursue the use of TRU or high-level waste after the basic technology is proven. Wasterock can be tailor-made to fit the requirements of the storage areas and of the waste by using additives to the wasterock matrix.

\subsubsection{Administrative and Training Requirements}

Personnel will be trained on the equipment used to inject the wasterock matrix into burial boxes or to place the wasterock in waste trenches. When this technology is transferred from the technology development group to the end users, the latter will have to be trained in handling the wastes used, in operating the equipment necessary, and in following safety procedures specific to this type of operation.

\subsubsection{Results}

- Costs. Co-disposal technology saves costs because it uses void spaces in waste trenches and burial boxes. Savings are computed to be approximately $\$ 125$ million per waste trench. 
- Volume reduction ratio and rates. A significant reduction in volume can be achieved by using previously contaminated material for void fill, rather than by using the clean soil, which is current practice.

- Recycle/reuse. Materials previously considered waste can be recycled and reused.

\subsubsection{Advantages, Disadvantages, and Problems}

Benefits and advantages include subsidence control, which addresses personnel safety issues at the Hanford Site, and proactive land management, due to better use of waste loading in waste trenches and burial boxes. Cost savings, waste minimization, and reuse of materials are additional benefits. No disadvantages are associated with co-disposal technology. Co-disposal will not solve every problem with radioactive and hazardous waste at the Hanford Site, but it does address many of the concerns about final waste forms.

\subsubsection{Contacts}

Steven Phillips, Co-disposal Contact

Westinghouse Hanford Company

P.O. Box $1970 \mathrm{H} 4-14$

Richland, WA 99352

(509) 376-1720 Telephone

\subsubsection{Waste Minimization Philosophy at Pacific Northwest Laboratory}

Pacific Northwest Laboratory (PNL) uses scintillation cocktails for counting core samples and other radiochemistry efforts at the Hanford Site. Older cocktails contained xylene, toluene, methanol, and pseudocumene, all of which are regulated as hazardous wastes and are flammable, creating a fire hazard and limiting storage capabilities within the laboratories. Research staff were using the regulated scintillation cocktail in a liquid scintillation counter that used $20 \mathrm{~mL}$ vials per sample. The use of these cocktails generated radioactive mixed waste (RMW), which costs approximately $\$ 7,062 / \mathrm{m}^{3}\left(\$ 200 / \mathrm{ft}^{3}\right)$ to dispose of. The disposal of a 208-L (55-gal) lab-packed drum therefore costs approximately $\$ 1,500$.

Research staff at PNL investigated the use of 7-mL vials in place of the 20-mL vials and confirmed that (1) this change would not require a new scintillation counter (special carriers would be used) and (2) this switch would still produce statistically valid sample results. The result was a 
3:1 reduction. The staff then switched to Ultima Gold, a nonregulated scintillation cocktail, thus ceasing the generation of RMW. Finally, the staff researched and purchased a liquid scintillation counter that uses plates rather than the 7-mL vials. Each plate has 96 wells, and each well uses 0.2-mL cocktail. This second modification resulted in a 35:1 reduction (100:1 reduction total).

\subsubsection{Required Conditions and Characteristics of Waste}

The Required conditions and characteristics of waste are:

- Premicroscale: xylene/toluene based flammable scintillation cocktails; and

- Postmicroscale: nonregulated, nonflammable, nontoxic scintillation cocktails.

\subsubsection{Administrative and Training Requirements}

Research staff had to determine if the new scintillation cocktail and counter would give satisfactory statistical results compared to the previous cocktail/counter. Training in the use of the new cocktail/counter was minimal and was performed on the job.

\subsubsection{Results}

- Costs. The savings amounts to approximately $\$ 38,000 / \mathrm{yr}$ in disposal costs alone.

- Volume reduction ratio and rates. The total waste reduction from 20- to 0.2 -mL wells per sample is $100: 1$.

- Recycle/reuse. Recycle and reuse applications are incorporated into the PNL waste minimization philosophy where possible.

\subsubsection{Advantages, Disadvantages, and Problems}

The advantages of the PNL technique are (1) vastly decreased staff time spent on disposal paperwork/handling; (2) many more samples can be run during a single counting; (3) flammability hazards of cocktails have been removed by switching to a nonflammable cocktail; and (4) significantly fewer liquid wastes are handled, thus reducing the hazard of radionuclide contamination. 
The disadvantages of the PNL technique are the potential for statistically invalid sample results. Researchers interested in converting to microscale must investigate the sample protocol. A potential also exists that the new sampling/analysis method will be in conflict with established EPA guidelines.

\subsubsection{Contacts}

Kevin Selby, P2 Program Manager

Pacific Northwest Laboratory

P.O. Box 550

Richland, WA 99352

(509) 372-0307 Telephone

\subsubsection{Waste Minimization Philosophy at the Winfrith Technology Center}

The Winfrith Technology Center is the United Kingdom's center for technology development for decontamination. Researchers there have examined a wide range of decontamination techniques on various materials found during decommissioning activities. The waste minimization techniques used at Winfrith include decontamination (mechanical and electrochemical), size reduction, compaction, chemical processing, and cross-flow filtration.

Winfrith has developed administrative procedures effective for minimizing the generation of radioactive waste. An engineered transfer system has been developed to move material from one contaminated area to another. It is somewhat similar to the French La Calhene system, but it has been modified to include an air purge system (to prevent contamination of the seal) and to incorporate a twist ring. After 10 operations, the airborne contamination on the inner side of the system was $60 \mathrm{GBq}\left(10^{9} \mathrm{dpm}\right) / \mathrm{m}^{3}$, while the concentration on the clean side was $600 \mathrm{~Bq}$ $(10 \mathrm{dpm}) / \mathrm{m}^{3}$.

Winfrith also uses modular containment systems (ModuCon ${ }^{\mathrm{TM}}$ ) for plutonium glovebox size reduction. The systems consist of fiberglass panels bolted together with portable ventilation systems. Strippable paint (ALARA decontamination paint) is used inside after the joints have been taped. After use, the strippable paint is removed, leaving the unit free of contamination so that it can be dismantled for reuse elsewhere. Many paint layers can be applied on top of each other, which means that ModuCon greatly reduces waste volumes compared with conventional plastic tented enclosures. It is also much safer. Panels come in variable sizes and can contain windows, lightports, connections, etc. These items are lighter and less expensive than stainless steel models. However, they may not meet U.S. National Fire Protection Association requirements. 
Plastic suits are used when tents and containments are being reduced in size. Fifty entries are normally achieved per suit because disposable oversuits are worn, and personnel shower in the suit after leaving a contaminated area.

\subsubsection{Required Conditions and Characteristics of Waste}

The Winfrith waste minimization philosophy applies to all generated LLW.

\subsubsection{Administrative and Training Requirements}

All personnel involved in the generation and processing of LLW at Winfrith must be trained in applicable waste minimization procedures.

\subsubsection{Results}

- Costs. Costs are approximately $\$ 5,000$ /port for gloveboxes for the engineered transfer system.

- Volume reduction ratio and rates. Although the waste minimization philosophy at Winfrith reduces the overall volume of generated LLW, specific data were not available.

- Recycle/reuse. Recycle and reuse applications are incorporated into the Winfrith waste minimization philosophy where possible.

\subsubsection{Advantages, Disadvantages, and Problems}

The advantages of this engineered transfer system include a reduced amount of TRU waste, built-in safety without heat sealing plastic bags, a reduction in the process time, and the introduction of additional shielding. However, the system is more expensive than a conventional bagout system, and it is difficult to retrofit existing gloveboxes. 


\subsubsection{Contacts}

Tim Boorman

AEA O'Donnell

241 Curry Hollow Road

Pittsburgh, PA 15236-7696

(412) 655-1200 Telephone

(412) 655-2928 Fax

\subsubsection{Waste Minimization Philosophy at the Sellafield Nuclear Facility}

British Nuclear Fuels applies administrative procedures and working practices to ensure that a minimal amount of radioactive waste is generated. Some operations require an individual to wear a protective PVC suit and respirator or breaking air line. In these cases, the individual will pass through a modular construction shower. The shower removes loose contamination from the suit, thus allowing its reuse rather than disposing it as secondary waste. Water used in the shower is recycled after passing through the shower's filtration and ion-exchange system. Clothing, gloves, booties, packaging material, and other items are considered secondary waste. Any equipment or material is unpacked before it is delivered to a controlled area. The duration of entry times into contaminated areas has been increased to reduce the number entries required, thereby reducing the volume of secondary waste. The modernized site laundry is increasingly used to recycle more material, such as boots and shoes.

As part of a total quality management culture, seminars are held with maintenance and decontamination workers to discuss and ensure the implementation of waste minimization ideas.

Currently, HEPA filters with metal cases are used at the Sellafield Nuclear Facility. A schedule is being developed in which filters are changed before contamination levels reach the intermediate level or TRU waste. This technique reduces classification of waste by administrative controls and reduces the costs of disposal.

\subsubsection{Required Conditions and Characteristics of Waste}

The Sellafield waste minimization philosophy applies to all generated LLW. 


\subsubsection{Administrative and Training Requirements}

All personnel involved in the generation and processing of LLW at Sellafield must be trained in applicable waste minimization procedures.

\subsubsection{Results}

- Costs. A cost analysis of the Sellafield waste minimization program was not available.

- Volume reduction ratio and rates. Although the waste minimization philosophy at Sellafield reduces the overall volume of generated LLW, specific data were not available.

- Recycle/reuse. Recycle and reuse applications are incorporated into the Sellafield waste minimization philosophy where possible.

\subsubsection{Advantages, Disadvantages, and Problems}

The waste philosophy at Sellafield does not have any appreciable limitations.

\subsubsection{Contacts}

Richard Davage, Commercial Manager for Decommissioning

British Nuclear Fuels, plc

Risley, Warrington, Cheshire

United Kingdom, WA3 6AS

$01044925835397 \quad$ Telephone

$01044925822773 \quad$ Fax

\subsubsection{Waste Minimization Philosophy at Kernkraftwerke Gundremmingen Betriebsgesellschaft mbH}

The Gundremmingen site contains two operating commercial power plants and one small nuclear plant currently undergoing decommissioning. The waste minimization techniques being used by Gundremmingen include melting, sorting, electropolishing, mechanical decontamination, and evaporation. Sixty percent of the material removed during decommissioning is unconditionally 
released, $33 \%$ is recycled, and $7 \%$ is disposed of as radioactive waste. Free release limits were established for clean and recycled material before the initiation of D\&D operations.

Plastic tents are used for minor cutting of piping. Metal containments are used for plasma and oxy-acetylene torch cutting of large pieces of metal. Automatic band saws are used for cutting valves, piping, and I beams. Material is sorted by type of metal and general contamination levels. Everything greater than $10 \mathrm{~kg}$ is issued a unique identification number for tracking purposes. Contaminated metal generated during the Gundremmingen decommissioning project is given directly to Gesellschaft für Nuklear-Service (GNS). GNS then sends the contaminated metal to the Siempelkamp melting facility, which produces radioactive storage containers (Section 2.1.1). Recycling costs are on a per metric ton basis and are less costly if different types of metal are separated at the site and cut into drum lengths.

The Gundremmingen decommissioning project has initiated a waste minimization program for all workers. Workers are exposed to the philosophy, value, and importance of waste minimization, and basic waste minimization practices are reinforced. Coveralls, cloth gloves, and shoe covers are washed locally and reused.

\subsubsection{Required Conditions and Characteristics of Waste}

The Gundremmingen waste minimization philosophy applies to all generated LLW.

\subsubsection{Administrative and Training Requirements}

All personnel involved in the generation and processing of LLW at Gundremmingen must be trained in applicable waste minimization procedures.

\subsubsection{Results}

- Costs. A cost analysis of the Gundremmingen waste minimization program was not available.

- Volume reduction ratio and rates. Although the waste minimization philosophy at Gundremmingen reduces the overall volume of generated LLW, specific data were not available.

- Recycle/reuse. Recycle and reuse applications are incorporated into the Gundremmingen waste minimization philosophy where possible. 


\subsubsection{Advantages, Disadvantages, and Problems}

The waste philosophy at Gundremmingen does not have any appreciable limitations.

\subsubsection{Contacts}

Dr. Helmut Steiner, D\&D Manager

Kernkraftwerke Gundremmingen Betriebsgesellschaft mbH

Postfach 89355

Gundremmingen, Germany

498224783730

Telephone

498224782900

Fax

\subsubsection{Waste Minimization Philosophy at the Savannah River Site}

The SRS has developed an awareness and training program to minimize waste. SRS has a waste minimization policy, a program plan, and waste minimization procedures that describe general guidelines to follow during operating, decommissioning, and maintenance operations. Waste minimization is part of the general employee and annual update training. A waste minimization checklist is prepared as part of each job package. Waste Management also requires all waste coordinators and waste minimization personnel to complete a self-paced, computer-based training program. Articles concerning waste minimization are printed in the plant newspaper and environmental newsletters. SRS also prepares short programs and announcements for airing over television. Currently, a main emphasis for waste minimization is paper recycling.

One of the most important waste reduction projects currently ongoing in the reactor area is the separation of clean waste from contaminated waste. Many buildings within the reactor area have been used to store miscellaneous material. SRS has set up a staging area and is surveying large pieces of equipment. The large components are disassembled, and all clean material is released as scrap wherever possible. Contaminated material is separated into appropriate waste streams. Approximately $\$ 20$ million worth of equipment has been recycled back into the supply system. SRS is also developing a radioactively contaminated stainless steel recycle program. The purpose is to find additional uses for contaminated steel.

A major concern is the acceptance of risk. Currently, a policy of near-zero risk appears to be in effect relative to the unconditional release of potentially contaminated materials. It is the general feeling that some sort of risk analysis should be performed to determine what is acceptable and still meets all federal and state requirements. 
A sitewide chemical management program is being developed to dispose of excess chemicals and recycle usable chemicals. The program is based on the commodity management concept, with one group responsible for most chemical purchases. Laboratories at SRS are also finding ways to reduce sample frequencies and volumes required for analysis.

The central shops area has a cask decontamination area. This area is being reconfigured for use as an equipment decontamination area. It will use a vacuum-blast unit. Some disassembly will also take place there.

\subsubsection{Required Conditions and Characteristics of Waste}

The SRS waste minimization philosophy applies to all generated LLW.

\subsubsection{Administrative and Training Requirements}

All personnel involved in the generation and processing of radioactive and hazardous waste at SRS are trained in applicable waste minimization procedures.

\subsubsection{Results}

- Costs. A cost analysis of the SRS waste minimization program was not available.

- Volume reduction ratio and rates. Contact John Harley for data. (See Section 6.2.7.5.)

- Recycle/reuse. Recycle and reuse applications are incorporated into the SRS waste minimization program.

\subsubsection{Advantages, Disadvantages, and Problems}

The waste philosophy at SRS does not have any appreciable limitations. 


\subsubsection{Contacts}

John P. Harley, Jr.

Savannah River Site

P.O. Box 616

Aiken, SC 29802

(803) 557-6332 Telephone

\subsubsection{Waste Minimization Philosophy at Argonne National Laboratory-East}

It is the policy of Argonne National Laboratory (ANL) to incorporate the principles of source reduction, pollution prevention, waste minimization, and comprehensive life cycle management into the everyday conduct of laboratory operations. For example, research and development activities, including design, planning, and experimental activities, emphasize the principle of inception-to-grave management of all materials. ANL recognizes that part of its research mission is to develop and transfer effective pollution prevention and waste minimization technology to other DOE organizations and U.S. industry.

This philosophy is being implemented by reviewing waste streams, beginning with larger or more hazardous streams and implementing cost-effective changes. Many programs have incorporated pollution prevention changes as a way of doing business simply because they make sense and are cost-effective for the programs. Examples include the following:

- Adaptation of nonhazardous scintillation fluids,

- Adaptation of alternate cleaning solutions for accelerator components,

- Recycling of slightly activated metals,

- Refined packaging methods to reduce total package volume,

- Adaptation of training and awareness concepts, and

- Minimal inventory of materials and just-in-time procurement.

\subsubsection{Required Conditions and Characteristics of Waste}

The ANL waste minimization philosophy applies to all generated LLW. 


\subsubsection{Administrative and Training Requirements}

All personnel involved in the generation and processing of LLW at ANL must be trained in applicable waste minimization procedures.

\subsubsection{Results}

- Costs. Pollution Prevention has just begun an active program, and actual cost savings are currently unavailable. The use of alternate solvents can result in a one-time savings in excess of $\$ 600,000$ along with lesser future savings. The recycling project saved significant costs in the areas of materials, transportation, and disposal.

- Volume reduction ratio and rates. Volume reduction ratio and rates are not now being used because no tangible means is available for correlating specific actions to results on a broad scale.

- Recycle/reuse. Materials being recycled or reused are increasing, and additional effort is being focused on these activities to increase recycling activities.

\subsubsection{Advantages, Disadvantages, and Problems}

The ANL program focuses on two types of material users or waste generators. The first is the large-scale user, typically associated with the operation of the laboratory. Activities in this area are easily assessed, and cost-effective changes can be implemented relatively easily. The second focal area is programmatic research and development. This area becomes more difficult to assess because more than 1,000 researchers on-site often generate very small quantities of waste in a very diverse manner. Development of this program will be very slow because of the inherent complexity of the problem.

\subsubsection{Contacts}

James R. Thuot

Environmental Management Operations

Argonne National Laboratory, Bldg. 214

Argonne, IL 60439-4836

(708) 252-4911 Telephone

(708) 252-9642 Fax 


\subsection{INDEPENDENT STUDIES AND DEVELOPING TECHNOLOGIES}

The final section of the Waste Minimization Handbook is devoted to developing technologies and independent research. The first example highlights the Size Reduction Facility at LANL (see the entry on the plasma arc cutting system currently used at the facility in Section 2). This facility is used to minimize TRU generated at national laboratories. The second entry highlights the published results of an American Society of Mechanical Engineers' (ASME) study on the waste minimization and disposal practices at various nuclear power plants around the country. The last summary examines the developing technology of waste disposal via a molten metal bath. This technology is currently being developed by Molten Metal Technologies and applies to almost any type of waste, including hazardous, toxic, clean, and radioactive waste in almost any form.

\subsubsection{Transuranic Size Reducing Facility at Los Alamos National Laboratory}

Los Alamos National Laboratory has developed a Transuranic Waste SRF. The facility has an airlock area, disassembly area, cutting area, and packaging area. Waste containers are put in the airlock, and contaminated material is removed from the container and sorted. Large components are moved into the disassembly area and either mechanically disassembled or cut. The components are then packaged into disposal containers acceptable for WIPP disposal.

The facility is approximately $42 \mathrm{~m}^{2}$ with $4.75-\mathrm{mm}$ stainless-steel walls. The disassembly and cutting area contains a PAK-44 plasma torch, a PAR 3000 electromechanical manipulator, a hydraulic work table, and a 1,814-kg (2-ton) bridge crane. The PAR 3000 has a $68-\mathrm{kg}$ (150-lb) capacity. The hydraulic work table has a $2,722-\mathrm{kg}(6,000-\mathrm{lb})$ capacity and is capable of rotating $360^{\circ}$ both clockwise and counterclockwise and rising vertically from $0.6-1.8 \mathrm{~m}$ above the floor. The table can also move laterally in the east-west direction. A 4,536-kg (5-ton) gantry crane supports the entire facility. The facility ventilation system includes roughing filters, $90 \%$ prefilters, and $99.95 \%$ HEPA filters. The exhaust air filtration is monitored, and a breathing air system is installed. The vehicle airlock area and the unpacking area are each $33.5 \mathrm{~m}^{2}$.

Future plans for the TRU size reduction facility include wastewater filtering for lead removal, an increased gram loading to 200-g fissile equivalent (see below), special transportation capabilities with trucks, and the distribution of wastewater in the facility to the radioactive industrial waste line. 


\subsubsection{Required Conditions and Characteristics of Waste}

The following are the SRF nuclear limits:

Maximum Allowed Limit

- $150 \mathrm{~g}$ of plutonium-52 (weapons-grade plutonium)

- $10 \mathrm{~g}$ of plutonium-83 (heat source plutonium)

- $15 \mathrm{~g}$ of americium-241

Administrative Limit (2/3 of maximum)

- $100 \mathrm{~g}$ of plutonium-52 (weapons-grade plutonium)

- $6.6 \mathrm{~g}$ of plutonium-83 (heat source plutonium)

- $10 \mathrm{~g}$ of americium-241

Mixtures:

$$
\frac{\mathrm{g} \text { plutonium }-52}{100 \mathrm{~g}}+\frac{\mathrm{g} \text { plutonium }-83}{6.6 \mathrm{~g}}+\frac{\mathrm{g} \text { americium }-241}{10 \mathrm{~g}} \leq 1
$$

\subsubsection{Administrative and Training Requirements}

The following must be completed for all TRU waste:

- Waste profile request form,

- Radioactive solid waste disposal form,

- Visual inspection before packaging for shipment to a SRF,

- Document review by the TRU Certification Office, 
- TRU waste shipment coordination, and

- U.S. Department of Transportation transportation requirements (Hazardous Waste Transfer Form) MAT-2.

\subsubsection{Results}

- Costs. The costs per TRU load processed were not available.

- Volume reduction ratio and rates. The volume reduction is approximately 3.5:1.

- Recycle/reuse. The sectioned TRU waste is packaged for final disposition to a permanent TRU waste disposal facility.

\subsubsection{Advantages, Disadvantages, and Problems}

No limitations have been identified for the TRU facility at LANL.

\subsubsection{Contacts}

Tony Drypolcher, Manager of Waste Management

HSE-7, MS E517

Los Alamos, NM 87545

(505) 667-8293 Telephone

\subsubsection{ASME Radwaste Systems Transportation Packaging and Disposal Subcommittee Questionnaire: Power Plant Waste Minimization Techniques}

The ASME subcommittee on systems transportation packaging and disposal distributed a questionnaire to nuclear power utilities across the country concerning the treatment of LLW. This questionnaire requested information about the various waste streams generated at power plants, including current processing techniques for spent resins, dry active waste, mechanical filters, and used oil.

Respondents from 19 nuclear utilities contributed the information for this survey. The following sections discuss the results of this survey. 


\subsubsection{Waste Processing Centers}

Three of the four respondents who identified the use of an outside contractor for waste processing mentioned SEG. Quadrex and Chem Nuclear were mentioned twice. Table 17 lists the types of wastes the four respondents have processed by the contractors mentioned.

\subsubsection{DAW Processing}

Off-site processing was mentioned most often (95\%) by respondents when asked how they handle their DAW. Eighteen respondents identified off-site processing as a means to process DAW. Three respondents (16\%) identified on-site compaction, while no respondents identified on-site contractor process as a means to process DAW. One responding utility sorts clean RCA trash and frisks it for free release.

Of the three respondents who perform on-site compaction, two said they do so using boxes. The other respondent did not specify which container was used.

\subsubsection{Segregation for Decontamination or Release}

Respondents who said they segregate or decontaminate material for release were asked, "What type of monitoring equipment do you have and what are your release criteria?" Eleven of the

TABLE 17 Types of Wastes Processed by Contractor and Number of Survey Mentions

\begin{tabular}{lll}
\hline Contractor & \multicolumn{1}{c}{ Waste Processed } & $\begin{array}{c}\text { No. of } \\
\text { Mentions }\end{array}$ \\
\hline \multirow{3}{*}{ SEG } & Dry active waste (DAW) & 3 \\
& Metals & 2 \\
& Resins & 2 \\
& Charcoal & 1 \\
\multirow{3}{*}{ Quadrex } & Oil & 1 \\
& Asbestos & 1 \\
& DAW & 1 \\
\multirow{4}{*}{ Chem Nuclear } & Monitor/release & 1 \\
& ALPS & 1 \\
& Oil & 1 \\
\hline
\end{tabular}


19 respondents to the survey answered this question. Three of the respondents indicated that they send waste to an off-site vendor who selects the monitoring equipment to segregate their waste. Others use monitoring equipment, including a final agratic monitor, RM-14 and surface smears, a standard hand-held frisker, a standard frisking and bag monitor, and an NC waste sorting table. Seventeen respondents identified bulk-release limits per decommissioning order as the release criteria, while one identified release procedure criteria.

\subsubsection{Contaminated Oil Processing}

Eighteen respondents $(95 \%)$ have their contaminated oil incinerated off-site. Four respondents $(21 \%)$ solidify waste oil, while none incinerate it on-site. Figure 15 compares the numbers of respondents who use each method to process contaminated oil as well as the media used by those who solidify their oil (some generators use more than one process). Of the three respondents who mentioned Petroset as a solidification media, two said they had done so in the past.

\subsubsection{Miscellaneous}

Most respondents said they already have on-site facilities to store radioactive waste. Fifty-eight percent said they either have or plan to build a waste storage building.

Respondents were asked to identify the most effective radwaste volume reduction methods. No single method stood out amongst the others. Table 18 lists the methods identified by one respondent as the most effective method of waste reduction.

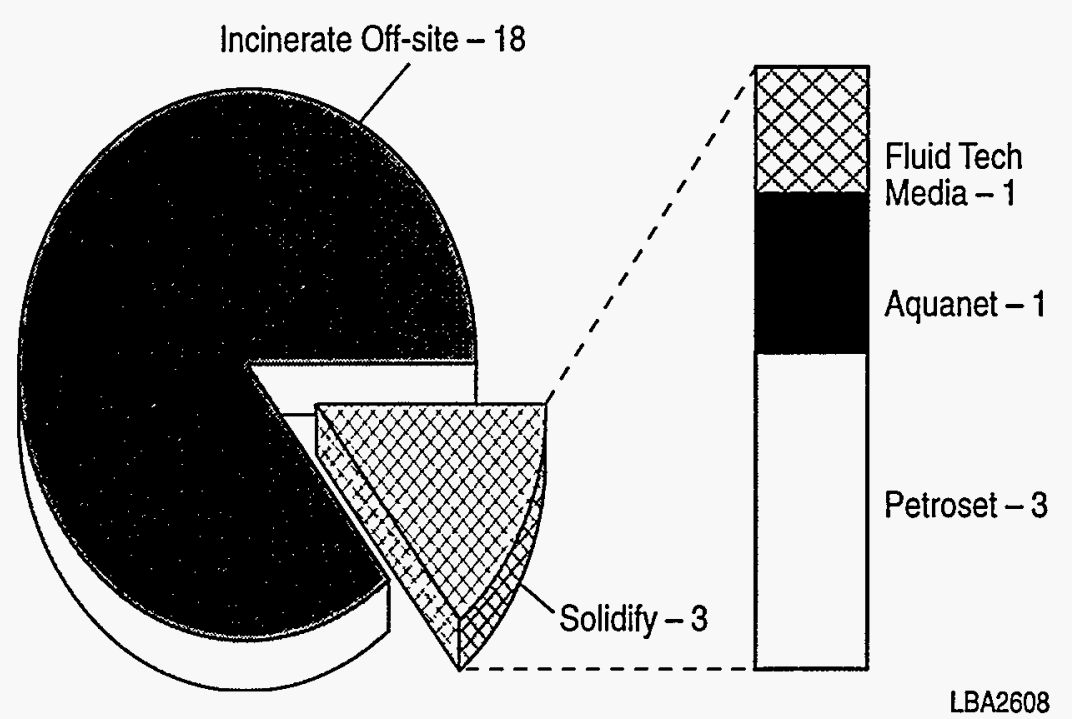

FIGURE 15 Liquid Waste Disposal Process (LBA2608-E) 
TABLE 18 Radwaste Volume Reduction Methods Identified as "Most Effective" by One Respondent

\section{Segregate DAW}

Assign dedicated equipment operators

Assign dedicated radwaste and decontamination personnel

Use certified incinerable products

Implement good liquid processing

Implement "Green Is Clean" program

Purchase reusable material

Limit contaminated areas

Maintain clean RCA
Set performance goals

Presort before off-site processing

Prevent unnecessary material from entering the RCA

Regenerate resin

Shorten the duration of refuel outage

Use expired condensate resin to process laundry/floor drain water

Use off-site processors

Respondents were also asked, "If you could buy it or implement it, what do you feel would help you reduce radwaste?" The techniques identified by one respondent as the technique he/she would implement are identified in Table 19.

\subsubsection{Required Conditions and Characteristics of Waste}

The study pertained to LLW generated at U.S. nuclear power plants.

\subsubsection{Administrative and Training Requirements}

All personnel involved in the generation and processing of LLW must be trained in applicable waste minimization procedures.

\subsubsection{Results}

- Costs. A cost analysis applicable to this study was not available.

- Volume reduction ratio and rates. Specific data on volume reduction ratios and rates were not available.

- Recycle/reuse. Recycle and reuse applications data concerning the LLW were not identified. 


\section{TABLE 19 Techniques Identified by One Respondent as Worthy of Implementation}

Efficiently segregate clean waste from contaminated DAW

Eliminate plastic sheeting, but provide contamination control on grating

Eliminate plastic, paper, and wooden materials from RCA as much as possible

Incinerate waste

Place large guard at entryway to challenge workers bringing material into RCA

Clean low-activity resins

Implement employee awareness techniques

Incinerate on-site

Construct on-site storage facility for contaminated outage equipment

Obtain management commitment to fix leaking systems

Reclaim material in the reactor building

Store and reuse radioactive material

\subsubsection{Advantages, Disadvantages, and Problems}

This survey did not identify limitations to the various waste processing techniques.

\subsubsection{Contacts}

More information can be obtained by contacting the ASME.

\subsubsection{Molten Metal Technology, Inc.: CEP and Quantum-CEP ${ }^{\mathrm{TM}}$}

Molten Metal Technology, Inc. (MMT) has developed a process known as catalytic extraction processing (CEP) for recycling hazardous and nonhazardous waste. The process uses a molten metal bath to convert wastes to useful raw materials. Wastes are injected into a molten metal bath. The catalytic and solvation properties of the molten metal break down molecular bonds, reducing compounds to their constituent elements, which dissolve in the liquid metal. The elements are then used as building blocks to form commodity gases, ceramics, and metals for sale to established markets. The CEP completely destroys hazardous compounds, exceeding regulatory standards for emissions and residuals.

The Quantum-CEPTM process (Figure 16) is an extension of CEP technology, in which a molten metal bath is used to partition radioactive elements to desired phases and destroy hazardous organics. Radioactive elements can be sealed into a volume-reduced stable form for final disposal. 


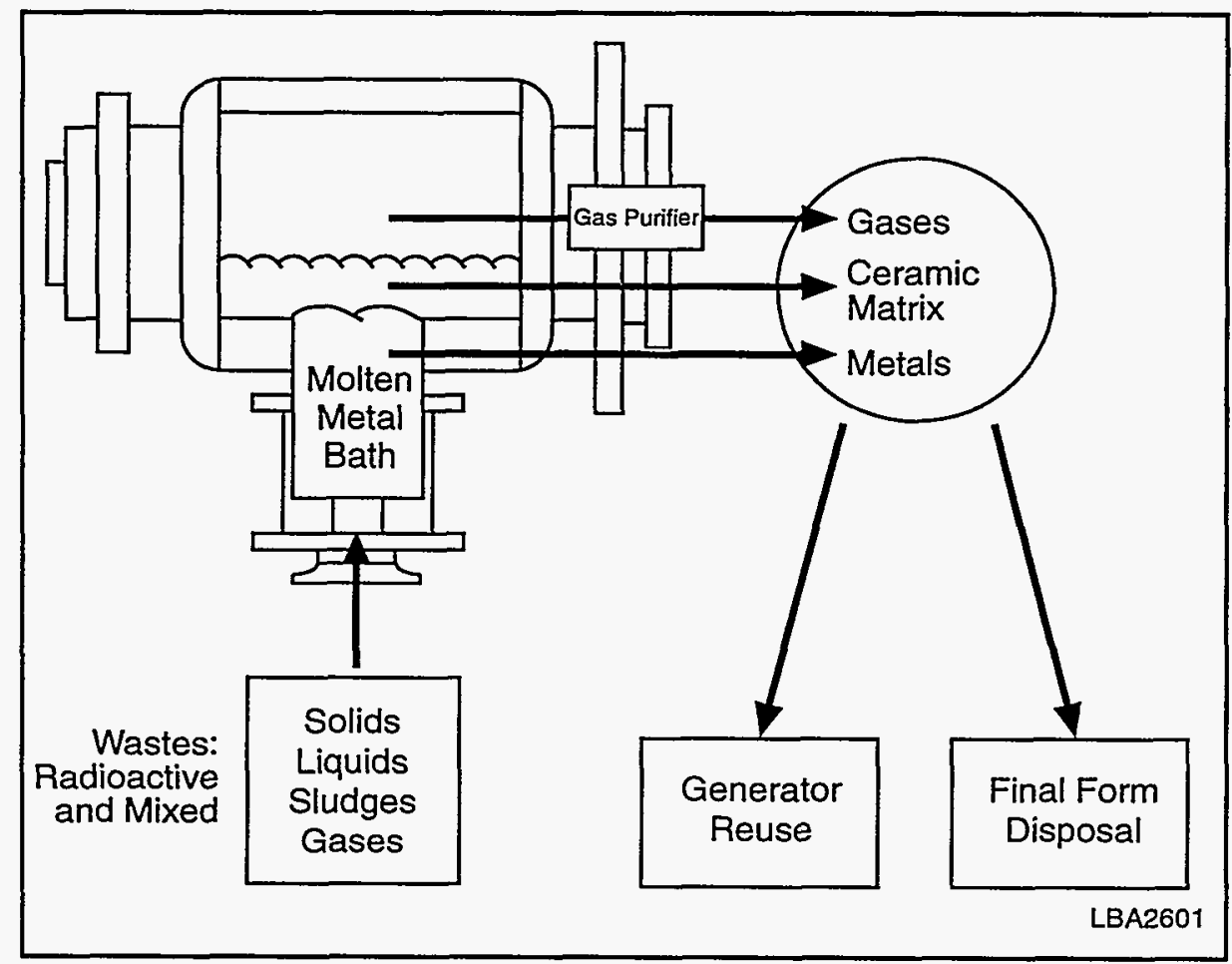

FIGURE 16 Quantum-CEPTM Process (LBA2601-E)

Nonradioactive materials can be returned to generators for reuse. Quantum-CEPTM technology can be used to decontaminate radioactive, hazardous, and mixed waste.

Both CEP and Quantum-CEPTM use a molten metal bath that acts as a catalyst and solvent in the dissociation of the feed, the synthesis of products, and/or the concentration of radionuclides. Feed introduced into the molten metal breaks down to its constituent elements, which dissolve in the metal solution. Addition of co-reactants into the metal solution promotes the reformation and partitioning of the desired products. The composition and amounts of the co-reagents control the partitioning of the various products. The system consists of the Catalytic Processing Unit, the reactor holding the liquid-metal catalyst and solvent, and a hermetically sealed gas-handling train.

Molten Metal Technology has performed two series of bench-scale tests using Quantum-CEP ${ }^{\mathrm{TM}}$ technology. The first involved processing contaminated scrap metal, and the second involved processing contaminated ion-exchange resins. Hafnium was used as a radioactive surrogate to show that uranium and plutonium in contaminated scrap metal could be selectively removed from the metal phase and concentrated in a separable, vitreous oxide phase. Hafnium was chosen for its thermodynamic and physical similarities to uranium. The lower limit of detection for hafnium is $0.2 \mathrm{ppm}$ in iron and $2 \mathrm{ppm}$ in nickel. Results show that uniform hafnium stabilization and 
distribution in the vitreous phase. Operating conditions and vitreous phase composition were found to affect radionuclide capture and stabilization. The second series of bench tests involved ion-exchange resins that were radioactively contaminated, primarily with cobalt and cesium. The organic content of the resins was converted into synthesis gas, with the cobalt accumulating in the molten metal bath and the cesium volatilizing and being captured and condensed in a proprietary cold trap design system at the reactor's exit. The tests involved partitioning the specific feed components to the desired phase (ceramic, metal, gas) by manipulating operating conditions.

\subsubsection{Required Conditions and Characteristics of Waste}

The molten metal solvent and catalyst depends on the elemental makeup of the feed and not the physical form. The molten metal reactor chamber can hold feeds of most physical forms. Gases, fine solids, pumpable liquids, and slurries can be fed through tuyeres at the bottom of the reactor. Bulk solids can be added through lock-hopper systems at the top of the reactor.

\subsubsection{Administrative and Training Requirements}

All personnel involved in the use of the CEP and Quantum-CEPTM process must be trained in applicable administrative and safety requirements.

\subsubsection{Results}

- Costs. Costs vary as a function of the specific operating parameters, including the physical form and chemistry of the feed material, throughput, desired product form, local energy costs, etc. Costs are evaluated on a case-by-case basis between MMT and potential users of the technology.

- Volume reduction ratio and rates. Throughput capacity depends on the chemical and physical form of the feed material, operating parameters, and reactor design. Current reactors are designed for throughputs from $1,800-13,600 \mathrm{t} / \mathrm{yr}(2,000-15,000 \mathrm{ton} / \mathrm{yr})$. Reactors under development will handle $27,200-45,400 \mathrm{t} / \mathrm{yr}(30,000-50,000 \mathrm{ton} / \mathrm{yr})$. Table 20 shows the decontamination results for the bench tests involving hafnium as the radioactive surrogate contamination material is as follows:

The hafnium concentrated within the vitreous phase, while the test metals were decontaminated to the stated levels, which were limited by the lower detection limit of hafnium in iron and nickel. 
TABLE 20 Radionuclide Partitioning for Contaminated Metals

\begin{tabular}{llc}
\hline Metal & Vitreous Phase & $\begin{array}{c}\text { Decontamination } \\
(\%)\end{array}$ \\
\hline & & \\
Iron & Aluminosilicate vitreous & $\geq 99.62$ \\
Nickel & Aluminosilicate vitreous & 299.76 \\
Iron & Borosilicate vitreous & $\geq 99.08$ \\
\hline
\end{tabular}

Contaminants in the ion-exchange resins underwent significant volume reduction and decontamination factors. Table 21 shows the impact on volume reduction for partitioning a specific component to the ceramic, metal, or gaseous phase. All scenarios are based on the thermodynamic prediction and experimental observations that cobalt accumulates in the metal phase and cesium is condensed from the gas phase.

Table 22 presents the decontamination factors as a ratio of the initial activity of the feed material ("activity in") to the final activity of the gaseous stream ("activity out"). Optimization of operating conditions can increase the decontamination factor by several orders of magnitude.

Specific volume reduction and decontamination ratios are customer specific and depend on operational parameters. The optimal volume reduction/ decontamination ratios are determined by balancing the cost of high-volume reduction with increased cost of disposal due to raising curie loadings on the final reduced volume.

- Recycle/reuse. The molten metal bath can be recycled and reused. The decontaminated material is released for unrestricted reuse.

\subsubsection{Advantages, Disadvantages, and Problems}

Molten Metal Technology has several advantages over conventional melting technologies. These include the ability to add co-feeds, including oxygen, to enhance and control oxidation of the radioactive and nonradioactive components. Turbulence caused by gas injection into the CEP bath also facilitates mass transfer, which increases the overall partitioning of radionuclides. CEP produces no dioxins, furans, products of incomplete combustion (PICs), nitrogen oxide $\left(\mathrm{NO}_{\mathrm{x}}\right)$, or sulfur oxide 
TABLE 21 Ion-Exchange Resin Bench-Scale

Tests - Partitioning Strategy vs. Volume Reduction

\begin{tabular}{ll}
\multicolumn{1}{c}{ Partitioning Strategy } & $\begin{array}{c}\text { Volume } \\
\text { Reduction Ratios }\end{array}$ \\
\hline Component partitions to ceramic phase & $12: 1$ \\
Component partitions to metal phase & $17: 1$ \\
Component partitions to gas phase & $84: 1$ \\
\hline
\end{tabular}

TABLE 22 Ion-Exchange Resins

Bench Tests - Decontamination

Factor

\begin{tabular}{lc}
\hline \multicolumn{1}{c}{ Nuclide } & $\begin{array}{c}\text { Decontamination } \\
\text { Factor }\end{array}$ \\
\hline Cobalt-60 & $\geq 169,532$ \\
Cesium-137 & $\geq 138,350$ \\
Manganese-54 & $\geq 162,771$ \\
Zinc-65 & $\geq 190,838$ \\
\hline
\end{tabular}

$\left(\mathrm{SO}_{\mathrm{x}}\right)$. CEP requires minimal feed pretreatment or handling, minimizes operator interaction and environmental exposure, and provides a broadly applicable, cost-effective solution for LLW and mixed waste.

\subsubsection{Contacts}

Kelly Fitzgibbons, Government Relations

Molten Metal Technology, Inc.

51 Sawyer Road

Waltham, MA 02154

(617) 487-9700 Telephone

(617) $487-7870 \quad$ Fax

(O1994 Molten Metal Technology, Inc. (Permission granted to use in this document.) 


\subsubsection{Plasma Hearth Process Demonstration at Argonne National Laboratory-West}

The Plasma Hearth Process (PHP) project is being conducted for DOE's Mixed Waste Integrated Program. As part of this project, Science Applications International Corporation (SAIC) and ANL-West are conducting bench-scale radioactive testing in an existing facility at the ANL-West site on INEL's site Idaho Falls. SAIC is the technology developer, while ANL-West provides the test facility and operations support for the project. SAIC constructed a non-radioactive demonstration PHP system at another site to conduct "proof-of-principle" tests as the first phase of a multiphase project. Wastes were effectively destroyed in the process, and the process produced a vitrified, high-integrity final waste form.

The PHP is a fixed-hearth, plasma-arc thermal treatment unit that uses a DC-arc generated in a gas flowing between two electrodes. For solid materials, one electrode is a "plasma torch," while the other is the material being treated. Energy is resistively dissipated in the arc in the form of heat and light as the electric current flows through the gas between the electrodes. Joule heating generates plasma temperatures on the order of thousands of degrees Celsius in the gas, which melt or combust the waste. Organic materials are destroyed, while metals and inorganic materials are melted. A vitrified "glassy-slag" waste form is the final product of the process, along with a metal phase that collects at the bottom of the hearth. A complete treatment system includes a drum feed system, a primary reaction chamber, air pollution control equipment, and a product removal system.

A bench-scale PHP system is expected to begin operation at ANL-West in 1995 and will involve testing on both surrogate and actual radioactive materials. Radioactive testing results will help to determine the behavior and partitioning of specific radioisotopes, in particular those that are alpha emitting (actinides). Bench-scale testing will focus on determining the quantity of each radionuclide retained in the slag phase, the quantity partitioned to the metal phase, and the quantity volatilized or otherwise partitioned to the off-gas.

Bench-scale testing will be paralleled by surrogate studies of a larger-scale nonradioactive unit at another site to verify expected system performance. Together with the bench-scale testing, this testing will determine if nonradioactive surrogate studies correctly model the behavior of radionuclides during treatment. Later, as the final step, a prototype PHP system will be constructed to demonstrate for full-scale radioactive waste treatment.

\subsubsection{Required Conditions and Characteristics of Waste}

One of the key advantages of the PHP technology is its ability to process many kinds of waste materials. Whole drums of waste materials, including heterogeneous matrices, are fed into the 
primary reaction chamber. This process minimizes pretreatment characterization, sorting, and handling.

The PHP technology is primarily applicable to solid or sludge wastes in which a stabilized by-product is required for disposal. The technology is suited for heterogeneous wastes of nearly any category, in particular those that require destruction of hazardous organics and stabilization of toxic metals.

\subsubsection{Administrative and Training Requirements}

The target waste stream for this treatment technology is alpha low-level mixed waste, which has an actinide concentration of $370-3700 \mathrm{~Bq} / \mathrm{g}$. It may also be possible to treat TRU (>3700 Bq/g) mixed waste with PHP technology.

Training requirements are expected to be the same as those for any facility that handles alpha-contaminated materials.

\subsubsection{Results}

- Costs. Because the PHP is in the demonstration phase, costs of a production facility are not available.

- Volume reduction ratio and rates. Volume reduction ratios for waste forms treated in the PHP proof-of-principle tests were as follows:

- Inorganic sludge

- Heterogeneous debris

$11: 1$

- Organic sludge

9:1

The processing rate for a full-scale system is expected to be about two $210-\mathrm{L}$ drums per hour.

- Recycle/reuse. The intent of the fixed-hearth PHP process is to separate the slag and metal phases. It is expected that the metal will be decontaminated enough to be classified as LLW or to be reused in some manner within the DOE complex. 


\subsubsection{Advantages, Disadvantages, and Problems}

The advantages of the PHP technology include the capability to process whole waste drums and the expected partitioning of actinides to the vitrified slag product. The disadvantage of this technology is that, because it is in the development phase, not all aspects of operation with contaminated materials and a complete air pollution control system have been demonstrated.

\subsubsection{Contacts}

Carla C. Dwight, PHP Project Manager

Technology Development Division

Argonne National Laboratory-West

P.O. Box 2528

Idaho Falls, ID 83403-2528

(208) 533-7651 Telephone

(208) 533-7735 Fax

R. M. Geimer or R. L. Gillins

Science Applications International Corporation

545 Shoup Avenue

Idaho Falls, ID 83402-3575

(208) 528-2144 Telephone

(208) 528-2194 Fax 


\section{REFERENCES}

Archibald, K.E., 1993, $\mathrm{CO}_{2}$ Pellet Blasting Literature Search and Decontamination Scoping Tests Report, WINCO-1180, Westinghouse Idaho Nuclear Company, Inc., Idaho Falls, Idaho, Dec.

Bosse, H., et al., 1993, "Separation of Metals by Melting," paper presented at a conference held in Krefeld, Germany, October 27-29.

Darnell, G.R., and W.C. Aldrich, 1983, Low-Speed Shredder and Waste Shreddability Tests, Idaho National Engineering Laboratory, Idaho Falls, Idaho, April.

Demmer, R., 1994, Testing and Evaluation of Eight Decontamination Chemicals, WINCO-1228, Westinghouse Idaho Nuclear Company, Inc., Idaho Falls, Idaho, Sept.

Demmer, R., et al., 1994, Testing and Evaluation of Light Ablation Decontamination, INEL-94-0134, Idaho National Engineering Laboratory, Idaho Falls, Idaho, Oct.

Ferguson, R.L., 1993, Liquid Abrasive Grit Blasting Literature Search and Decontamination Scoping Tests Report, WINCO-1163, Westinghouse Idaho Nuclear Company, Inc., Idaho Falls, Idaho, Oct.

Harper, J., and J. Warren, 1987, "Los Alamos Transuranic Waste Size Reduction Facility," Proceedings of the International Decommissioning Symposium, CONF-871018, Pittsburgh, Penn., October 4, 1987; available from the Remedial Action Program Information Center, Oak Ridge National Laboratory, Oak Ridge, Tenn.

Rocky Flats Environmental Technology Site, 1993, Cleaning Low-Level Contaminated Unclassified Metals Using Carbon Dioxide Pellet Blast Method, 4-B10-WMO-001, Rev. 1.

Scientific Ecology Group (SEG), 1995, Waste Acceptance Criteria, OP-4.35, Oak Ridge, Tenn., Aug. 18.

Tripp, J.L., 1994, Criteria and Evaluation of Three Decontamination Techniques, WINCO-1187, Westinghouse Idaho Nuclear Company, Inc., Idaho Falls, Idaho, Jan. 
APPENDIX:

\section{INDEX TO VOLUME 2}




\section{APPENDIX:}

\section{INDEX to Volume 2}

(Numbers refer to abstract number in Volume 2 to be published in late 1996.)

\begin{tabular}{|c|c|c|c|}
\hline & $-\mathrm{A}-$ & Carbon steel & $\begin{array}{l}57,201,206,209,270,499 \\
510,515,603,609\end{array}$ \\
\hline \multirow[t]{2}{*}{ Abrasive } & $26,186,462,505,513,515$ & Cation & 546,586 \\
\hline & 592,623 & Ceramic filter & 35 \\
\hline Absorption & 405 & Cesium & $19,212,226,256,296,409$ \\
\hline \multirow{5}{*}{$\begin{array}{l}\text { Acid (see also } \\
\text { Boric, Citric, } \\
\text { Hydrochloric, } \\
\text { Hydrofluoric, } \\
\text { Nitric, Oxalic, } \\
\text { Spent, Sulfuric) }\end{array}$} & $11,37,48,55,66,69,117$ & & $504,509,546,569,586$ \\
\hline & $141,176,397,505,520$ & Chemical & \\
\hline & $532,546,555,591,615$ & decontamination & $1,48,183,199,363,505$ \\
\hline & 621 & $\begin{array}{l}\text { Chemical } \\
\text { extraction }\end{array}$ & 512,621 \\
\hline & & Citric acid & $540,551,558,566,622$ \\
\hline \multirow[t]{2}{*}{ Alpha } & $6,80,84,96,149,161,183$ & Coal & $400,540,591$ \\
\hline & $\begin{array}{l}260,293,295,398,405 \\
510\end{array}$ & Cobalt & $\begin{array}{l}17,19,80,177,212,226 \\
280,409,412,488,498\end{array}$ \\
\hline Americium & $3,47,54,568,577$ & & $504,509,540,555,557$ \\
\hline Anion & $69,197,301,405$ & Cogema & $22,28,84,123,146$ \\
\hline Arc cutting & 92 & Combustibles & 342 \\
\hline Arc melter & 572 & Combustion & $260,300,313,319,384$ \\
\hline \multirow[t]{4}{*}{ Arc saw } & $152,154,184,410$ & & $480,486,531$ \\
\hline & & Compacting & $220,289,352$ \\
\hline & & Compaction & $7,14,27,52,81,83,91,92$ \\
\hline & $-B-$ & & $\begin{array}{l}108,115,159,196,208 \\
224,242,249,263,288\end{array}$ \\
\hline \multirow[t]{2}{*}{ Beta } & $60,84,161,183,190,197$ & & $289,299,322,351,352$ \\
\hline & 421,427 & & $383,426,606$ \\
\hline Bismuth & 296,535 & Compactor & $92,115,125,220,224,335$, \\
\hline \multirow{2}{*}{$\begin{array}{l}\text { Bismuth } \\
\text { hydroxide }\end{array}$} & 33 & & 352,383 \\
\hline & & Compacts & $372,548,553$ \\
\hline $\begin{array}{l}\text { British Nuclear } \\
\text { Fuels (BNFL) }\end{array}$ & $22,135,281$ & Concrete & $\begin{array}{l}24,26,65,101,138,161 \\
166,182,186,192,194\end{array}$ \\
\hline Boric acid & $105,358,392$ & & $294,299,413,491,508$ \\
\hline \multirow{4}{*}{$\begin{array}{l}\text { Bulk } \\
\text { decontamination }\end{array}$} & 56 & & $565,577,579,598$ \\
\hline & & & $-D-$ \\
\hline & $-\mathrm{C}$ & & \\
\hline & & Depleted uranium & $39,60,119$ \\
\hline Cadmium & 535 & Devolume & $13,44,605$ \\
\hline Capenhurst & 281 & Disposal facility & $72,90,161,325,347,548$ \\
\hline Carbon-14 & $16,351,371,510$ & Distillate & $42,57,618$ \\
\hline $\begin{array}{l}\text { Carbon dioxide } \\
\qquad\left(\mathrm{CO}_{2}\right)\end{array}$ & $\begin{array}{l}15,16,65,107,122,229 \\
524,555,557,615\end{array}$ & & \\
\hline
\end{tabular}


Drying

$117,158,176,263,334$, $351,358,392,483,599$, 612

-E-

Electrochemical

Electrolyte

Electrolytic decontamination Electropolishing

Encapsulation

Enriched

Enriched uranium

Evaporator $498,515,520,555,557$, 601 $48,69,77,206,497,499$, $551,552,555,557,575$, $576,579,590$ $38,95,199,619$ 498,603 479,554

$60,280,578$

$60,96,166,281$
$11,15,107,153,315,363$,

$5,48,182,408,411,462$, $32,59,66,124,158,168$, $226,250,292,335,354$, $364,581,618$

-F-

Fission products

Fissionable

Flame

Fluidity

Fluidized

Fluids

Foam

Fuel channel

Gamma

Gas chromatography

Gaseous

Gaseous waste

Gassified

Gel
$60,166,218,296,569$

96

591

44,61

$62,133,300,354,364,392$, 615

$5,12,130,334,395,404$, 455,577

$11,14,89,185,187,550$, 561,581

596

$-G-$

$16,60,84,96,161,190$, $197,405,421,427,504$ 15,107

$65,130,132,137,166$ $34,47,453$

33

11,375
Glovebox

Graphite

Gundremmingen reactor

$-\mathrm{H}-$

Hanford

Hazardous

Hazardous waste

Hazardous waste generation

Heavy metals

$85,135,136,162,166,400,405$, $492,533,544,577,584,600,603$, 621

High-level waste

Hot cell

Hydrochloric acid

Hydrofluoric acid

$62,285,552$

$137,181,282$

183

133,183

-I-

IAEA

Incineration

$14,20,47,508,517$

$7,27,57,74,91,92,101,106,130$, $132,170,190,220,244,252,263$, 288, 293, 294, 299, 300, 310, 315, $322,343,348,355,392,426,480$, $508,526,534,548,591,611$

Incinerator $\quad 57,102,111,166,343,380,484$, $486,526,534,535,608,615$

INEL $92,94,97,111,187,190,218,224$, $230,240,527,583,610$

Inhalation $\quad 539$

Inorganic salts $\quad 37,44,176$ 
Intermediate

level

Ion exchange
$17,20,47,67,169,426,484,547$, 568

$14,16,50,103,123,124,226,250$, $292,300,313,336,363,375,392$, $483,573,601,614$

$-\mathrm{K}-$

$\mathrm{K}-25$

118,617

$-\mathbf{L}$ -

$\begin{array}{ll}\text { Land burial } & 47,161,335,398,609 \\ \text { LANL } & 45,49,54,100,170, \\ \quad \text { Los Alamos) } & 203,229,401,405,408,410,455, \\ & 580,619 \\ \text { Laser } & 56 \\ \quad \text { decontami- } & \\ \quad \text { nation } & \end{array}$

Leaching

Lead

Liquid radwaste

Liquid waste

LLNL

(Lawrence

$30,84,106,121,134,141,203,391$, $397,399,604$

$68,121,150,166,409,455,501$, $504,526,535,540,577$

$183,263,366,376,612$

$14,19,29,32,33,35,38,42,44,58$, $62,66,67,69,71,90,105,126,130$, $133,165,168,171,176,182,218$, $279,297,358,383,392,394,552$, $560,576,586,591,596,603$ $51,88,97,115,116,142,233,236$, $255,291,589,591$

Livermore)

LLW

Low-level radioactive waste (LLW)

Low-level waste

$18,20,72,74,82,91,92,99,102$, $216,244,249,286,288,291,294$, $299,304,306,309-312,347,360$, $371,372,409,411,419,548,563$, $579,606,609$

$7,15,24,63,101,104,107,133$, $212,215,265,283,289,297,303$, $322,323,342,373,484,574,596$, 598,610

$9,27,53,65,79,100,131,155,159$, $161,204,231,247,272,314,334-$ $336,339,343-345,348,355,381$, $383,564,594,607$

$-\mathrm{M}-$

Melting

Membrane

Metal

Metal scrap

Metal waste

Metallic

Metallic scrap

Metallic waste

Microbes

Micro-

encapsulation

Microorganism

Microwave

Minimization plan

Minimization program

Mixed waste

Moiten salt
$2,14,27,31,61,80,81,92,139$, $141,154,172,177,190,196,200$, $202,207,208,210,211,213-215$, $221,223,225,270,275,282,287$, $395,397,398,402-404,412,417$, $421,427,495,503,509,547,554$, $556,572,574,575,578,599,604$, 605

$38,58,69,279,536,546$

$17,37,50,56,68,69,143,159,163$, 197, 203, 210, 246, 247, 253, 263, $266,270,280,294,299,317,397$, $406,407,412,421,427,462,480$, $513,527,535,539,540,547,552$, $558,561,566-568,578,579,605$, $609,622,623$

$6,184,222,223,225,395,402-404$, $500,501,509,518$

$2,38,48,95,117,199,206,211$, $213,215,221,296,305,318,398$, $409,417,497,499,551,575,590$, $592,598,604$

$5,54,134,183,269,274,275,399$, $409,410,453,498,503,511$

190

$152,200,202,208,223,224,265$, $403,455,601,607$

524

121

$122,522,567$

$192,287,351,355,358,579,554$, 599

$230,233,234,255,583$

$39,43,45,51,88,96,140,145,171$, $173,216,228,232,235,236,239$, 240, 241, 243, 246-248, 253, 254, $286,306,334,336-338,353,589$, 594

$12,15,40,65,68,82,90,104,107$, $115,118,121,127,131,164,204$, $216,230,241,243,247,248,286$, $291,294,306,322,341,481,492$, $505,543,544,553-557,593,607$, $608,610,621$ $148,170,394,556,591$ 
$-\mathrm{N}$ -

Nitric acid

$42,66,84,133,486,498,550,555$, 557

Nuclear fuel $\quad 14,64,215,285,508$ cycle

Nuclear weapons $45,93,97,119,147,519$

$-0-$

ORNL

(Oak Ridge

National

Laboratory)

Oxalic acid

550,551

$-\mathbf{P -}$

$\begin{array}{ll}\text { Petroleum } & 122,530 \\ \text { Plasma } & 12,130,132,410,453, \\ & 547,574,578,599\end{array}$

Plasma arc $\quad 86,455,462$

Plastic

Plutonium

$29,121,122,159,170,259,272$, $282,482,524,591$

$3,45,54,60,68,84,93,111,130$, $154,170,222,288,298,391,396$, $398,401,409,417,462,491,568$, 577

Plutonium-238 266, 485

Plutonium-239 109, 443, 444, $485,486,505$

$-Q-$

$\begin{array}{ll}\text { Quality } & 60,161,188,239, \\ \text { assurance } & 554,588\end{array}$

-R-

$\begin{array}{ll}\text { Radium } & 47,399,405,512,614 \\ \text { Recycled fuel } & 281 \\ \begin{array}{l}\text { Recycling } \\ \text { program }\end{array} & 188,541 \\ \text { Refining } & 50,141,148,202,223,225,398, \\ & 403,412,417,514,607\end{array}$

Resin

$16,32,103,105,121,123,124,197$ $250,272,292,300,301,308,313$, $319,323,334,346,349,351,355$, $356,358,375,376,381,383,392$, $426,480,482,483,601,614$

-S-

Scientific

Ecology

Group (SEG)

Scrap metal

Shredder

Shredding

Siempelkamp

Slag

Sludge

melting

Soil

Solidification

Spent acid

Spent fuel

Stainless steel

Steel (See also

Stainless,

Carbon)

Sulfuric acid
$27,50,159,301,513,515,614$

$119,141,148,207,269,505,513-$

$515,541,565,571,577,616,617$

$383,443,444$

$7,81,159,522$

$210,270,412$

$6,59,61,80,141,166,177,202$, 221-223, 225, 270, 395, 397, 398, $402-404,409,412,417,480,504$, $505,509,510,572,607$

$31,54,59,85,112,162$, 164-166, 206, 323, 349, 492, 505, $519,523,527,551,569,584,596$, 600

$6,224,500,505,539$

$3,31,75,109,122,135,162,164$, $203,224,296,391,396,400,478$, $491,493,512,518,522,524,526-$ $534,540,542,544,545,558,566$, $568,572,591,597,613,614,621$, 622,624

$29,44,78,103-106,117,123,155$, $163,165,168,169,182,252,287$. $294,301,308,322,323,334,336$, $343,348,354,355,360,378,397$, $483,484,545,562,596,598,605$, 612,613

142

$123,252,266,293,596$

$19,133,151,197,206$, $214,305,313,317,397,409,410$, $412,417,455,491,499,515,518$, $579,603,619$

$11,80,101,124,139,143,189$, 190, 194, 196, 210, 224, 269, 292, $294,299,398,413,495,500,502$, $504,505,508,514,578,595$ $399,497,499,555,557$ 
Supercompaction $74,81,91,249,263,303,307,309$, $322,343,348,548,606$

Supercompactor $125,327,381,606$

Surface- $\quad 192,278,561$

contamination

$-T$ -

\section{Technetium}

$36,77,158,166,266$, $505,514,569,577$

Thermochemical 403

Thorium

Transuranic

$60,399,405,540,577$

(TRU)

$23,55,68,91,111$,

$115,131,133,135,218,225,285$, $295,311,312,417,424,455,514$, $518,569,572,607$

Transuranic $\quad 8,165,204,216,220,221,244$, waste (TRU $286,288,291,406,408,409,444$, Waste)

Tritium $485,519,591,609$ $45,57,93,130,134,175$

-U-

Ultracompactor 159

Uranium

$6,13,45,55,62,76,93,137,141$, $159,190,202,222,225,246,247$, $253,296,399,400,402,403,405$, $417,492,500,502,510,511,514$, $540,544,558,567,577,579,603$, 614,622

Uranium-235 $60,96,505$ (U-235)

Uranium-238 443, 444, 485, 505
-V-

Vacuum $152-154,176,196,351,528,542$

Vacuum arc 141

Ventilation $52,453,491,492,513$

Vitrification $31,101,131,294,365,493,519,544$

$-W-$

Waste $23,27,68,74,108,137,168,176$, processing $237,256,290,334,335,354,360$, $376,383,491$

Waste recycling 211,487

Wastewater $24,66,78,85,112,218,295,376$, $523,533,567,584,600$

$-Y-$

$\mathrm{Y}-12$ $39,45,97,118,122,141,173,254$, 617

(U-238) 


\section{DISTRIBUTION LIST}

\section{ANL}

ANL-East Library (2)

ANL-PRS

ANL-West

Bhattacharyya, S.K.

Black, D.

Boing, L.

Coffey, $M$.

D\&D Library

Ditch, R.

Fellhauer, C.

Helt, J.

Henley, D.

IPD (4)

Knox, A.

Leong, $\mathrm{K}$.

Lineberry, $M$.

McFarlane, $\mathrm{H}$.

Mezaraups, J.

Novick, V.

OSTI (12)

Rose, R.

Seifert, L.

Surles, $\mathrm{T}$.

Thuot, J.R.

Yule, $T$.

DOE/HR-EM-30

McBride, $\mathrm{G}$.

\section{Additional Distribution}

Beasley, J.

Bonem, M.W.

Boorman, $\mathrm{T}$.

Clements, D.W.

Crivella, E.C.

Davage, R.E.

de Lange, R.C.

Dirks, G.

Drypolcher, A.F.

Dwight, C.C.

Fitzgibbons, K.

Geimer, R.M.

Graham, D.

Harley, J.P., Jr.

Hoberg, G.

Ischay, $\mathrm{C}$.

Knight, L.

Laraia, $M$.

Lasch, $M$.

Ludlum, R.

Lyons, W.R.

Marie-Sainte, E.

Markiewicz, D.J.

Michaud, S.

Neilson, J.D.

Pfeiffer, R.

Phillips, S.J.

Phillips, W.S.

Sappok, M.

Selby, K.B.

Simmons, M.

Steiner, $\mathrm{H}$.

Tripp, J.L.

Williams, R.P. 